US Army Corps of Engineers $s_{\circledast}$

Engineer Research and

Development Center

\title{
Development of Deceleration-based Runway Friction Measurement Methods
}

Andrew B. Ward, Craig A. Rutland, and Jeb S. Tingle

June 2019

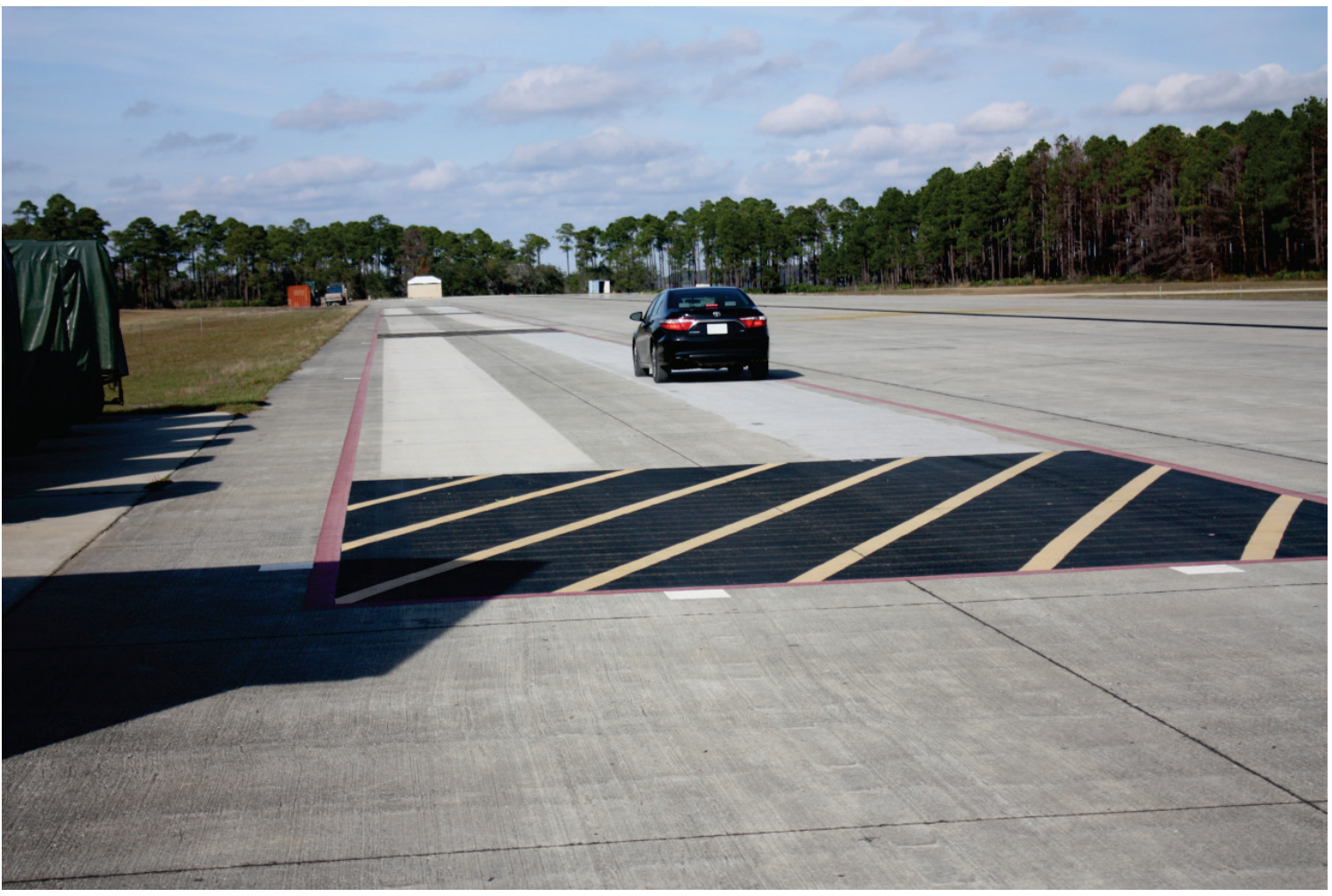


The U.S. Army Engineer Research and Development Center (ERDC) solves the nation's toughest engineering and environmental challenges. ERDC develops innovative solutions in civil and military engineering, geospatial sciences, water resources, and environmental sciences for the Army, the Department of Defense, civilian agencies, and our nation's public good. Find out more at www.erdc.usace.army.mil.

To search for other technical reports published by ERDC, visit the ERDC online library at http://acwc.sdp.sirsi.net/client/default. 
ERDC TR-19-10

June 2019

\section{Development of Deceleration-based Runway Friction Measurement Methods}

Andrew B. Ward and Jeb S. Tingle

Geotechnical and Structures Laboratory

U.S. Army Engineer Research and Development Center

3909 Halls Ferry Road

Vicksburg, MS 39180-6199

Craig A. Rutland

Civil Engineering Branch, Engineering Division

Air Force Civil Engineer Center

Tyndall Air Force Base, FL 32403-5319

Final report

Approved for public release; distribution is unlimited.

Prepared for Headquarters, U.S. Air Force Civil Engineer Center

Tyndall Air Force Base, FL 32403-5319

Under Project Number 473719 


\section{Abstract}

Runway surface friction is a critical safety concern on all airfields; however, current friction measurement equipment is expensive. Airfield managers have identified a need for contingency friction assessment tools that are cost-effective and commonly found. The current Air Force standard for pavement friction measurement is a high-speed continuous friction measuring equipment (CFME) device, the Findley Irvine GripTester. Operation of the GripTester is both labor-intensive and cost-prohibitive. This report details the development of an alternative, more economical measure of a surface's frictional characteristics using accelerometers. Accelerometers were standard friction assessment tools in the late $20^{\text {th }}$ century before CFMEs became standard practice. Accelerometer-based friction testers measure the peak deceleration of a vehicle during the braking motion. The vehicle's deceleration is proportional to the surface's friction coefficient. This report documents research conducted to evaluate the use of smartphone accelerometers and vehicle engine control units (ECUs) having sufficient accuracy and precision to function as decelerationbased friction assessment tools. Findings herein show that smartphone accelerometers, given sufficient experimental controls, can operate as deceleration-based friction assessment tools. This report also details unsuccessful attempts to extract usable deceleration data from vehicle ECUs and the potential future of such efforts. Regressions are presented that show correlation between smartphone deceleration measurements and highspeed GripTester measurements.

DISCLAIMER: The contents of this report are not to be used for advertising, publication, or promotional purposes. Citation of trade names does not constitute an official endorsement or approval of the use of such commercial products. All product names and trademarks cited are the property of their respective owners. The findings of this report are not to be construed as an official Department of the Army position unless so designated by other authorized documents. 


\section{Contents}

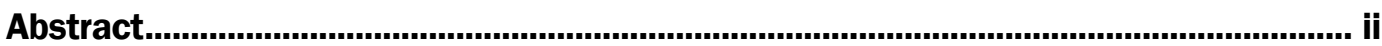

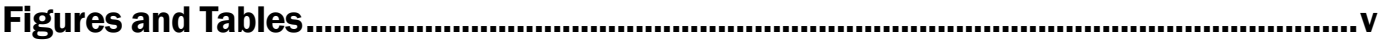

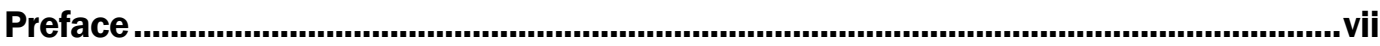

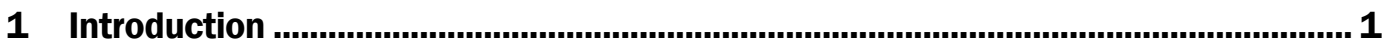

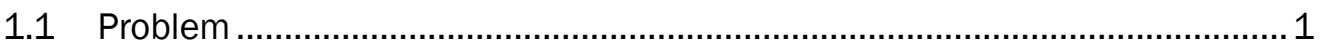

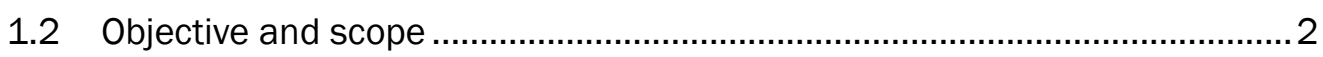

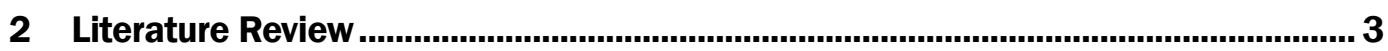

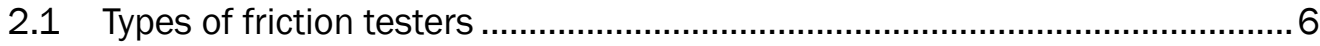

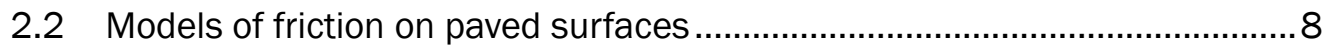

2.3 Models of friction on unpaved surfaces....................................................10

2.3.1 Friction on unpaved soil surfaces .................................................................. 10

2.3.2 Friction on unpaved viscous surfaces................................................................ 11

2.3.3 Friction on unpaved snow-covered surfaces ...................................................... 12

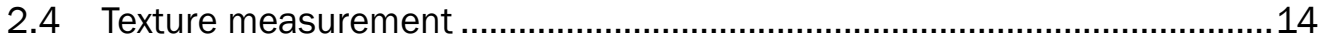

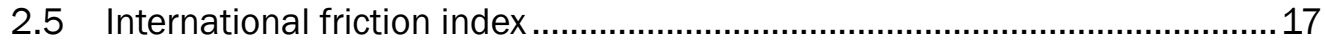

2.6 Vehicle on-board diagnostic interface .................................................... 19

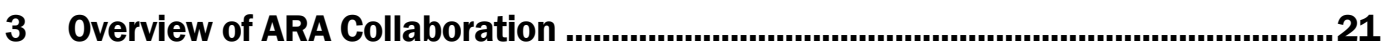

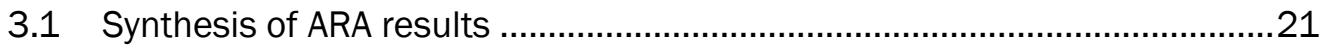

3.2 Tow-behind CFME results .......................................................................21

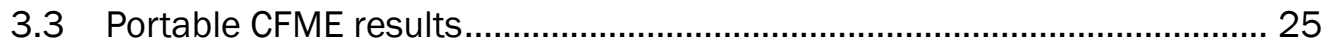

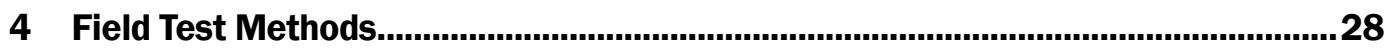

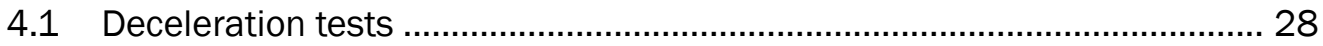

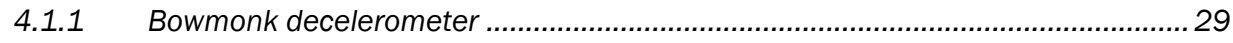

4.1.2 Smartphone decelerometer ....................................................................... 31

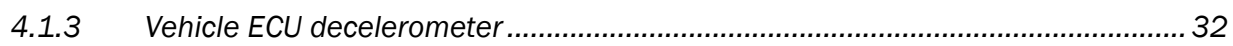

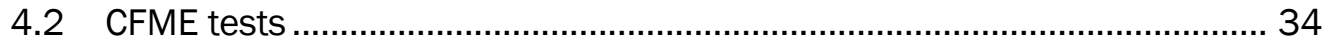

4.3 Texture measurements ............................................................... 34

5 Hardware and Software Development ................................................................36

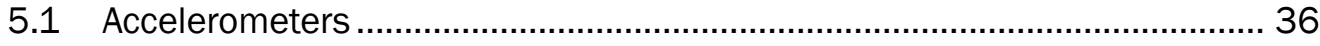

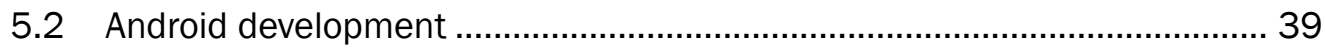

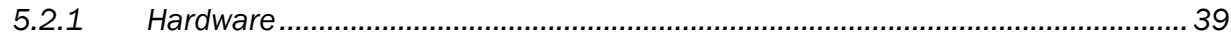

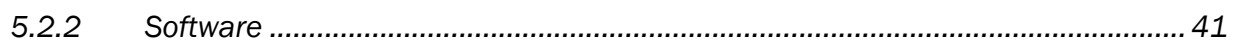

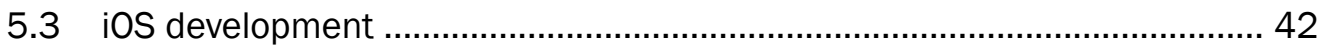

5.3.1 Hardware ........................................................................................ 42

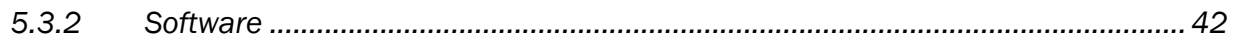

5.4 Bowmonk decelerometer .................................................................... 43 


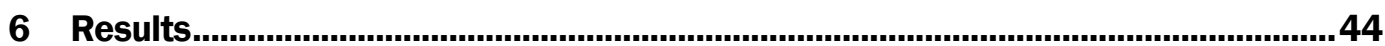

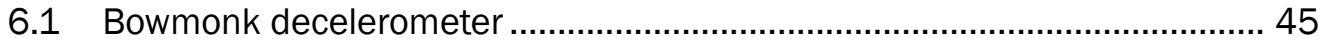

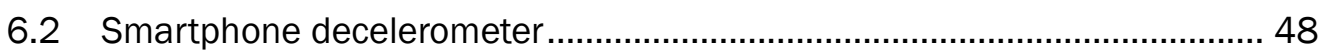

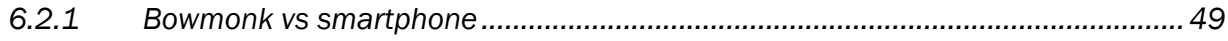

6.2.2 Mk2 GripTester vs smartphone...................................................................... 52

6.2.3 IFI model conversion of smartphone data.........................................................54

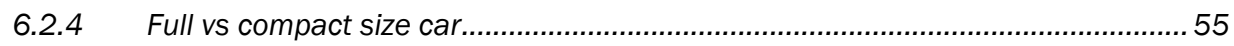

6.2.5 Consistency within full size vehicle range ........................................................56

6.2.6 Results during wet-pavement conditions ............................................................60

6.2.7 Smartphone repeatability within manufacturer .....................................................60

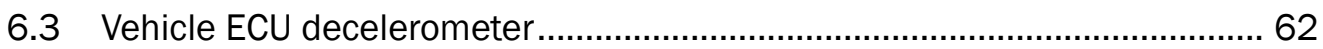

6.4 Texture measurement ..................................................................... 64

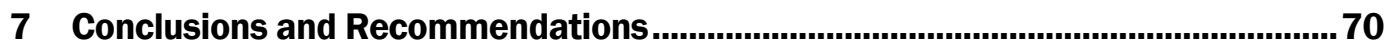

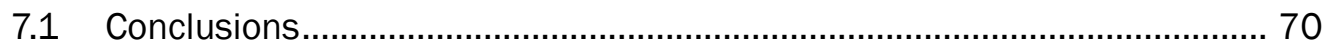

7.2 Recommendations ............................................................................ 71

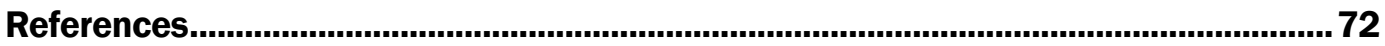

\section{Report Documentation Page}




\section{Figures and Tables}

\section{Figures}

Figure 1. Rado (1994) model plot for three sets of parameters. ....................................... 9

Figure 2. OBDII interface installed in a vehicle............................................................... 20

Figure 3. Mk1 GripTester vs Lane for various operating speeds. ...................................... 22

Figure 4. Mk2 GripTester vs Lane for various operating speeds. .......................................2 22

Figure 5. Mk2 GripTester vs speed for all six SF test sections (L1-R3).............................. 23

Figure 6. mGT vs Lane for three replicate mGT devices................................................... 26

Figure 7. T2Go vs Lane for three replicate T2Go devices....................................................... 26

Figure 8. mGT vs Lane for 1.6 and 3.0 mph............................................................... 27

Figure 9. Two Bowmonk devices used during brake testing............................................. 29

Figure 10. Bowmonk devices mounted in the floorboard (a) and seat (b)........................ 30

Figure 11. Smartphone mount and smartphones installed in test car............................... 31

Figure 12. OBD devices next to a ruler (OBD side has a major mark every $2 / 3 \mathrm{in}$.).........33

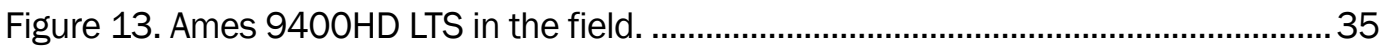

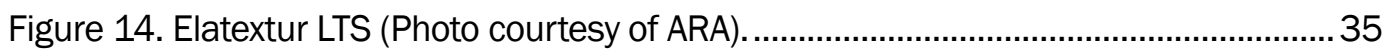

Figure 15. SEM image of a MEMS accelerometer (Photo courtesy of Chipworks).............36

Figure 16. Thermal image of smartphones following prolonged operation. ...................... 37

Figure 17. Deceleration vs Lane for the thermal example................................................ 38

Figure 18. Smartphone 3D orientation............................................................................. 40

Figure 19. Android ERDC DECEL screenshots................................................................ 41

Figure 20. iOS ERDC DECEL screenshots.................................................................... 42

Figure 21. Bowmonk deceleration vs Lane with multiple drivers...................................... 45

Figure 22. Bowmonk2 vs Bowmonk1 deceleration linear regression. .............................. 46

Figure 23. Bowmonk Back vs Bowmonk Front deceleration linear regression.................. 47

Figure 24. Mk2 GripTester 25mph vs Bowmonk linear regression................................... 48

Figure 25. Deceleration vs Lane for all eight smartphones (excluding HTC 10)................ 49

Figure 26. Phone layout during Round 4 testing.............................................................. 50

Figure 27. Bowmonk vs Smartphone for both seat and floor mounts............................... 51

Figure 28. Mk2 GT 25mph vs Smartphone for both seat and floor mounts.....................53

Figure 29. Mk2 GT 25mph predictions for iPhone 7 and V20 deceleration data.............54

Figure 30. Mk2 GT 60mph predictions for iPhone 7 and V20 deceleration data.............55

Figure 31. Smartphone Deceleration vs Lane using a compact size car. ..........................56

Figure 32. Round 4 vs Round 2 smartphone deceleration. ...............................................58

Figure 33. Smartphone deceleration vs lane during rainfall conditions. ............................60

Figure 34. Smartphone deceleration vs lane Replicate Testing....................................... 61

Figure 35. Deceleration vs time comparison of the LG V2O and OBDLink MX.................62 
Figure 36. Deceleration vs Lane for the OBDLink MX OBDII device. .................................63

Figure 37. Bowmonk vs OBDLink peak deceleration....................................................... 64

Figure 38. Texture measurements for the Silver Flag test track....................................... 65

Figure 39. Comparison of three texture measurement devices.........................................69

\section{Tables}

Table 1. Pavement texture and wavelength designations................................................... 5

Table 2. Tire pressure and snow density correlations. .....................................................13

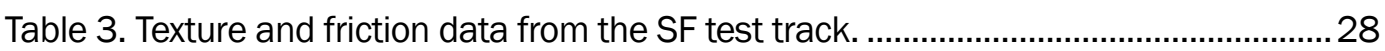

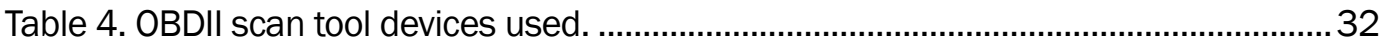

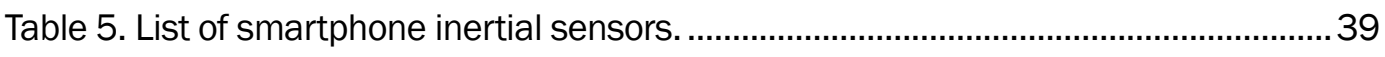

Table 6. Testing breakdown by round............................................................................ 44

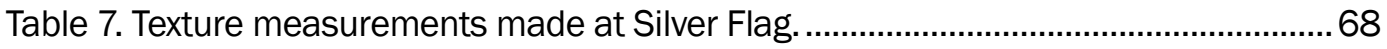




\section{Preface}

This study was conducted for the U.S. Air Force Civil Engineer Center (AFCEC) under the project "Evaluation of Runway Friction Measurement Methods." The technical monitor was Dr. Craig Rutland, AFCEC.

The work was performed by the Airfields and Pavements Branch (GMA) of the Engineering Systems and Materials Division (GM), U.S. Army Engineer Research and Development Center, Geotechnical and Structures Laboratory (ERDC-GSL). At the time of publication, Dr. Timothy W. Rushing was Chief, CEERD-GMA; Mr. Justin Strickler was Acting Chief, CEERD-GM; and Mr. R. Nicholas Boone, CEERD-GZT, was the Technical Director for Force Projection and Maneuver Support. The Deputy Director of ERDC-GSL was Mr. Charles W. Ertle II, and the Director was Mr. Bartley P. Durst.

COL Ivan P. Beckman was the Commander of ERDC, and Dr. David W. Pittman was the Director. 


\section{Introduction}

\subsection{Problem}

Friction surveys are a critical part of airfield management and pavement inspection. The frictional properties of a surface determine vehicle skid and rolling resistance. Friction surveys can also give a measure of a surface's relative safety in case of surface contamination such as rubber, snow, oil, etc. A widely used device by both military and civilian airfield managers to conduct friction surveys is the Findlay Irvine Mark 2 GripTester (Mk2 GT) operating at 40 and 60 miles per hour (mph). The Mk2 GT is in the class of continuous friction measuring equipment (CFME). It is typically pulled behind a full-size truck or van. Onboard the driving vehicle is a water system that sends a 1 millimeter $(\mathrm{mm})$ water-file depth to the rear testing tire of the Mk2 GT. High-speed Mk2 GT friction surveys require not only an expensive friction tester but also multiple technicians to operate it. There are few options available to airfield managers and pavement inspection teams in emergency situations to make a quick measure of a surface's friction response when such equipment and technician support are unavailable. One such alternative is a slower walk-behind CFME like the Findlay Irvine micro GripTester (mGT) or ASFT T2Go. These friction testers operate under the same fixedslip principle as the full-size Mk2 GT but at much lower speeds, i.e., 1 to 3 $\mathrm{mph}$. While these walk-behind devices operate at lower, more convenient speeds, they are expensive, require trained technician support, are not widely available, and may not readily correlate to the faster Mk2 GT.

An alternative to the fixed-slip friction measurement technique relies on the principle that vehicle deceleration on a surface is related to the surface's friction response. Decelerometers are devices that measure the deceleration of a vehicle during the braking action. This technique relies on an inertial sensor, i.e. an accelerometer, to measure deceleration. The accelerometers are typically packaged alongside other inertial sensors into a single inertial measurement unit (IMU) chip. It is these small IMUs that are found inside modern smartphones. Testing of the smartphone inertial sensors was necessary to determine the smartphone's suitability for deceleration-based friction testing. Throughout this report, the terms accelerometer and decelerometer are considered synonymous. 


\subsection{Objective and scope}

The objectives of this project were three-fold:

1. Evaluate the use of modern smartphones as deceleration-based friction measuring equipment;

2. Evaluate the use of a vehicle engine control unit (ECU) as decelerationbased friction measuring equipment; and

3. Evaluate the use of walk-behind CFMEs.

The primary objective of this research was to evaluate the use of modern smartphones as deceleration-based friction assessment tools. Android and iOS-based apps were developed and various smartphones were tested for accuracy and repeatability of deceleration measurements. Braking tests were performed on concrete surfaces in dry and wet pavement conditions. Smartphone accelerometers were tested against ASTM-accepted deceleration equipment, namely the Bowmonk Airfield Friction Meter $2 \mathrm{Mk} 3$ (Bowmonk). Correlation was found between the smartphone accelerometers and the Bowmonks as well as with the Mk2 GT at various speeds. Methods for smartphone accelerometer friction testing and correlations with accepted friction testing equipment are presented in this report.

A secondary objective of this work was to evaluate the use of vehicle ECUs as deceleration-based friction assessment tools. Wheel speed data were collected from the onboard computer of a test vehicle and were timeintegrated to produce an acceleration measurement. This acceleration measurement was calculated during the braking action to determine the device's suitability in friction measurement.

The final objective of this work was to collaborate with Applied Research Associates (ARA) in an effort to test and correlate full-size CFMEs to smaller walk-behind CFMEs. As a part of ARAs effort, the U.S. Army Engineer Research and Development Center (ERDC) provided a measure of friction from a Dynamic Friction Tester (DFT) and a measure of texture from an Ames 940oHD Laser Tester Scanner (Ames LTS). 


\section{Literature Review}

The friction characteristics of runway and highway surfaces are of considerable interest to both aeronautic and highway agencies. These characteristics dictate stopping distances and relative safety of operating aircraft and land vehicles in dry and contaminated conditions. This chapter reviews literature regarding the practical and theoretical considerations of pavement surface friction in order to shed light on the current state of research and practice.

Of particular interest in this field is the interaction of rubber tires with a hard surface, namely asphalt and concrete. A measurement of frictional force from such an interface relies on both the properties of the rubber tire and the surface. The tire has a much lower elastic modulus (Young's modulus) than the hard surface, and therefore undergoes most of the deformation during the interaction, whereas the size and amount of aggregate particles in the pavement surface dictate the maximum friction available. Friction measurements are affected by a number of factors like the temperature of the surface and tire, molecular makeup of surface (texture) and tire, weight distribution of the driving force behind the tire, contamination of the pavement, etc.; however, early work by Tabor (1959), Grosch (1963), and Kummer and Meyer (1962) shows that much of this interaction can be described empirically as the sum of two distinct forces: hysteresis and adhesion, such that

$$
F_{f}=F_{h}+F_{a}
$$

where $F_{f}$ is the total force of friction. The hysteresis force, $F_{h}$, is a result of the bulk deformation of the rubber tire about the aggregate particles present in the hard surface and the corresponding loss of kinetic energy as thermal energy. Simply stated, the hysteresis force takes into account the internal friction of the rubber tire and allows some of the tire's energy to be dissipated as heat. The adhesion force, $F_{a}$, results from the micro-scale bonding of the tire to the hard surface.

While these parameters are sufficient for an empirical measurement of friction, it will become important to later discuss the more complex aspects of rubber-pavement friction in numerical terms. In practice, however, this broad examination of rubber-pavement friction is sufficient 
for determining important aspects of pavement such as rolling resistance and skid resistance.

It should be noted here that friction is rarely presented as a measure of force. It is often preferred to present friction as a dimensionless coefficient, written as $\mu$ or FC. This friction coefficient is the ratio of the total frictional force between an interface and the total vertical load on the interface, such that

$$
\mu=\frac{F_{f}}{F_{v}}
$$

where $F_{v}$ is the total vertical load. In tire-surface interfaces, $F_{v}$ is the magnitude of the total gravitational force, $F_{g}$, acting on the interface. One could also write the friction coefficient as the ratio of the total friction force and the magnitude of the normal reaction force, $F_{N}$, provided by the hard surface.

The two friction coefficients this research will focus on are the static and dynamic (kinetic) coefficients. The coefficient of static friction describes the frictional force while two objects are stationary with respect to each other, i.e., a car tire rolling (without slipping) across pavement. The coefficient of dynamic friction describes the frictional force between two objects that are moving with respect to each other, such as a car tire skidding across a pavement.

For agencies interested in the interface of a ground-based vehicle and a hard surface, it is beneficial to measure the coefficient of friction, as it is proportional to the relative safety of the surface during both wet and dry conditions, tire wear, splash and spray, and exterior and interior noise (Henry 2000). Similarly, for agencies interested in the interface of aircraft tires and a hard surface, the coefficient of friction gives a measure of how safe it is for an aircraft to land during both dry and contaminated conditions and how much rolling resistance is present when aircraft are taking off; have drag due to fluid spray; and there is tire wear.

The characteristics of the hard surface also contribute to the frictional resistance. The surface characteristics control the magnitude of the measured friction; therefore, it is important to understand the surface's 
contribution to friction. The overall texture profile of the hard surface is of particular importance to the measurement of friction. The hard surface's texture can be characterized by four components: microtexture, macrotexture, megatexture, and roughness (PIARC 1987). See Table 1 for the breakdown of texture to wavelength. As expected, microtexture contributes to the adhesion (micro-scale) force of friction. Similarly, macrotexture and megatexture contribute to the hysteretic (deformation) force of friction. The roughness of the pavement greatly affects the rolling resistance of the pavement and tire wear.

Table 1. Pavement texture and wavelength designations.

\begin{tabular}{|l|l|}
\hline Texture & Wavelength $(\mathrm{mm})$ \\
\hline Microtexture & $<0.5$ \\
\hline Macrotexture & $0.5-50$ \\
\hline Megatexture & $50-500$ \\
\hline Roughness & $>500$ \\
\hline
\end{tabular}

Surface texture is of particular importance during wet pavement conditions. During wet pavement conditions, the tire-pavement interaction takes place in two steps. First, the leading edge of the rubber tire expels most of the water in the tire contact area. Second, the remaining film of water is removed by the tire based on the viscosity of the water and the microtexture profile of the surface (Kummer and Meyer 1967). In this interaction, the macrotexture and megatexture of the surface govern how efficiently water is drained from the pavement. At low speeds, where the tire is allowed ample time to expel the majority of water in the tire contact area, the microtexture of the surface dominates the frictional force (Henry 2000). A higher vehicle speed shortens the amount of time the tire has to contact the pavement and could result in wet skidding or hydroplaning.

Of less, but still significant, importance is the temperature of the rubber tire. As the temperature of the rubber decreases, the elasticity modulus increases, leading to a decrease in the hysteresis contribution to frictional force. In other words, as the rubber cools down it is less likely to deform when contacted by the aggregate particles in the pavement. A further look at the temperature dependence of friction measurements was conducted by Bianchini et al. (2011). It was proposed that a temperature correction factor, $C_{T}$, could be calculated that would offset the friction measurement. For example, if friction is measured at a fixed temperature and measured 
again at a higher temperature, the second friction measurement will be more positive than the first, and $C_{T}$ will reduce it accordingly.

\subsection{Types of friction testers}

There are a number of full-scale friction testers available that work at high speeds. These testers can be divided into five categories: locked-wheel, fixed-slip, variable-slip, side-force, and decelerometer.

Locked-wheel testers operate under a 100\% slip condition, i.e., they measure the frictional force while the tire is in the locked-wheel state (tire slip speed is the same as vehicle speed). The test tire is run at a constant speed and under a constant vertical load. Water is used to wet the pavement as the test tire runs over it. The force required to continue sliding the locked test tire over the pavement is recorded. This force is divided by the effective vertical load on the wheel, multiplied by 100 and then reported as the skid number (SN; ASTM 2015a). These locked-wheel testers usually take the form of a trailer that is towed behind a vehicle. Skid numbers must be reported differently depending on what kind of tire is used, i.e., for a standard ribbed tire (ASTM 2015b) and for a standard smooth tire (ASTM 2015c). Locked-wheel testers are most commonly used by state Departments of Transportation (DOTs), as they are heavy enough to resist bouncing while operating on large, rough road networks.

Fixed-slip skid testers measure friction at a fixed slip ratio. The braking slip ratio is defined as the ratio of the angular velocity of the tire, under application of torque, and the angular velocity of the tire unbraked. The slip ratio for fixed-slip testers is usually held to around 10\% to 20\% (Henry 2000). Fixed-slip testers typically take the form of a tow-behind trailer setup. These devices are in the family of continuous friction measurement equipment (CFME). The tester typically has multiple driving tires on the front axle and a single test tire on the rear axle. The test tire is slipped by a chain drive (at a lower speed than the driving tires) and allowed to contact the pavement. Water is used to wet the pavement where the test wheel contacts the pavement. The vertical load and braking force is measured and reported as the instantaneous friction reading or the braking force coefficient (BFC). The instantaneous friction reading is the braking force divided by the vertical load and the BFC is the mean of multiple instantaneous friction readings (ASTM 2015j). Fixed-slip CFMEs are most commonly used at military and civilian airfields. Fixed-slip CFMEs, like 
the Mk2 GT, are smaller and lighter than their locked-wheel counterparts and are suitable for the relatively flat pavements seen on airfields.

Variable-slip friction testers work much like the fixed-slip testers described above. Instead of using a fixed value for the slip ratio, variableslip testers run through a range of preset slip ratios. Water is used to wet the pavement immediately in front of the test tire or tires. This is also a continuous friction measuring device. Longitudinal braking slip friction force, vertical load, and the distance the test vehicle has traveled are used to calculate the braking slip friction coefficient. Finally, slip friction force is reported as a function of time and is the longitudinal friction force divided by the vertical load (ASTM 2015g).

Side-force friction testers usually consist of three wheels: a distance and speed sensing wheel at the rear and two friction testing wheels at the front. The testing wheels are held at an angle (yaw angle) to the direction of travel. This angle is usually held between 7.5 and 20 deg. The test tires are allowed to contact the pavement and the vertical load on the test tires, friction force perpendicular to the rotation plane, velocity of test tire, and yaw angle are measured. The side-force coefficient (SFC) is reported as 100 times the quotient of the perpendicular friction force and the vertical load. Unlike the other friction testers, the side-force tester gives a measurement of the cornering friction force (ASTM 2015d). The most popular side-force friction testers are the Mu-Meter and the Side-Force Coefficient Road Inventory Machine (SCRIM).

Decelerometers were used in the late 1960 s and early 1970 as a measure of aircraft stopping performance. Decelerometers measure the deceleration of a vehicle and report the value as a percentage of the acceleration of gravity, $\% g$. These devices were typically used to report the runway condition reading (RCR) or a pavement surface in certain conditions. The RCR value is determined by fitting a decelerometer securely to a vehicle and measuring the deceleration just as the vehicle enters the locked-wheel state. The peak deceleration value was then reported as the RCR in $\mathrm{ft} / \mathrm{s}^{2}$. A typical RCR for dry pavement is 23; for wet, 12; and icy, 5 . These decelerometer measurements were known to have poor correlation with actual aircraft stopping performance in wet and flooded pavement conditions (NASA 1969; Yager et al. 1970). The RCR was known, however, to report conservative values for aircraft stopping performance on snow- and ice-covered runways (Yager et al. 1970). The 
FAA does not approve decelerometers for friction condition surveys in wet-pavement conditions, but does approve them for friction surveys during winter conditions (FAA 1997).

\subsection{Models of friction on paved surfaces}

It has been known since the 1930s (Moyer 1934) that skid resistance has a negative correlation with speed. It is common today to draw this correlation not between the vehicle's speed and the skid resistance, but between the tire's slip speed and the skid resistance. Slip speed is the tire's velocity relative to the surface. There are a number of ways to model this behavior.

Work was conducted by Leu and Henry (1983) to develop the Penn State Model of friction. This model describes the dependence of friction on slip speed by writing the friction coefficient as an exponential function:

$$
\mu=\mu_{0} e^{-\frac{P N G}{100} S}
$$

where $\mu$ is the friction coefficient, $\mu_{0}$ is the zero-speed friction coefficient, $S$ is the slip speed, and $P N G$ is the percent normalized gradient, where

$$
P N G=-\frac{100}{\mu} \frac{d \mu}{d S}
$$

$P N G$ has been found to correlate highly with surface macrotexture and $\mu_{0}$ was found to highly correlate with microtexture. A more compact form of the Penn State Model later replaced the above form.

$$
\mu=\mu_{0} e^{-S / s_{p}}
$$

where $S_{p}$ is a speed constant empirically described as a linear relation of surface macrotexture.

The Rado Model was developed to model the behavior of friction under changing slip speed (Rado 1994). Take for example a car braking on pavement. As the brakes are applied, the friction applied to the car's tire 
increases from a minimum value to a peak value. After the peak value, the frictional force begins to exponentially decay as the tire reaches the locked-wheel state and the tire's slip speed matches the vehicle speed. Rado also modeled this behavior as an exponential function,

$$
\mu(s)=\mu_{\text {peak }} e^{-\left[\left[^{\operatorname{Ln}\left(S / S_{\text {peak }}\right)} / C\right]^{2}\right.}
$$

where $\mu(S)$ is the friction coefficient as a function of slip speed, $S, \mu_{\text {peak }}$ is the peak friction coefficient, $S_{\text {peak }}$ is the corresponding peak slip speed, and $C$ is the shape factor of the surface texture. Results from the Rado model are in Figure 1.

Figure 1. Rado (1994) model plot for three sets of parameters.

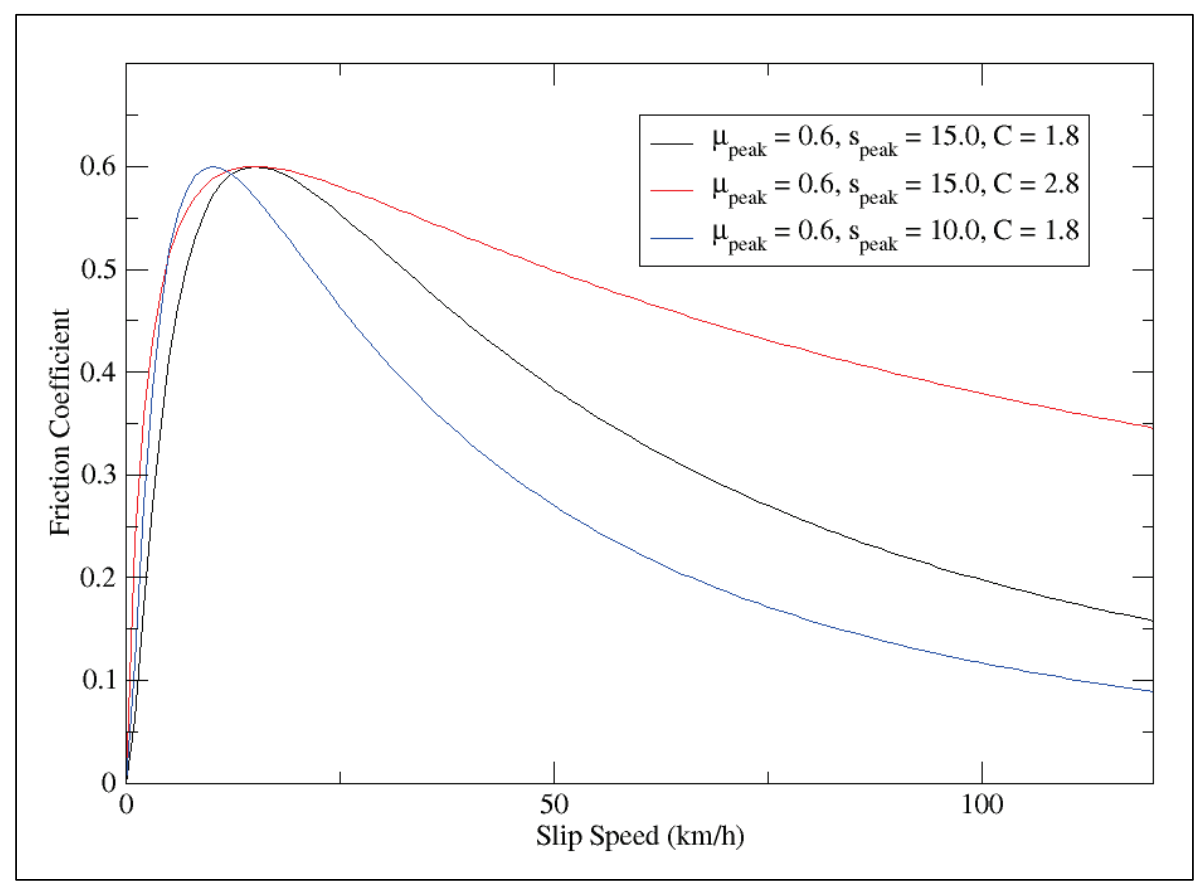

It should be noted that anti-lock braking systems take advantage of this behavior by applying the brakes until the peak friction value is found and then releasing the brakes momentarily so that the locked-wheel state is avoided, and then reapplying the brakes until peak friction is observed again.

The two preceding models allow for a fairly comprehensive look at braking friction. When the brakes are applied, the frictional force of a vehicle follows the Rado model until the locked-wheel state is reached; then the 
frictional force follows the Penn State model. If a vehicle is using an antilock braking system, as the brakes are applied, friction follows the Rado model until peak friction is found, then the brakes are released for a moment and when they are reapplied, the friction follows the Rado model for a lower vehicle speed (Henry 2000).

\subsection{Models of friction on unpaved surfaces}

The measurement of friction on unpaved (deformable or yielding) surfaces such as soil, sand, clay, mud, snow, and SPAM (Semi-prepared and Aluminum Matted), is more difficult. Specifically, one of the underlying assumptions made when considering friction on a paved surface is that the rubber tire undergoes all or most of the deformation during the interaction. On less rigid surfaces, like the ones listed above, the surface undergoes a significant deformation.

\subsubsection{Friction on unpaved soil surfaces}

It has been found that, on an unpaved soil surface the rolling friction, or drag load, is

$$
F_{x}=\left(\mu_{0}+\frac{Z}{L_{t}}\right) F_{t}+\frac{1}{2} \rho b Z C_{D} V^{2}
$$

where $\mu_{0}$ is the rolling friction coefficient for a rigid surface, $Z$ is the dynamic sinkage, $L_{t}$ is the tire footprint length, $F_{t}$ is the vertical tire force, $\rho$ is the soil density, $b$ is the tire width, $C_{D}$ is the soil drag coefficient, and $V$ is the velocity of the wheel axle (Crenshaw 1972). The computation of dynamic sinkage relies upon the soil mobility work of the U.S. Army Engineer Waterways Experiment Station (WES; Turnage 1967). The mobility numbers, $\Omega$, developed by WES wrote the tire properties in terms of the soil condition. The WES mobility numbers were then refined by Crenshaw (1972) to include tire pressure in the sinkage calculation. The modified mobility number, $\Omega^{\prime}$, and dynamic sinkage relationships were developed for clay, $Z_{C}$, and sand, $Z_{S}$.

$$
Z_{c}=d\left(\frac{0.1208}{\Omega_{C}^{\prime}-0.9468}-0.0095\right)
$$




$$
Z_{s}=d\left(\frac{0.3439}{\Omega_{S}^{\prime}-0.6239}-0.0017\right)
$$

A preliminary look at the skid resistance on soil surfaces was later conducted by (Lea and Jones 2007) and found that the skid resistance on a soil surface depends on three key factors: inter-surface friction, sliding, and plowing. The inter-surface friction component is the familiar interaction of a tire with a rigid surface in which the surface texture is the dominant factor. The sliding component refers to a tire sliding on a thin layer of loose material. The plowing component is the interaction of a tire moving through a thick layer of loose material. While Lea and Jones (2007) give various drag relationships with the above three factors, they are not statistically significant enough to provide reliable skid resistance measurements. Further work is needed to confidently write the skid resistance on soil surfaces.

\subsubsection{Friction on unpaved viscous surfaces}

The rolling resistance of a tire in a supersaturated viscous mud (wet soil) on top of a hard foundation was considered by Rowe and Hegedus (1959). In their work, the wet soil is considered as a fluid and the motion of a tire through mud is considered as viscous flow around a partially submerged object. The rolling resistance, or total drag, is written as the sum of two components, i.e., friction drag and pressure drag. Rowe and Hegedus write this drag as

$$
D=\frac{2 \mu U A_{2}}{\delta}+\frac{\gamma}{2}\left(h_{1}^{2}-h_{2}^{2}\right) b+\frac{1}{2} \rho U^{2} A_{1}
$$

where $D$ is the total drag on the tire, $\mu$ is the viscosity, $U$ is the velocity, $A_{2}$ is the tire contact area with the soil also called the wetted area, $\delta$ is the boundary layer thickness, $\gamma$ is the specific weight, $h_{1}$ is the elevation ahead of the tire, $h_{2}$ is the elevation behind the tire, $b$ is the characteristic width of the tire, $\rho$ is the density of the fluid, and $A_{1}$ is the projected area in the direction of motion. Rowe and Hegedus concluded that this fluid dynamics approach to drag in loose, supersaturated soil is in close agreement with experimental results conducted on rectangular, tire-shaped, and parabolic wheels. 


\subsubsection{Friction on unpaved snow-covered surfaces}

Work has been done on calculating the rolling resistance of a rubber tire on dry snow by Lidstrom (1979) and van Es $(1998,1999)$. Their work shows that the rolling resistance of a tire-snow interface results from two distinct forces: snow compression resistance, $D_{c}$, and vertical displacement resistance (also dynamic motion of snow), $D_{d}$.

The snow compression contribution to the rolling resistance, $D_{c}$, was determined by Lidstrom (1979) by first calculating the work needed to compress the snow and then taking the derivative of this work with respect to the distance traveled:

$$
D_{c}=\int_{h_{f}}^{h_{o}} b \sigma d h
$$

where $h_{f}$ is the final snow depth, $h_{o}$ is the initial snow depth, $b$ is the effective tire width at the point of snow contact, and $\sigma$ is the unconfined compressive strength of the snow. Using expressions from van Es (1998) and Mellor and Smith (1966), $D_{c}$ can be written as

$$
D_{c}=\frac{b \sigma_{i} \rho_{o} h_{o}}{\rho_{i} \sqrt{\lambda}} \int_{u_{f}}^{u_{o}} e^{-u^{2}} d u
$$

where $\rho_{o}$ is the initial snow density, $\sigma_{i}$ is the compressive strength of ice, $\rho_{i}$ is the density of ice $\left(920 \mathrm{~kg} / \mathrm{m}^{3}\right)$, and $\lambda$ is the grain structure index. The integral limits are written as

$$
u_{f}=\sqrt{\lambda}\left(\frac{\rho_{i}}{\rho_{f}}-1\right), u_{o}=\sqrt{\lambda}\left(\frac{\rho_{i}}{\rho_{o}}-1\right)
$$

where $\rho_{f}$ is the final snow density. The final snow density was determined empirically by Richmond (1990) as shown in Table 2. 
Table 2. Tire pressure and snow density correlations.

\begin{tabular}{|l|l|}
\hline Tire Pressure (psi) & $\begin{array}{l}\text { Final Snow Density } \\
\left(\mathrm{kg} / \mathrm{m}^{\wedge} \text { ) }\right.\end{array}$ \\
\hline$<22$ & 450 \\
\hline $22-31$ & 500 \\
\hline $31-50$ & 550 \\
\hline $51-101$ & 600 \\
\hline$>101$ & 650 \\
\hline
\end{tabular}

It should be noted that this form of $D_{c}$ applies to a single tire contacting dry snow. When applying this equation to an aircraft, one must compute $D_{c}$ for each tire and sum them.

The rolling resistance due to the vertical displacement of snow is given by calculating the work necessary to compact a volume of snow at some compacting velocity, $v_{z}$ (Lidstrom 1979, van Es 1998).

$$
D_{d}=\frac{b}{2} \int_{h_{f}}^{h_{o}} \rho V_{g}^{2} \sin ^{2} \alpha d h
$$

where $V_{g}$ is the ground speed and $\alpha$ is the angle between the negative vertical and the height of the snow contacting the tire. Using the geometrical representation of the tire-snow interface, van Es (1999) simplifies the above expression to

$$
\begin{aligned}
D_{d}=\frac{b}{2} h_{o} \rho_{o} V_{g}^{2} & {\left[\left(1-\cos ^{2} \alpha_{1}-\frac{2}{R} h_{f} \cos \alpha_{1}-\frac{h_{f}^{2}}{R^{2}}\right) \ln \left(\frac{h_{o}}{h_{f}}\right)\right.} \\
+ & \left(h_{o}-h_{f}\right)\left(\frac{2}{R} \cos \alpha_{1}+\frac{2 h_{f}}{R^{2}}\right) \\
& \left.-\frac{1}{2 R^{2}}\left(h_{o}^{2}-h_{f}^{2}\right)\right]
\end{aligned}
$$

where $R$ is the tire radius and $\alpha_{1}$ is the angle between the negative vertical and the final height of the snow. The final height of the snow, $h_{f}$, is approximated by assuming that all of the snow compaction by the leading edge of the tire is vertical (van Es 1999). 


$$
h_{f}=h_{o} \frac{\rho_{o}}{\rho_{f}}
$$

The total rolling resistance of the tire-snow interface, due only to dry snow, is

$$
D_{s}=D_{c}+D_{d}
$$

Van Es (1999) lists a number of limitations to this calculation of rolling resistance:

1. Snow depth must not exceed tire radius. This condition adds a "bulldozing" effect to the rolling resistance not considered above.

2. Only works for natural snow, not processed snow. Sinha (1998) shows that processed snow behaves differently than natural snow.

3. Only applies to dry snow.

Van Es (1999) reports good correlation between the above model and data taken from Citation II and Falcon 2000 aircraft on snow-covered runways.

\subsection{Texture measurement}

While microtexture and macrotexture are important to a surface's frictional response to a moving rubber tire, they have both historically been difficult or tedious to measure. Pavement surface texture is typically described in two dimensions by the mean profile depth (MPD) and in three dimensions by the mean texture depth (MTD). The MTD is typically measured by means of a linear relationship with the MPD. To calculate the MPD, a $100 \mathrm{~mm}$ segment of texture is broken into two $50 \mathrm{~mm}$ halves. The average of the peak segment height is reported as the mean segment depth, and the average of multiple mean segment depth measurements is reported as the MPD (ASTM 2015f).

As microtexture is difficult to measure directly, it is common for a related parameter to be measured instead. The British Pendulum Tester (BPT), or British Portable Tester, reports British Pendulum Numbers (BPNs) that correspond to microtexture. The BPT consists of a pendulum arm with a weighted rubber slider on its end. The pendulum is released from a 
horizontal position and the rubber slider contacts a sample of pavement. The retardation of the pendulum swing after contacting the sample pavement is reported as the BPN of the sample (ASTM 2013).

The Nippou Sangyo Dynamic Friction Tester is a friction measuring device that consists of a horizontally spinning disc (parallel to surface) and three spring-loaded rubber sliders mounted on the disc. A water supply is also used to saturate the pavement to be tested. A constant vertical load is applied to the disc and as the rubber sliders contact the pavement surface, the peripheral speed of the disc decreases to a stop. The torque generated by the slider contact with the pavement is measured and used to report the friction as a function of speed (ASTM 2009). It has been shown that DFT results at $20 \mathrm{~km} / \mathrm{h}(12.4 \mathrm{mph}$ ) highly correlate with BPN values (Wambold et al. 1998) and therefore also correlate highly with surface microtexture.

Low-speed locked-wheel skid trailer friction measurements with a ribbed tire (ASTM 2015b) have also been shown to be more sensitive to microtexture than macrotexture (Leu and Henry 1978).

In the United Kingdom (UK), side-force friction measurements using the SCRIM are considered to be analogous to surface microtexture (Henry 2000).

Work has been done on contactless measurement of 2-D surface microtexture in a laboratory setting using charge-coupled device (CCD)based photography (Ergun et al. 2005). This contactless measurement of microtexture was conducted by first taking a core sample from a pavement, then placing the sample under a CCD camera. A razor blade was then illuminated by a fiber optic light at an angle of 45 deg onto the sample. A picture was taken at the area where the razor blade's shadow stopped, revealing the microtexture profile. This procedure, while laborious, finds the coefficient of friction as a function of slip speed and the macro/micro texture measurements by

$$
\begin{aligned}
F(S)=(0.37 & +\frac{0.11}{M P D_{\text {mac }}} \\
& \left.\left.+\frac{0.15}{L a_{m i c}}\right) e^{\left[S / 149+81 \log \left(M P D_{m a c}\right)+80 \log \left(R q_{m i c}\right)\right.}\right]
\end{aligned}
$$


where $M P D_{m a c}$ is the macrotexture mean profile depth (MPD), $R q_{m i c}$ is the root mean square (RMS) deviation of the microtexture surface profile, and $L a_{m i c}$ is the average wavelength of the microtexture surface profile.

Macrotexture is considerably easier to measure than microtexture. The classic way to measure surface macrotexture is the so-called "sandpatch" method. This is a volumetric method characterized by its use of Ottawa sand or uniform glass spheres of known radius. The sand is spread out on the surface of the pavement in a roughly circular patch. Four equally spaced diameters are chosen and the volume of sand (or glass spheres) is measured for each. The volume of the sand for each diameter is divided by the area and reported as the MTD (ASTM 2015e). Glass spheres are now the ASTM standard in place of Ottawa sand. The glass spheres spread out more evenly on pavement and do not need to be sieved like sand.

The outflow meter is also used to measure surface macrotexture (ASTM 2015k). The outflow meter test has been used since the late sixties (Moore 1966, Hegmon and Mizoguchi 1970). An outflow meter consists of a plastic or glass cylinder with a rubber gasket fitted to the open bottom. The cylinder stands normal to the pavement surface with the rubber gasket making contact with the pavement texture. Water is released through the cylinder and the time it takes for the water to escape through the bottom of the cylinder is reported as outflow time (OFT). On an ideal glass surface, the rubber gasket makes perfect contact with the surface and no water is allowed to escape. On a textured pavement surface, macrotexture particles (aggregate particles) keep the rubber gasket from making a perfect seal. This imperfection allows water to escape and the time it takes for the water to escape (OFT) is proportional to the texture profile of the surface (Wambold et al. 1998). Long OFTs are expected for smooth, polished surfaces and short OFTs are indicative of a rough surface. While the outflow meter test can still be useful today, it is usually outclassed by more modern laser profiling techniques (Pullen et al. 2014).

In the late 1960s, a novel method to measure the surface macrotexture depth was developed by NASA called the NASA grease smear test (Leland et al. 1968). The method involves smearing a known volume of grease along a fixed-width track. The grease is spread carefully in the track with a rubber squeegee, taking care that all of the grease stays within the track. The volume of grease and the area it covers is used to measure the texture depth. The modern standard uses 1 cubic in. $(15 \mathrm{cc}$ ) of general purpose 
grease and a 4 in. (10 cm)-wide track. The track can be made of either masking tape or aluminum. The texture depth is computed by dividing the volume of grease by the area covered by the grease. Multiple tests can be conducted for one pavement surface and then averaged to yield the average texture depth. Although the NASA grease smear method is dated and subjective, it is still used today (Cotter et al. 2012, Pullen et al. 2014). Measurements of macrotexture profile follow ASTM standards (ASTM 2015f).

In the late 1990s, the Circular Track Meter (CTM or CT meter) was developed in order to measure surface macrotexture (Henry 2000). The CTM makes use of modern CCDs in order to convert incoming photons into an electrical charge. This conversion allows for the digitization of images, which in turn allows for images to be analyzed directly by a computer. The CT meter consists of a CCD mounted on the end of an arm. The CCD in this case operates as a laser displacement sensor (ASTM 2015i). The arm rotates at a fixed height and fixed rate and sweeps out a circle of diameter $284 \mathrm{~mm}$ (11.18 in). The CCD measures and reports the MPD and RMS of the macrotexture profiles. The circle is broken into eight equal arc segments and data is obtained for each segment.

Work has also been conducted to measure MPD of macrotexture by use of 3-D laser scanning technology (Sengoz et al. 2012). This work utilized a modern 3-D laser scanner to measure the macrotexture profile of a pavement surface and to relate the macrotexture MPD to the macrotexture MTD. Sengoz et al. developed a linear relationship between MPD and MTD that showed comparable results to the ASTM sand patch test standard (ASTM 2015e) and the NCAT standards from 2000 and 2003 (Hanson and Prowell 2004). Surface macrotexture is very important to wet pavement safety for both ground and air-based vehicles. This concern makes highspeed measurement of surface macrotexture in 2-D (MPD) and 3-D (MTD) very important. To this end, research has been conducted to relate the familiar skid number, from locked wheel testers, to surface texture (Ergun et al. 2005, Jackson et al. 2007, Khasawneh and Liang 2008, Meegoda and Gao 2015). This work allows for accurate measurement of the friction coefficient of a surface without disturbing traffic.

\subsection{International friction index}

Each of the previously mentioned devices/procedures reports a distinct value of either friction or texture profile. It can be complicated for 
researchers to choose which method to use when they all report unique values. In order to harmonize friction and texture measurement, the International Friction Index (IFI) was created by the Permanent International Association of Road Congresses (PIARC), or now the World Road Association (Wambold et al. 1995). The PIARC experiment was performed in Europe in 1992 and included participants from 14 different countries and 54 test sites (Henry 2000). PIARC adopted the Penn State model of friction to develop the IFI. The Penn State model used by PIARC was adjusted to

$$
F R 60=F R S e^{(S-60) / s_{p}}
$$

where $F R 60$ is the friction value adjusted to a slip speed of $60 \mathrm{~km} / \mathrm{h}, F R S$ is the friction value as a function of slip speed, $S$, and $S_{P}$ is the speed constant. The speed constant is found as a function of MPD (macrotexture measurement) as

$$
S_{p}=a+b \times T X
$$

where $T X$ is the macrotexture measurement and $a$ and $b$ are constants determined by what equipment is used to make the macrotexture measurement. If the CTM or similar technology is used as a macrotexture source, then $T X$ is reported as MPD, a $=14.2$, and $\mathrm{b}=89.7$ (ASTM 2015 $\mathrm{h}$ ). With $S_{p}$ and $F R 60$, the final step is to find the calibrated friction number, F60:

$$
F 60=A+B \times F R 60
$$

Combining the equation for $F 60, S_{P}$, and $F R 60$ gives

$$
F 60=A+B \times F R S \times e^{-(60-S) /(a+b \times T X)}
$$

It is common to use the CTM for the macrotexture measurement and the DFT for the friction measurement at $20 \mathrm{~km} / \mathrm{h}$. The calibration constants for those two machines yield the following (ASTM 2015h) 


$$
\begin{gathered}
S_{p}=14.2+89.7 M P D \\
F 60=0.081+0.732 D_{D T} T_{20} e^{-40 / S_{p}}
\end{gathered}
$$

The values of $S_{P}$ and $F 60$ are reported as the IFI. The robustness of the IFI is its ability to give both a friction and macrotexture measurement for a single strip of pavement. Also, since the value of friction is adjusted to 60 $\mathrm{km} / \mathrm{h}$ slip speed in the parameter $F 60$, an actual measurement of friction can be made at any slip speed. One significant limitation of the IFI is its reliance on data previously obtained on specific machines in specific conditions. It has been proposed that the various coefficients derived during the original PIARC experiment should be adjusted (Flintsch et al. 2009). It was also proposed by Descornet (2004) that a power model be used in place of PIARC's linear model in the determination of the speed constant, $S_{P}$. The so-called HERMES project reports better speed constant results using the following expression: $S_{p}=a \times T X^{b}$.

While Descornet (2004) reports better results using the power model of $S_{P}$, Flintsch et al. (2009) confirm this only for smooth tire tests, not ribbed tire tests on certain devices. It is clear that improvements can still be made to the International Friction Index and the correlation of friction measurements between various devices.

\subsection{Vehicle on-board diagnostic interface}

The on-board diagnostic (OBD) system was originally designed in the late 1980 s with the purpose of managing the environmental impacts of road vehicles. As such, the early OBD interfaces (OBDI) were required only to measure environmentally relevant sensors like oxygen $\left(\mathrm{O}_{2}\right)$ sensors and exhaust gas recirculation (EGR) sensors. Later OBD interfaces (OBDII) as shown in Figure 2 required a more robust set of sensor data. Of particular interest to the present work is the recording of wheel speed through antilock braking system (ABS) sensors. 
Figure 2. OBDII interface installed in a vehicle.
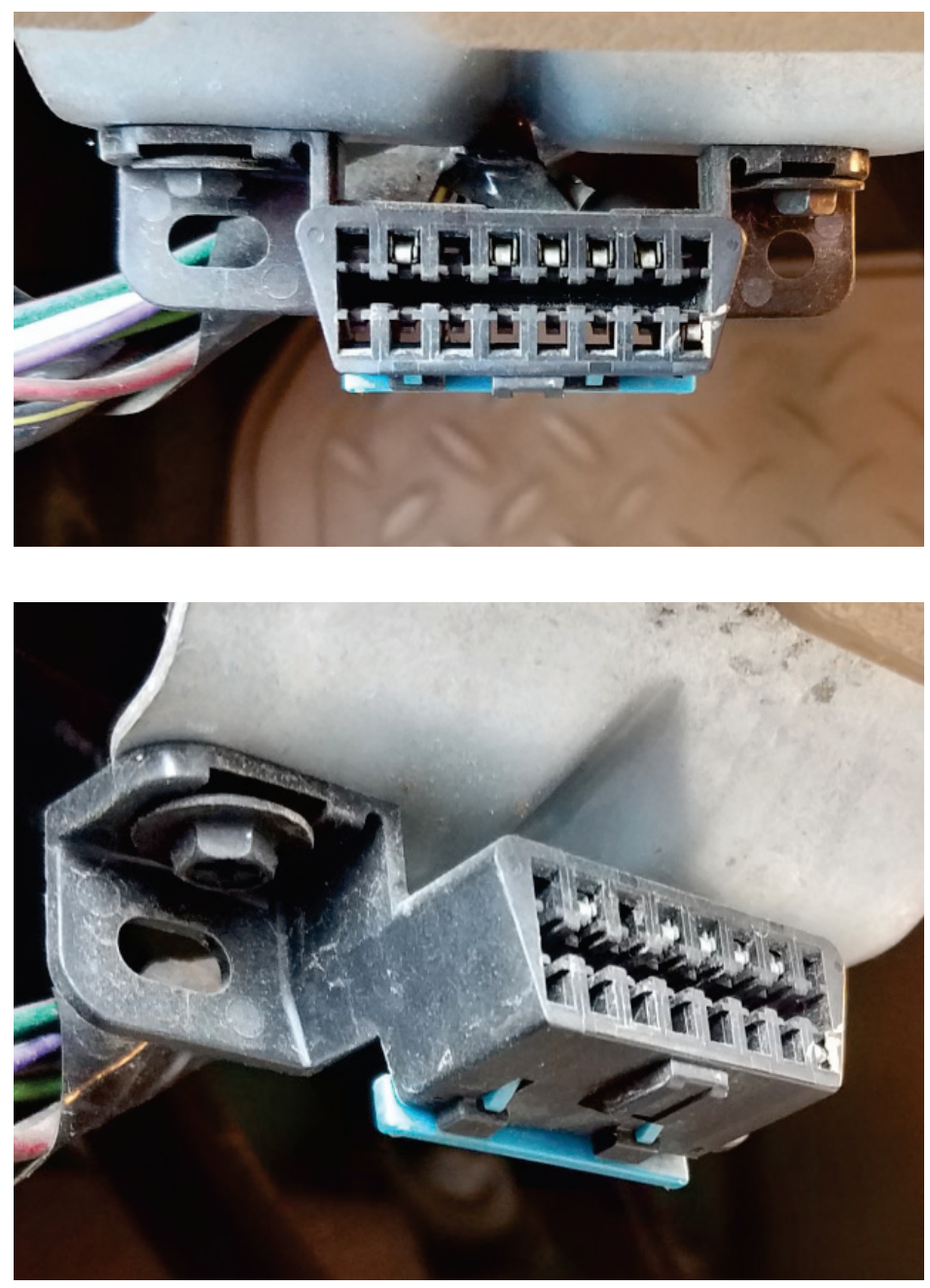

These devices connect to the diagnostic computer on board all major car brands in the United States and some others outside the United States. All major car manufacturers in the United States are required to provide access to the vehicles' diagnostic computer via the OBD port. Vehicles manufactured before 1996 are equipped with an OBDI (OBD one) interface. These interfaces typically transfer data at either 160 bits/sec or 8192 bits/sec. Vehicles manufactured after 1996 have an OBDII (OBD two) interface that transfers data at much higher rates, typically greater than 10.4 kilobits/sec. The shape and pinout diagrams of OBD interfaces were not standardized until the introduction of the OBDII interface. 


\section{Overview of ARA Collaboration}

A separate effort supported by the U.S. Air Force Civil Engineer Center (AFCEC) tasked ARA with providing variable speed friction data from various CFME devices. These tests were conducted on the Silver Flag (SF) test track at Tyndall Air Force Base, FL. The specific CFMEs targeted by this project were portable walk-behind devices: Findlay Irvine micro GripTester, the ASFT T2Go, and the Findlay Irvine GripTester in walkbehind mode. Collaboration with ARA in this work is ideal as variable speed CFME data are necessary for deceleration-CFME correlations. In support of ARAs effort, the ERDC provided DFT equipment and operation. The DFT results provided by the ERDC have assisted ARA in providing IFI conversions of CFME data. The ERDC also provided texture measurements collected using an Ames LTS.

\subsection{Synthesis of ARA results}

Data provided by ARA in support of the ERDC's effort show the unique relationship between friction, speed, and texture. The following sections cover data collected from walk-behind CFMEs (mGT, T2Go), tow-behind CFMEs (Mk1 GT, Mk2 GT), and texture measurement devices (Elatextur, Ames). CFME data were collected by ARA on the SF friction test track in replicate. CFME tests were conducted in one direction in order to remove texture directionality from empirical results. While CFME tests were also conducted under dry pavement conditions, only wet pavement tests are considered in the present work. Water film thickness was kept to nominal levels as per ASTM standards (ASTM 2015j).

\subsection{Tow-behind CFME results}

Tow-behind CFMEs tested at SF by ARA were the Findlay Irvine Mk1 and Mk2 GripTesters. These devices are the Department of Defense (DOD) standard for full-size, high-speed continuous friction measurement. GripTesters typically operate at two speeds, 40 and $60 \mathrm{mph}$. Testing conducted at SF included the standard speeds as well as lower speeds: 1.6, 3.0, and $25 \mathrm{mph}$. Friction coefficient data collected with the Mk1 and Mk2 GTs are shown in Figure 3 and Figure 4, respectively. 
Figure 3. Mk1 GripTester vs. Lane for various operating speeds.

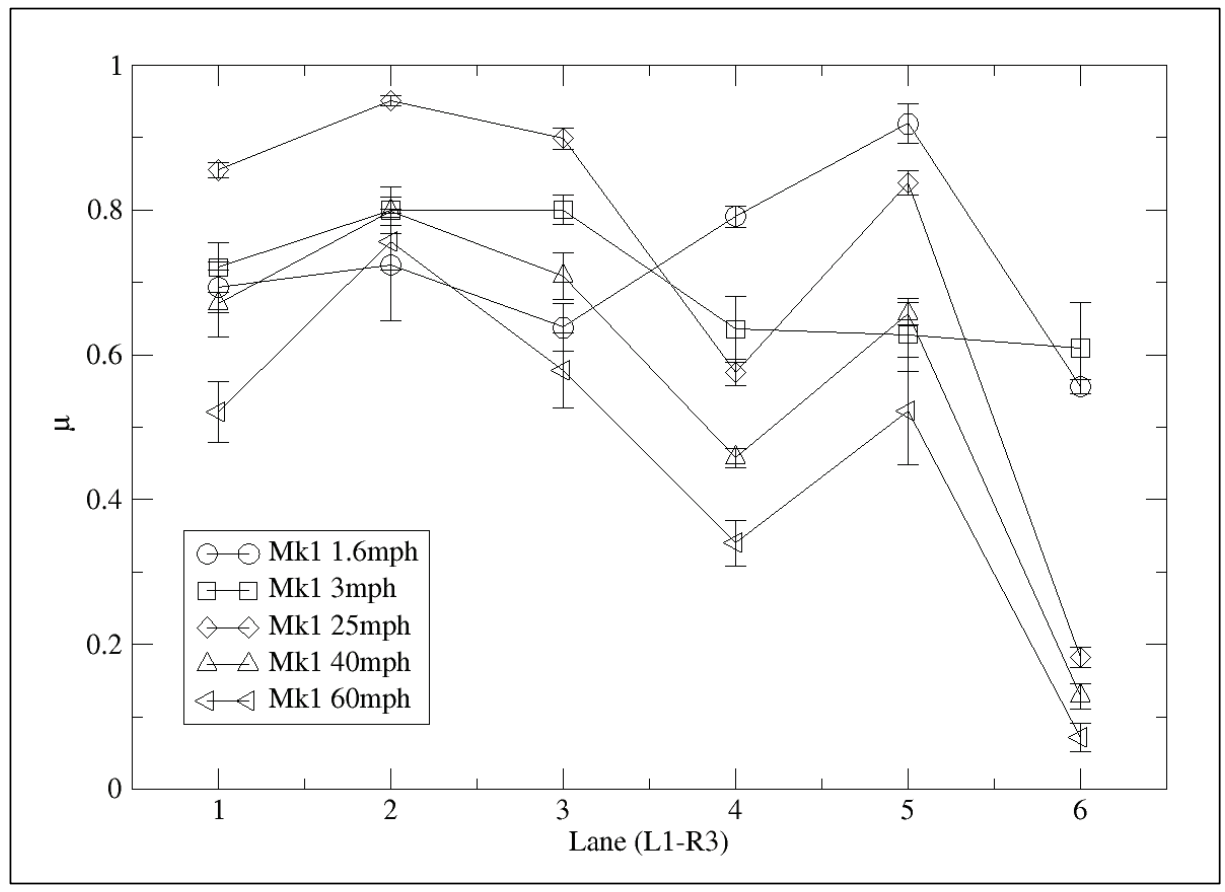

Figure 4. Mk2 GripTester vs. Lane for various operating speeds.

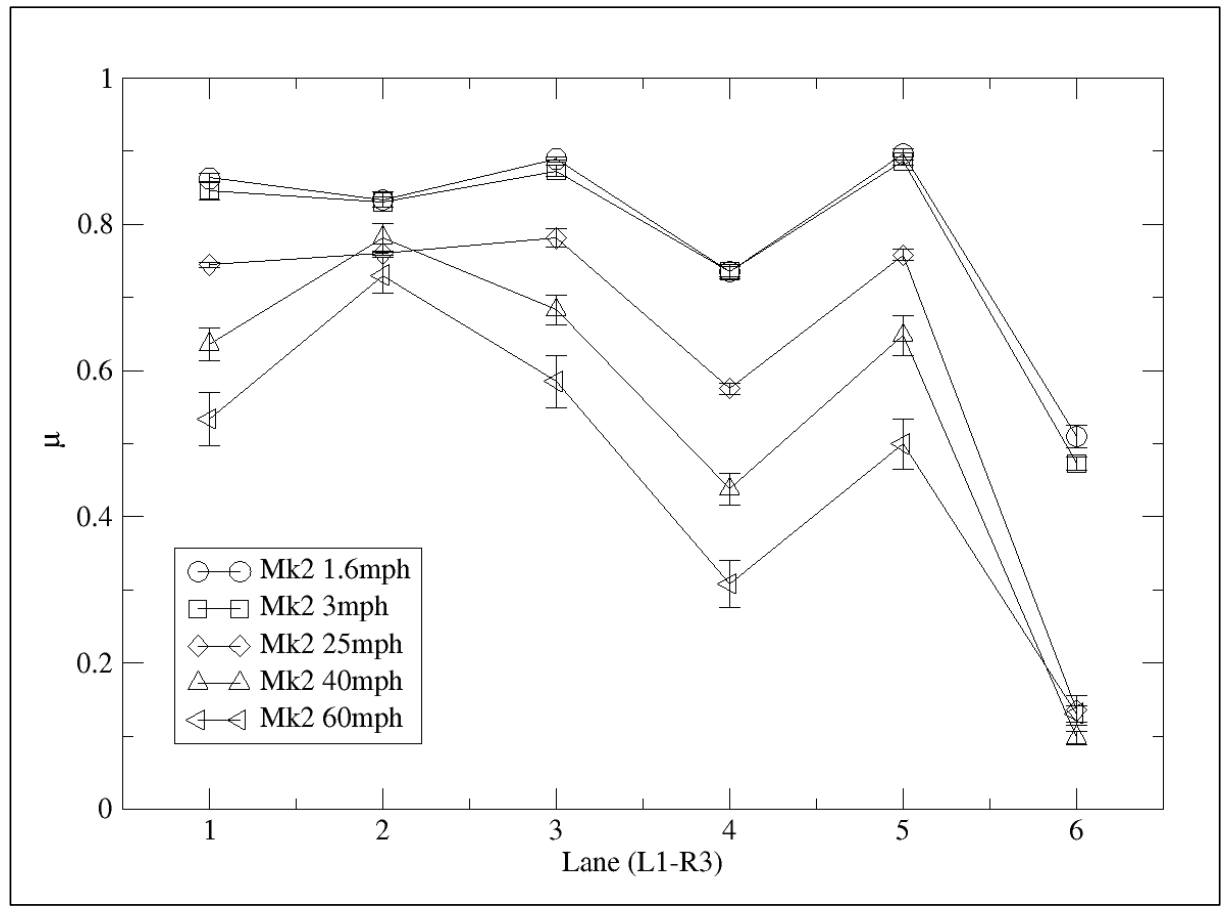


The same Mk2 GripTester (GT556) was used for all Mk2 GT testing; however, one Mk1 GT (GTo88) was used for the 1.6 and 3.0 mph speeds and another Mk1 GT (GT266) was used for the remaining speeds. Data in Figure 3 show significant differences in friction coefficient output between the GTo88 and GT226 GTs. ARA technicians reported a malfunction in the GTo88 device and remarked that the device was excluded from future testing.

Figure 5. Mk2 GripTester vs. speed for all six SF test sections (L1-R3).

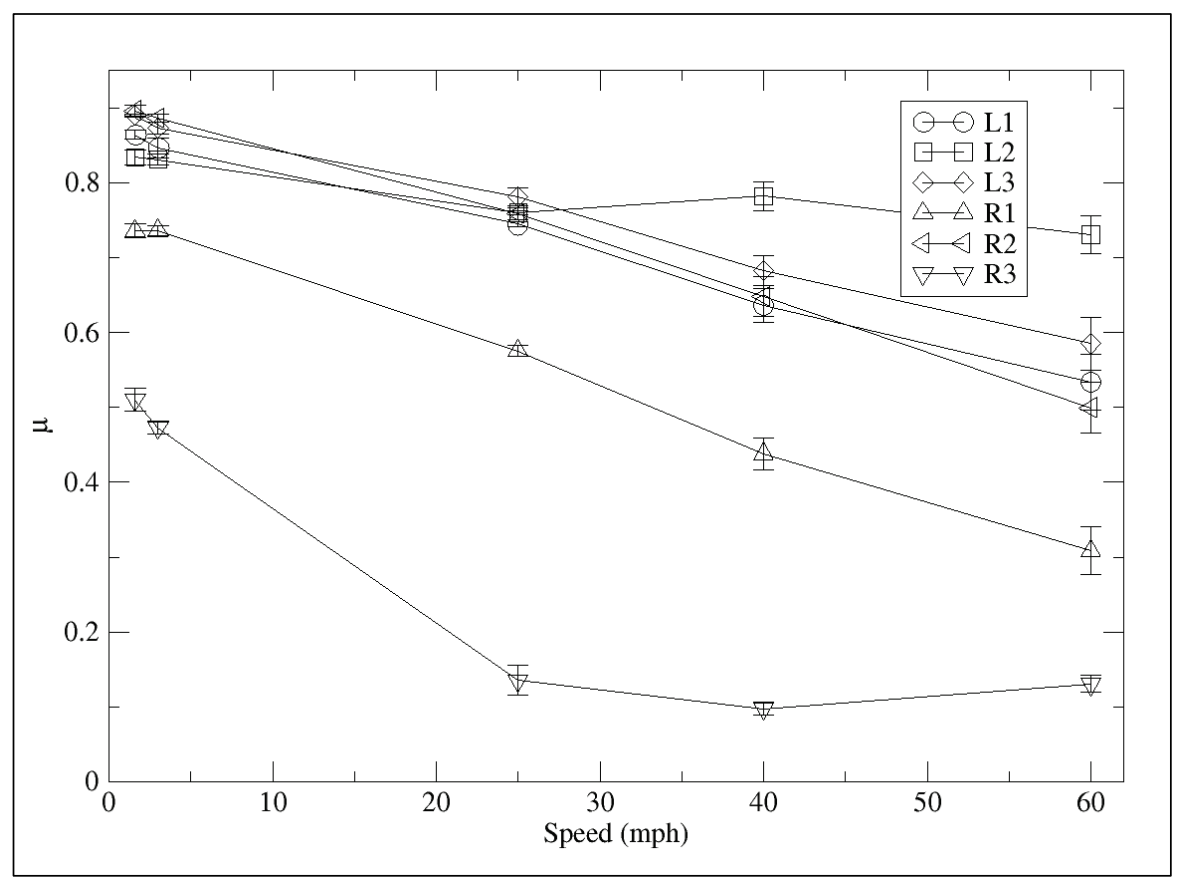

Mk2 GripTester results by speed in each of the six SF test lanes (see Figure 5) show a linear relationship between most SF lanes and speed. It should be noted that the two non-linear friction-speed curves in Figure 5 belong to the two extreme texture test sections, i.e., L2 at 1.245 MPD and R3 at 0.112 MPD. Friction response on $\mathrm{R}_{3}$ can be viewed as follows. Lower speeds increase the microtexture contribution (adhesion) of the surface thereby increasing the friction coefficient, and higher speeds diminish the microtexture contribution and increase the macrotexture contribution (hysteresis), of which the surface has very little, thereby decreasing the friction coefficient to a minimum value. Friction response in L2 is more nuanced. The apparent non-linear increase in friction at $40 \mathrm{mph}$ could be explained by the hindrance of high macrotexture at low speeds. At low speeds, the expected increase in the microtexture contribution could be impeded by the tire's inability to adhere to the surface due to large aggregate particles (macrotexture). This in conjunction with polished 
aggregate particles could lead to lower than expected friction response at lower speeds. It is also possible that there is some measure of equipment or user error in the high-speed tests due to the fact that the replicate measurement error in Mk2 GT friction output at high speed in L2 (0.020 at $40 \mathrm{mph}$ and 0.025 at $60 \mathrm{mph}$ ) is an order of magnitude higher than that at low speed in L2 (0.003 at $25 \mathrm{mph}$ and 0.007 at $3.0 \mathrm{mph}$ ).

Other than the abnormal high-speed nonlinearity in the L2 measurements and the expected exponential decrease in friction output in $\mathrm{R}_{3}$ at increasing speeds, it is appropriate to see a linear decrease in friction coefficient with increasing speed in the remaining test sections (L1, L3, R1, R2). Most importantly, data collected using the Mk2 GripTester clearly show a significant speed dependence in friction response. This speed dependence drives studies between varying friction measurement methods to be done at similar speeds. The comparison of friction measurement methods at varying speeds requires the use of information other than friction coefficient. Of particular interest to the present study is the inclusion of a macrotexture measurement in the reporting of friction response.

Also of note in Figure 4 is a change in texture dependence with speed. For instance, define $r_{n m}$ as the ratio of friction coefficient in the $n^{\text {th }}$ test section with that in the $m^{\text {th }}$ test section, such that

$$
r_{S n m}=1-\frac{f_{S n}}{f_{S m}}
$$

Now examine the relationship between sections L1 and L2 at speed. Recall that section L1 has an MPD of 0.576 and L2 an MPD of 1.245 or roughly double that of L1. At high speed, 40 and $60 \mathrm{mph}$, the Mk2 GT has a positive relationship with texture, $r_{L 12}$ of 0.187 and 0.269 respectively. That is, there is a clear increase in friction coefficient when going from low macrotexture to high macrotexture. This can be seen in the friction response in each SF test section at high speed such that in general friction coefficient will increase with macrotexture MPD. Applying this reasoning to the low speed CFME measurements would be a mistake. Based upon the CFME data collected from the Mk2 GT at low speed, it is not always given that an increase in texture will lead to an increase in friction coefficient. At low speed, 1.6 and $3.0 \mathrm{mph}$, the Mk2 GT has a negative relationship with texture, $r_{L 12}$ of -0.036 and -0.018 respectively. It is not guaranteed, 
however, that this negative relationship remains consistent at low speed. At low speed, the Mk2 GT has a positive relationship with texture between sections R1 and R2: $r_{R 12}$ of 0.179 at $1.6 \mathrm{mph}$ and 0.170 at $3.0 \mathrm{mph}$. It will be seen in the following section that this nuanced relationship between friction and texture at low speed exists in the smaller walk-behind CFMEs as well.

\subsection{Portable CFME results}

Replicate data (see Figure 6) collected by ARA show that the mGT is highly repeatable with a friction coefficient pooled standard deviation of 0.027 . This indicates that within manufacturer, mGT devices can be expected to repeat friction coefficients within 0.027 of each other. On the other hand, the T2Go device is highly variable within manufacturer (see Figure 7). With a friction coefficient pooled standard deviation of 0.104, the friction coefficient output from the T2Go device, an order of magnitude greater than the mGT pooled standard deviation, is poor. This indicates that replicate T2Go devices can only be expected to repeat each other within a friction coefficient of 0.104 .

With regards to the mGT device and operating speed, ARA researchers found that the manufacturer recommended speed of $1.6 \mathrm{mph}$ is ideal for friction measurement. Data collected using the mGT device at 1.6 and 3.0 mph show the operating speed dependence of the mGT friction tester (see Figure 8). From the figure, it is clear that friction coefficient resolution is much higher at the $1.6 \mathrm{mph}$ operating speed. Of particular interest is the resolution of friction data at the low-texture, low-friction end. At the operating speed of 3.0 mph (Figure 8), the mGT device observes little difference in friction coefficient between a L3 $(M P D=0.58)$ and R1 (MPD $=0.35$ ). This indicates that there is a "golden" speed at which the mGT must operate in order to at least have high-resolution low-friction coefficient data. Data collected thus far suggest that this "golden" speed for the mGT is the manufacturer's recommended speed of $1.6 \mathrm{mph}$. 
Figure 6. mGT vs. Lane for three replicate mGT devices.

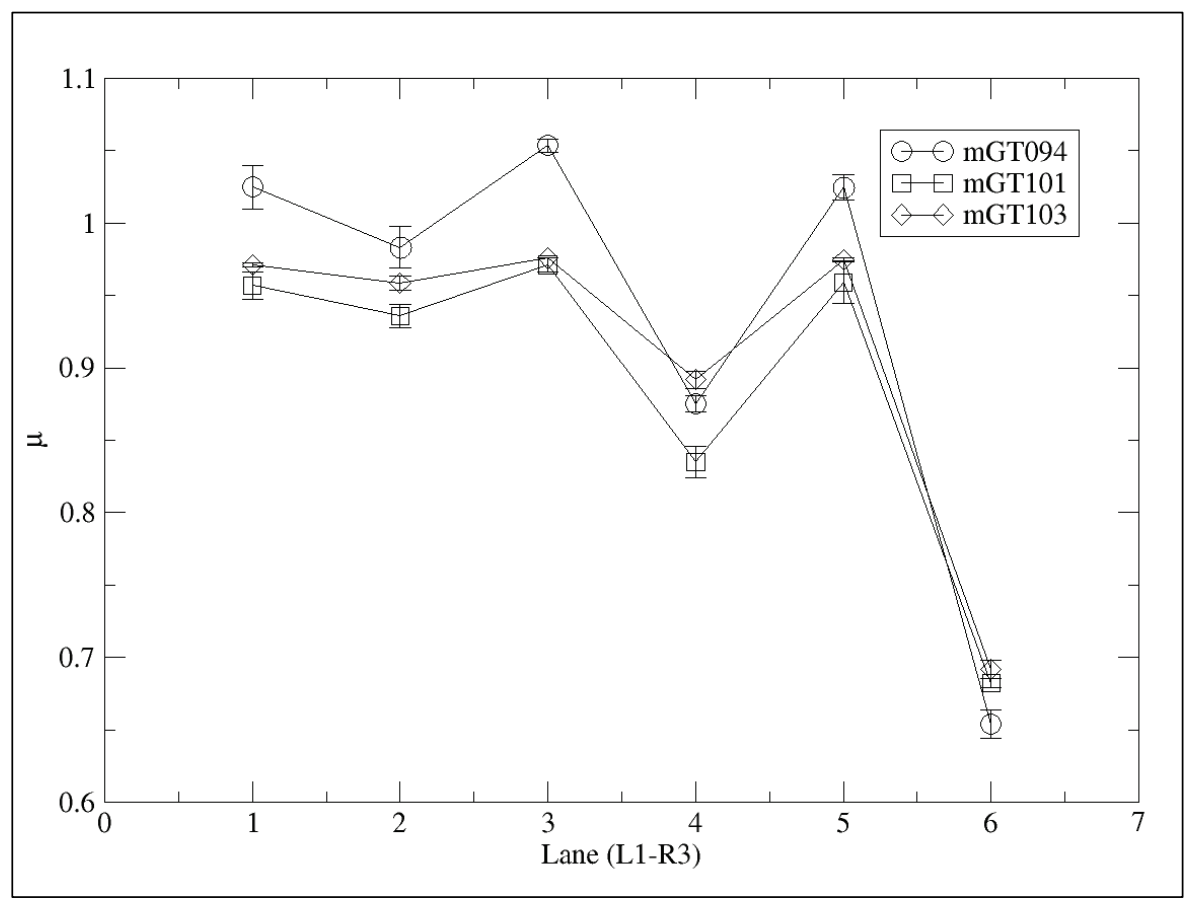

Figure 7. T2Go vs. Lane for three replicate T2Go devices.

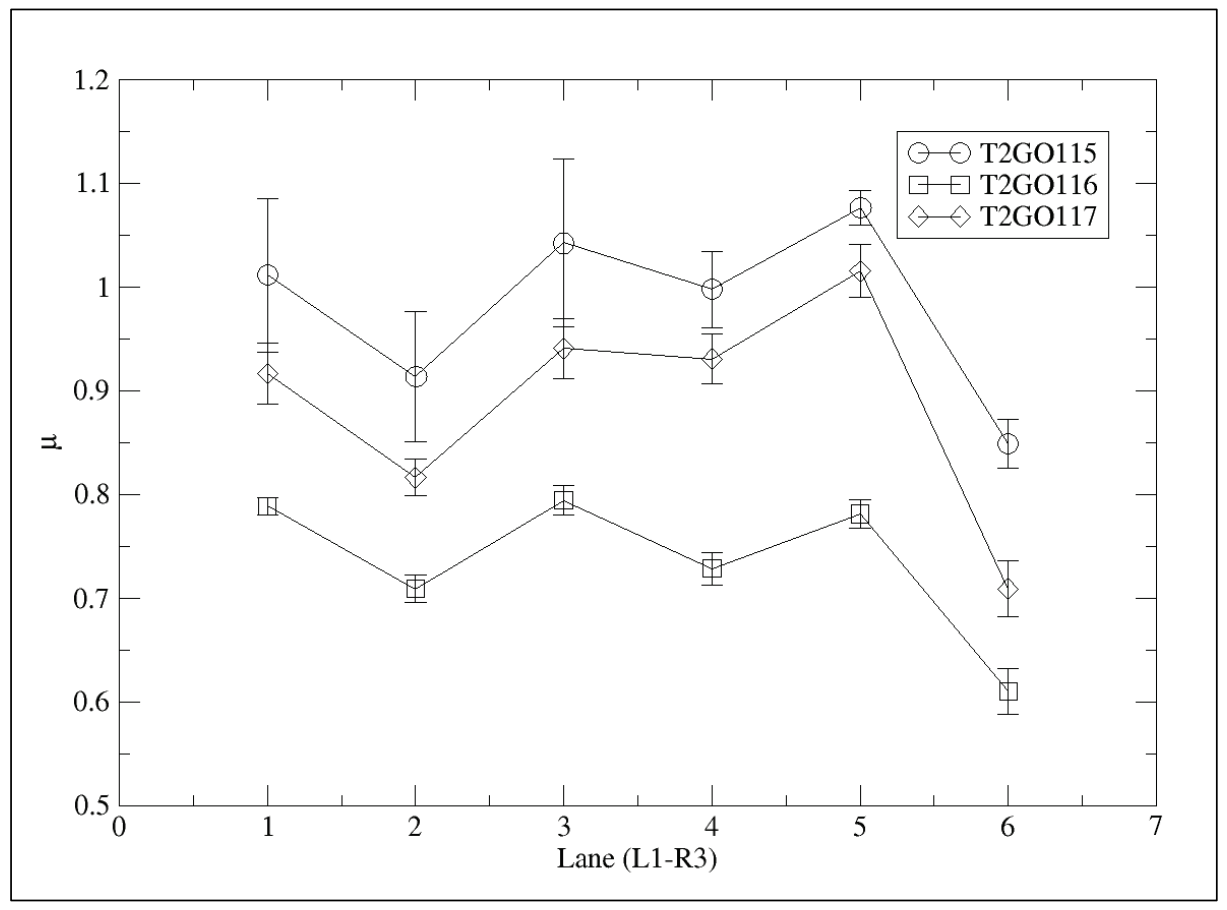


Figure 8. mGT vs. Lane for 1.6 and $3.0 \mathrm{mph}$.

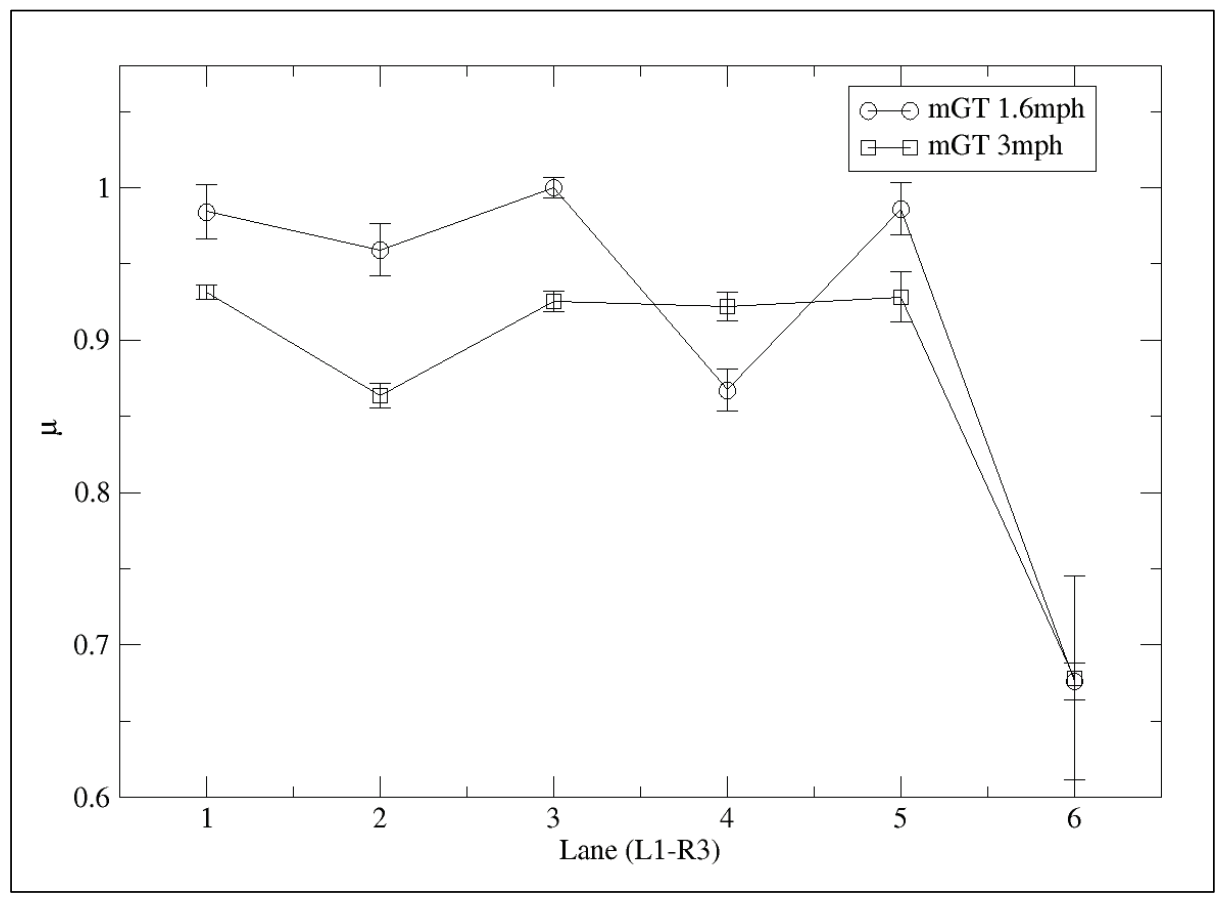




\section{Field Test Methods}

Field tests were performed at the Silver Flag test runway at Tyndall Air Force Base, FL. The SF test runway contained of six unique Portland Cement Concrete (PCC) pavement sections, each $200 \mathrm{ft}$ long by $8 \mathrm{ft}$ wide. The test track was split into left and right lanes with three test sections each. Each test section had a unique texture/friction characteristic. Table 3 shows the macrotexture and friction measurements from Elatextur and GT devices, respectively. For the purposes of the present work, the SF test sections were numbered from 1-6 representing the sections L1-L3 and R1-R3.

Table 3. Texture and friction data from the SF test track.

\begin{tabular}{|l|l|l|}
\hline & & $\begin{array}{l}\text { Friction } \\
\text { Coefficient (Mk2 } \\
\text { GT } 60 \mathrm{mph})\end{array}$ \\
\hline 1 & MPD (Elatextur) & 0.534 \\
\hline 2 & 0.576 & 0.730 \\
\hline 3 & 1.245 & 0.585 \\
\hline 4 & 0.580 & 0.308 \\
\hline 5 & 0.346 & 0.500 \\
\hline 6 & 0.440 & 0.131 \\
\hline
\end{tabular}

\subsection{Deceleration tests}

Vehicle braking tests were also performed in order to test Bowmonk, smartphone, and vehicle ECU deceleration techniques. Vehicle braking tests consisted of accelerating to a constant speed of $20 \mathrm{mph}$ in a test vehicle and then braking hard to a complete stop at a pre-designated position. The brake-to-stop action is important as early results using a brake-stab braking action were inconsistent. Deceleration equipment was secured to the vehicle in a number of ways. The following sections provide specifics on equipment placement during testing. Two types of test vehicles were operated: a full-size standard car and a compact-size standard car. The two full-size vehicles tested were the 2016 Chevy Malibu LT and the 2017 Toyota Camry. The compact-size car tested was the 2016 Nissan Versa. The full-size vehicles weighed approximately 3,400 lb. The compact-size test car weighed approximately $2,400 \mathrm{lb}$. Test vehicles of varying size and weight were chosen to test weight control during braking tests. All three test vehicles were equipped with ribbed tires. Tire pressure was maintained at the manufacturer's recommended value. 


\subsubsection{Bowmonk decelerometer}

Figure 9. Two Bowmonk devices used during brake testing.

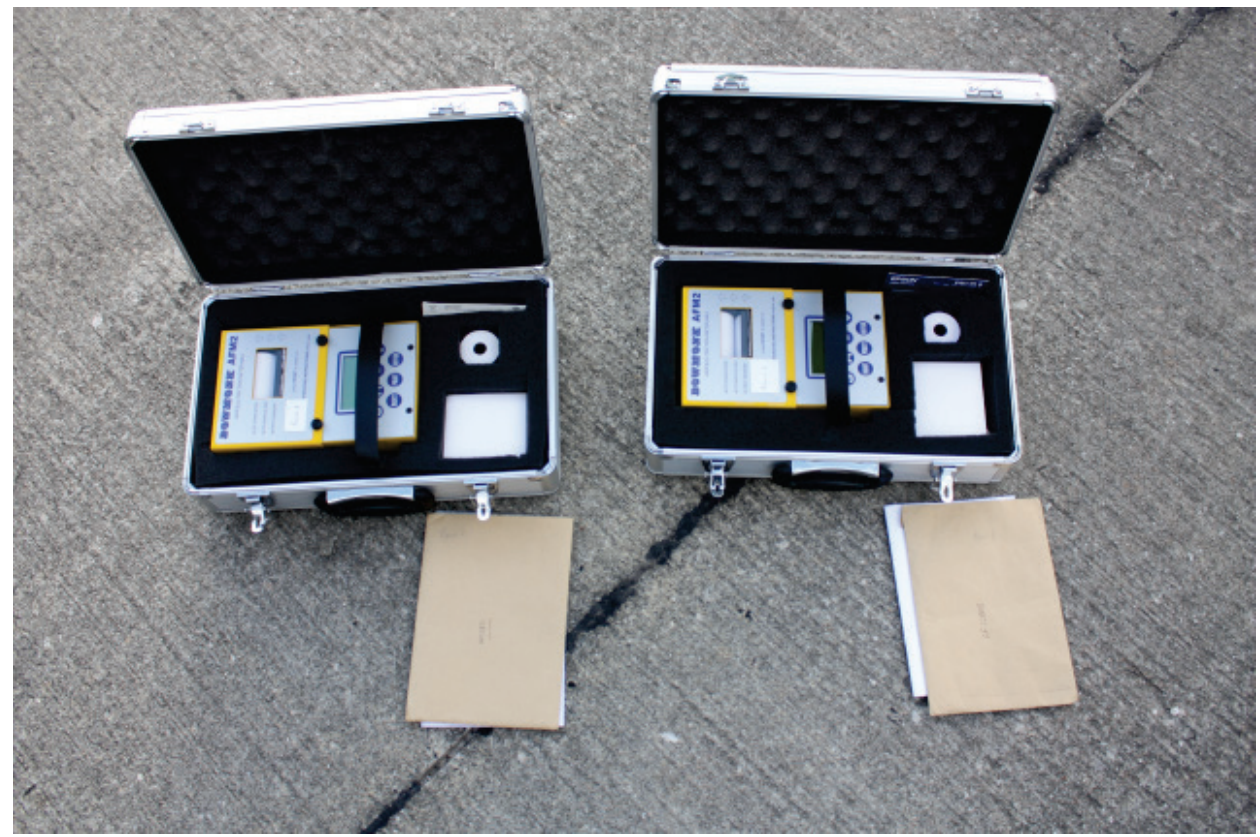

Two Bowmonk decelerometers were used during testing (see Figure 9). Bowmonk decelerometers were secured in a number of places in order to test experimental controls related to device position relative to vehicle center of mass. The Bowmonk decelerometers are difficult to properly mount in the vehicle as they weigh approximately $6 \mathrm{lb}$ and are much larger than the smartphones with dimensions of $5.5 \times 8.7 \times 3.1 \mathrm{in}$. The most used position of the Bowmonk devices was the front passenger floorboard (see Figure 10a). The Bowmonks were secured to the floorboard using Velcro. The Bowmonks were also mounted in the front passenger seat and the rear passenger seat using the seatbelt as a securing mechanism (see Figure 10b). Before deceleration data can be collected with the Bowmonk devices, a slope measurement must be made. The slope measurement allows the Bowmonk software to back out the effect of the Earth's gravitational pull from the succeeding deceleration measurements. The slope measurement was made prior to each set of tests in a test section, i.e., a slope measurement was made prior to beginning tests on section L1, then again prior to the beginning of tests on section L2, and so on. The Bowmonk's automatic deceleration trigger was used to start and stop data collection during braking tests. This feature allowed for rapid succession of braking tests without the need to manually stop data collection at the conclusion of a braking test. 
Figure 10. Bowmonk devices mounted in the floorboard (a) and seat (b).

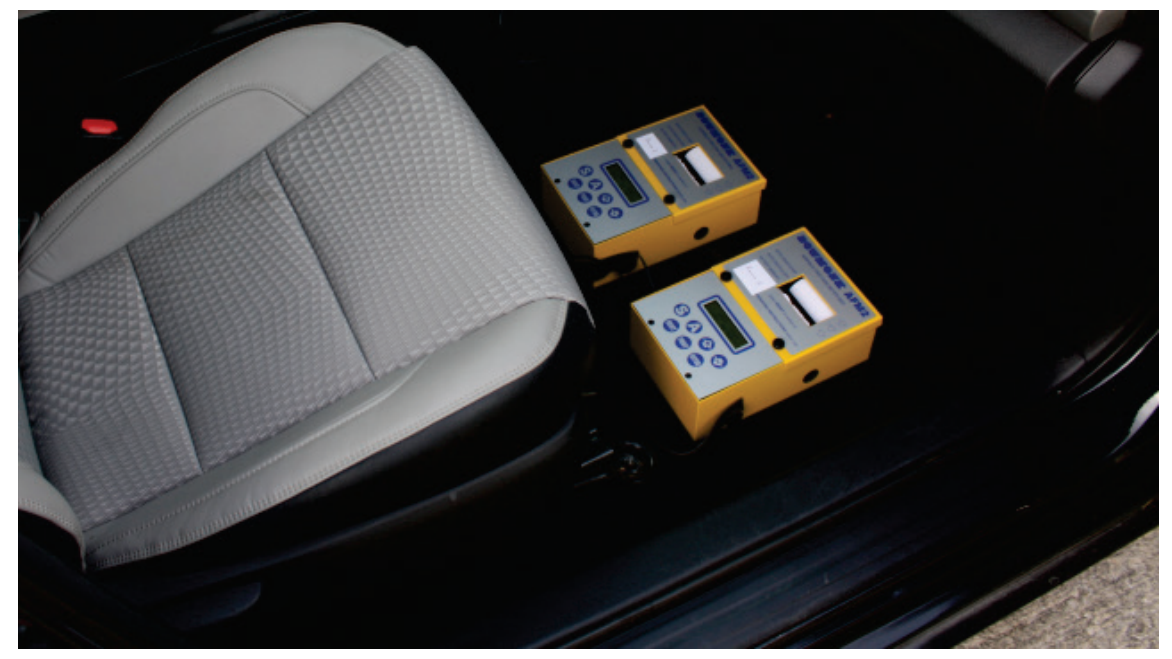

a) Bowmonks mounted on the floorboard

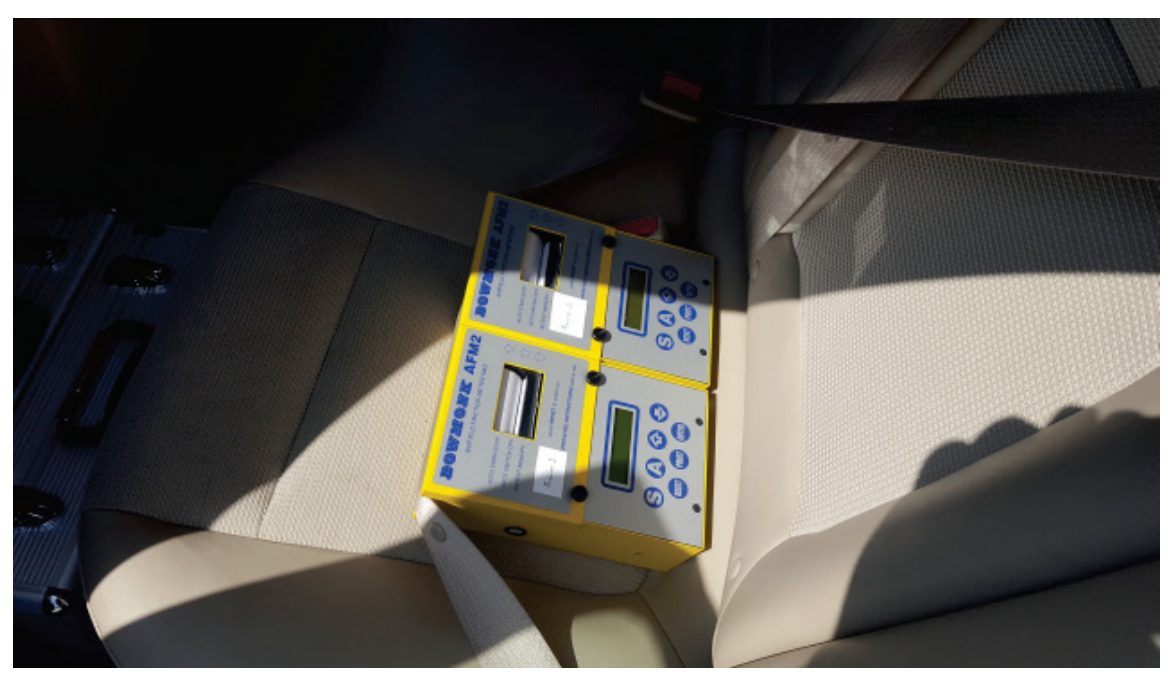

b) Bowmonks mounted in the backseat

At the conclusion of a braking test, the deceleration in $\% g$ is displayed on the screen of the Bowmonk. Each test is saved into a database managed by the Bowmonk software and is accessible at the conclusion of a series of tests via a Bowmonk to serial cable. The Bowmonk device also comes with a built-in printer that allows for each test or a series of tests to be printed on paper. During field testing, the printer was not used to print test results. Test results from the Bowmonk device were recorded on separate paper with detailed test number information. 


\subsubsection{Smartphone decelerometer}

Smartphones were secured to the test vehicle in two areas: front passenger seat and front passenger floorboard. In order to mount the phones in the front passenger seat, an acrylic mount was fabricated (see Figure 11a and Figure 11b). The smartphone mount was secured to the front passenger seat by the seatbelt. Slits were cut into the legs of the smartphone mount to allow multiple securing positions. The top of the smartphone mount was covered with Velcro. Velcro was attached to the smartphones themselves to allow for adherence to the smartphone mount. Velcro attached to the smartphones also allowed for the smartphones to be mounted in the front passenger floorboard (Figure 11c).

Figure 11. Smartphone mount and smartphones installed in test car.

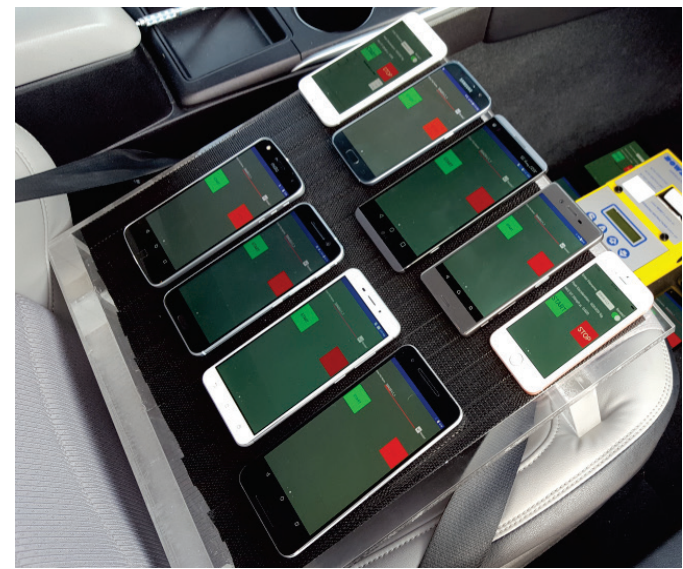

a) Smartphone mount side

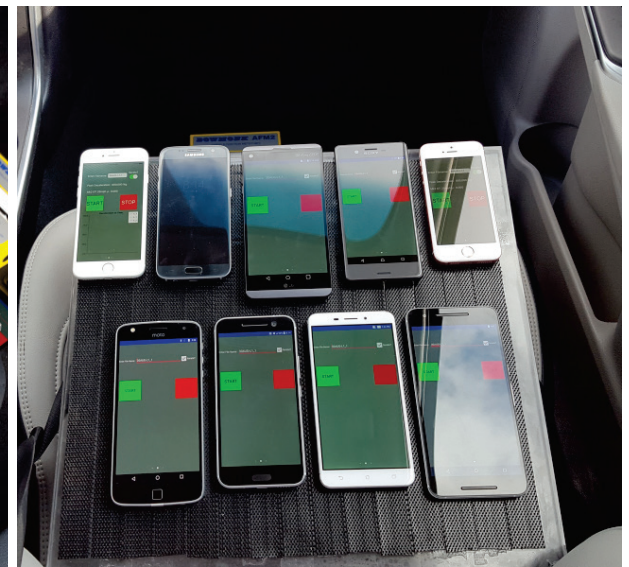

b) Smartphone mount top

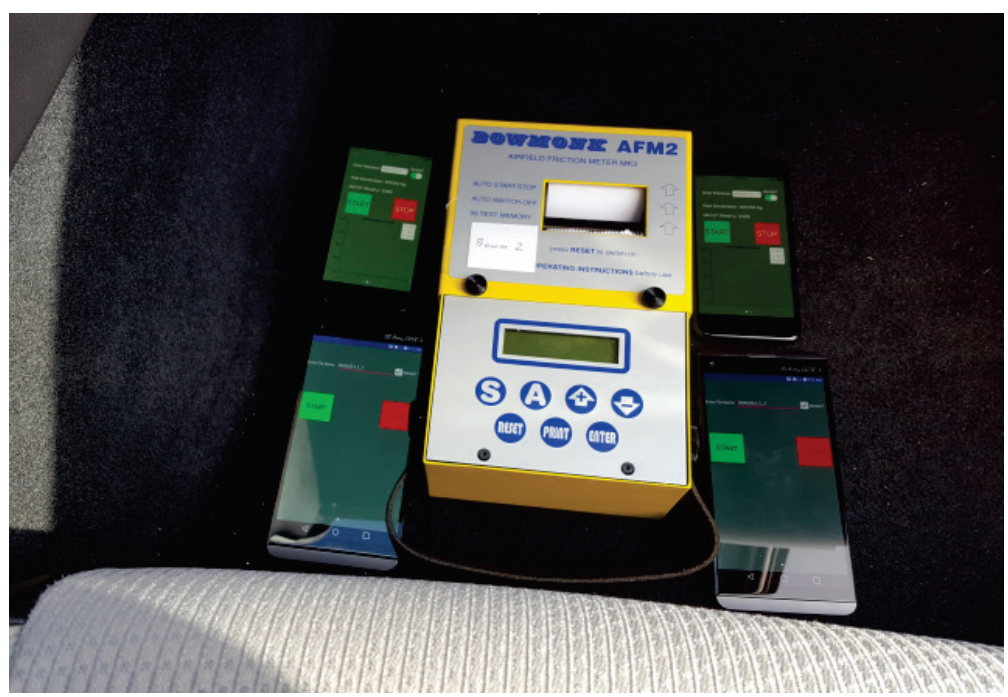

c) Smartphones in floorboard 
Much like the slope measurement required for the Bowmonk device, the smartphone software is capable of backing out Earth's gravity from acceleration measurements. Rotation was measured on-the-fly in conjunction with acceleration measurements and was used to remove any rotations from the acceleration data during the braking action. Unlike the Bowmonk devices, a constant gravity value was not removed from the entire acceleration data set, the acceleration due to Earth's gravity was removed from the accelerometer output using a Kalman filter. In some cases this provides a more accurate representation of actual linear acceleration (with gravitational acceleration removed); however, it could also introduce unnecessary error in the acceleration measurement by relying on a software filter to remove gravity during a braking action.

\subsubsection{Vehicle ECU decelerometer}

A market survey was conducted and three scan tools capable of measuring diagnostic and sensor data from vehicle ECUs were purchased. Table 4 shows the device manufacturer and model as well as the device connection type. Two of the devices, BAFX (Figure 12a) and OBDLink (Figure 12b), connect to a mobile device in order to change settings and collect data. The third device, Auto Enginuity (Figure 12c), connects to a Windows PC through a hardline serial cable. Data are collected by the OBD device and stored on the PC.

Table 4. OBDII scan tool devices used.

\begin{tabular}{|l|l|l|}
\hline Manufacturer & Model & Data Transfer Type \\
\hline Auto Enginuity & $\begin{array}{l}\text { ProLine VCI PC } \\
\text { ScanTool }\end{array}$ & USB \\
\hline OBDLink & $\begin{array}{l}\text { MX Bluetooth Scan } \\
\text { Tool }\end{array}$ & Bluetooth \\
\hline BAFX & $\begin{array}{l}\text { OBDII Diagnostic } \\
\text { Interface }\end{array}$ & Bluetooth \\
\hline
\end{tabular}

The OBD devices are used to measure wheel speed that, when time integrated, produces a measure of the wheel acceleration. This acceleration value is calculated during the braking action to produce a deceleration measurement. It was determined during initial testing that the speeds associated with the OBDI interface are too slow for deceleration measurement; thus, vehicles manufactured before 1996 have not been considered in the present work. 
Figure 12. OBD devices next to a ruler (OBD side has a major mark every $2 / 3$ in.)

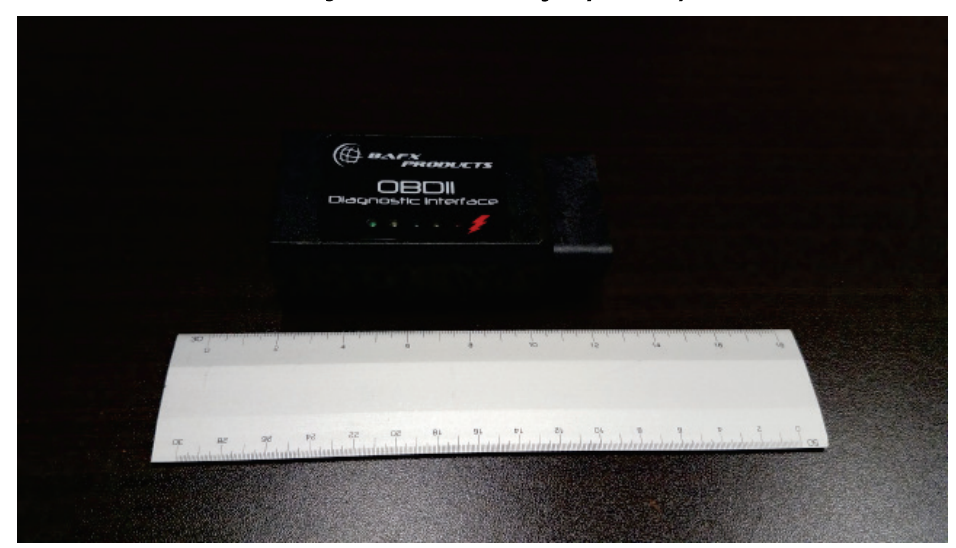

a) BAFX OBDII Diagnostic Interface (3.5 x $1.8 \times 1.0$ in.)

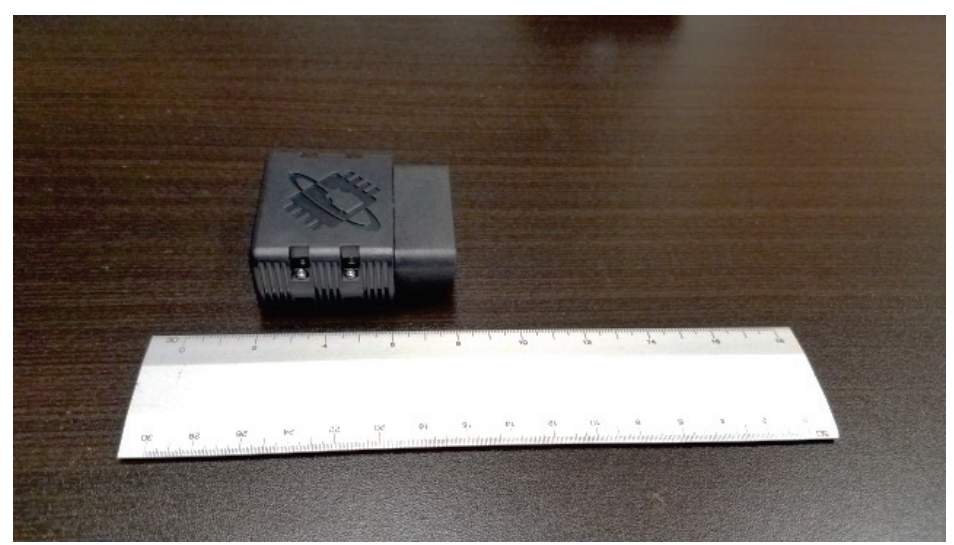

b) OBDLink MX Bluetooth Scan Tool (2.0 x $1.7 \times 0.8$ in.)

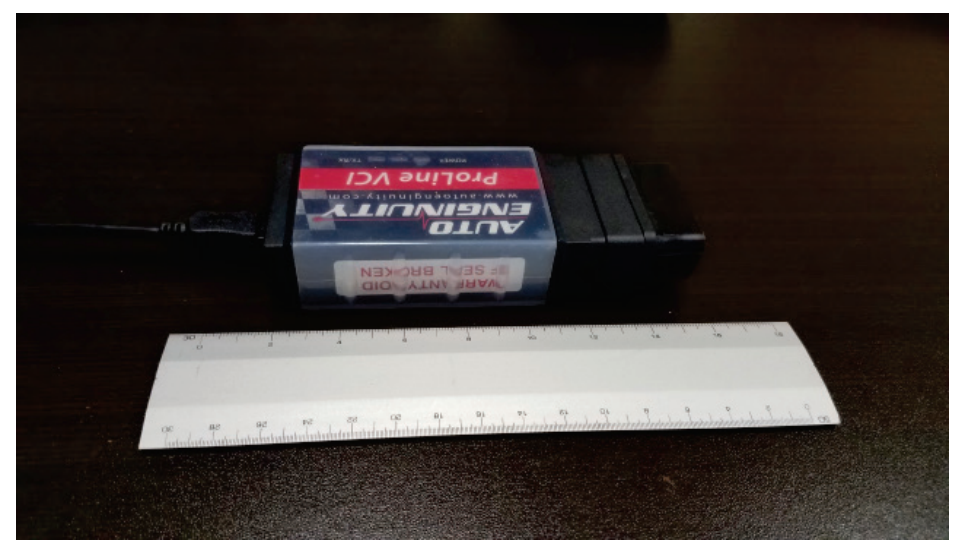

c) Auto Enginuity ProLine VCI PC Scan Tool (4.7 x 1.7 x 0.8 in.)

The OBDII scan tools (also known as data loggers) were installed one at a time in the test vehicle prior to braking tests. Only one OBD port was available on each test vehicle and therefore required the testing of one OBDII scan tool at a time. OBDII scan tools activate data recording in conjunction with vehicle ignition. The acceleration measurement 
mechanism used with these devices does not require the removal of Earth's gravity from deceleration data.

\subsection{CFME tests}

CFME data collected on the SF friction test track were collected by ARA.* The water flow rates were kept to ASTM standards and the walk-behind CFMEs were operated at manufacturers' recommended speeds.

\subsection{Texture measurements}

Texture measurements were made using line laser scanner (LLS) devices also known as laser texture scanners (LTS). The ERDC operated an Ames 9400HD LTS (Figure 13) and FAA personnel in collaboration with ARA operated an Elatextur LTS (Figure 14). Measurements taken by FAA personnel were made in the center of the SF test slabs. The ERDC operated the Ames LTS in both the center of the SF test track slabs and the car wheel path. The measurement window on the Ames device is 4 in. long by 2.5 in. wide. Three Ames measurements were made in the car wheel path of each slab on the SF test track. A single high-resolution scan was made at the center of each SF test section.

The Ames LTS allows for scan resolution to be set by modifying scan line width. Choosing a smaller scan line width increases transverse resolution of the texture scan, while decreasing scan line width has the opposite effect. Low-resolution scans were made with a scan line width of 0.05 in. $(1.27 \mathrm{~mm})$ or 50 vertical scan lines. High-resolution scans were made with a scan line width of $0.0025 \mathrm{in}$. (0.0635 mm) or 1,000 vertical scan lines.

\footnotetext{
* Pullen, A., C. Ishee, and B. Cotter. (in preparation). Evaluation of portable push-mode continuous friction measurement devices for airfield use. Tyndall AFB, FL: Air Force Civil Engineer Center (AFCEC).
} 
Figure 13. Ames $9400 H D$ LTS in the field.

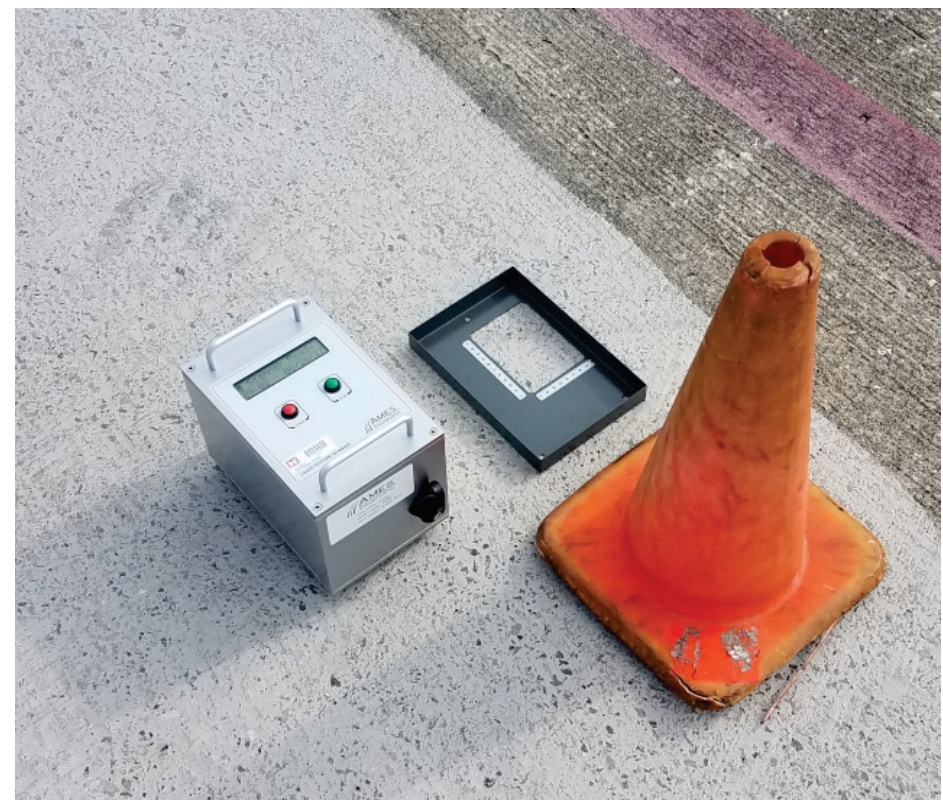

Figure 14. Elatextur LTS (Photo courtesy of ARA).

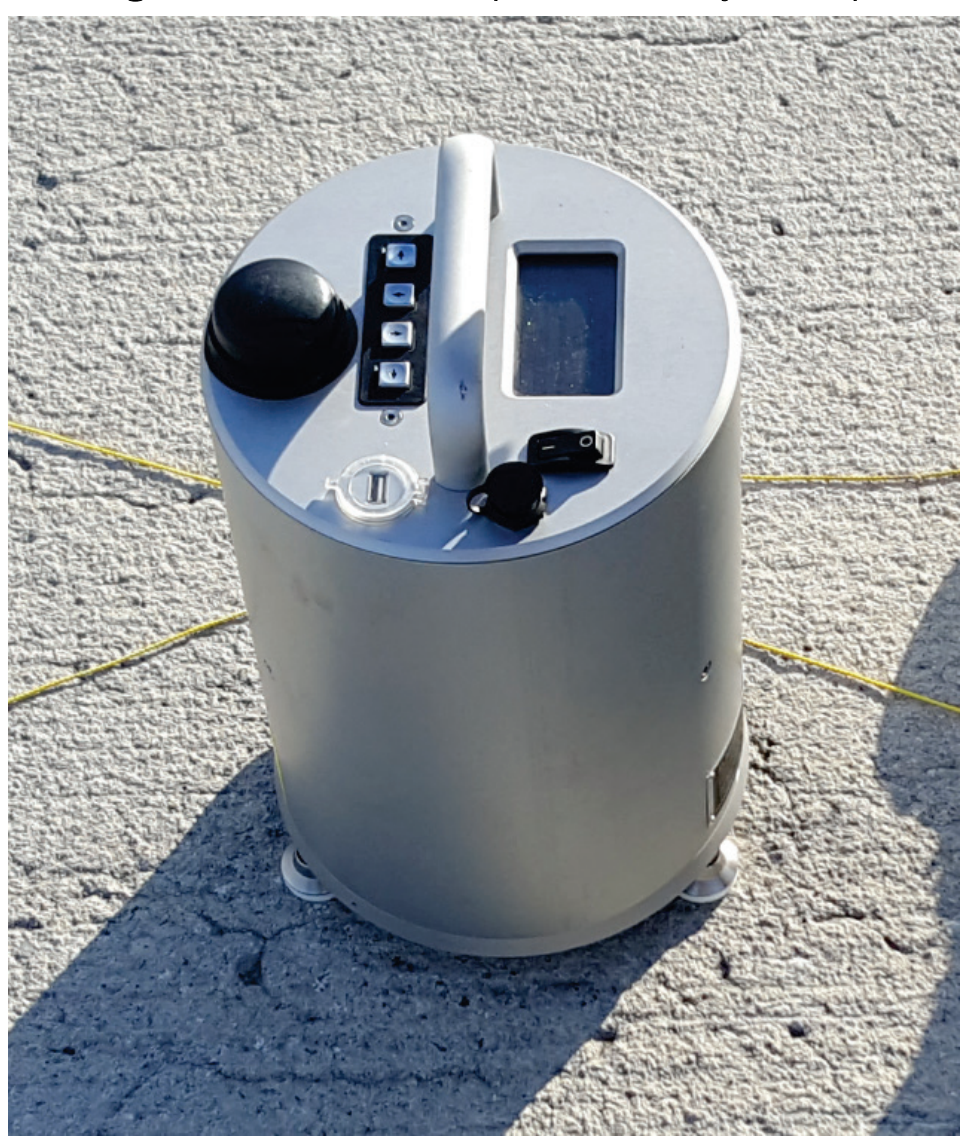




\section{Hardware and Software Development}

Modern smartphones are equipped with sufficient sensor technology to serve as deceleration-based friction assessment tools. What remains is to develop specialized software capable of utilizing the smartphone as a sensor platform. With the use of the Bowmonk AFM2 Mk3 as a deceleration measurement standard, smartphone hardware was acquired and mobile software was developed in order to use smartphones as deceleration-based friction assessment tools. The following sections detail the hardware and software development for both Android and iOS operating systems. The following sections also provide information pertaining to accelerometer sensor theory and Bowmonk AFM2 Mk3 hardware and software.

\subsection{Accelerometers}

Figure 15. SEM image of a MEMS accelerometer (Photo courtesy of Chipworks).

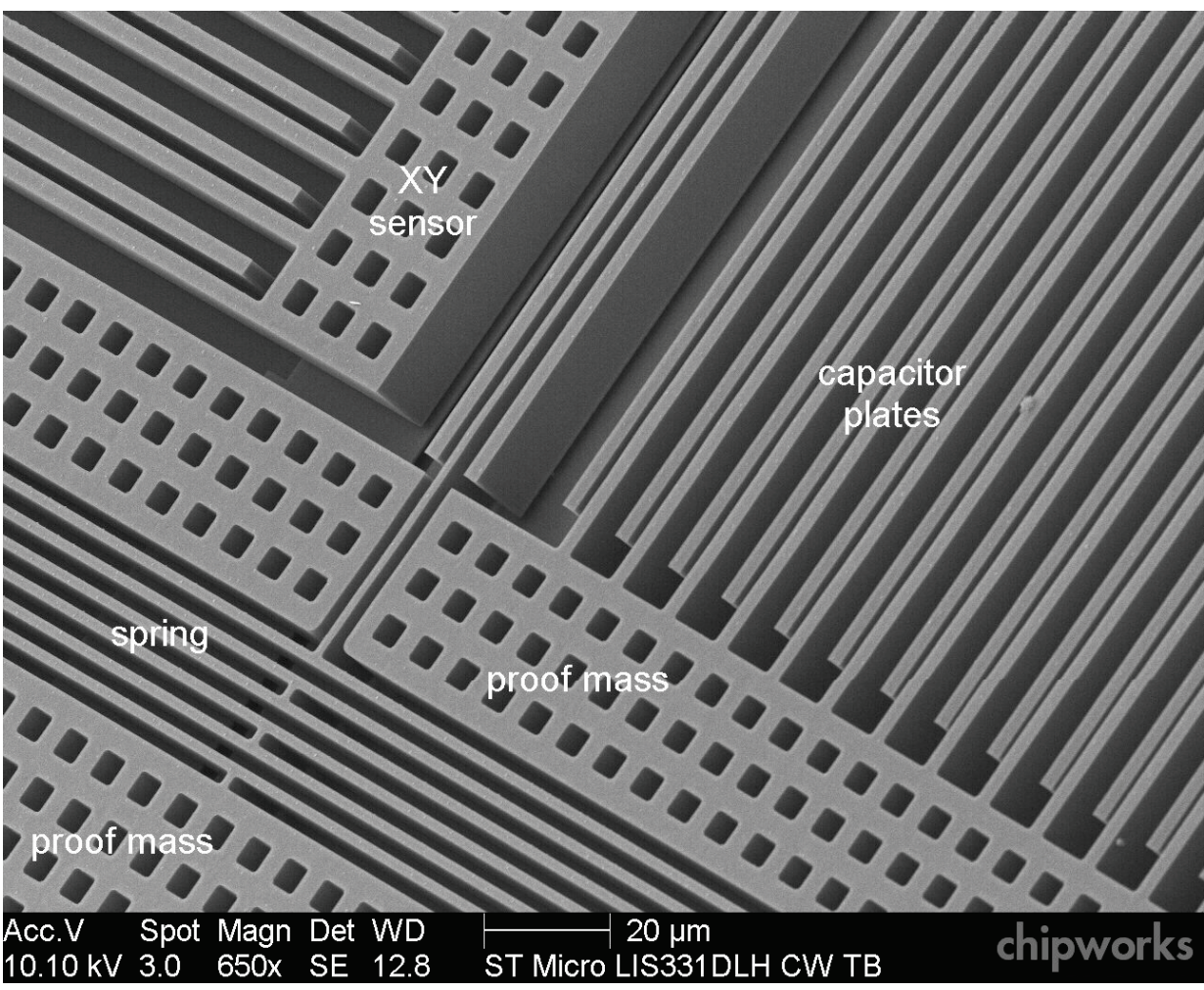

There are three types of accelerometers: mechanical, solid state, and microelectromechanical systems (MEMS) based. Mechanical accelerometers operate under the principle of a mass on a spring. When the mass is acted upon by an outside acceleration, it moves from its 
reference position. The displacement of the mass in 3-D space from its reference position is proportional to the acceleration that acted on it. Solid state accelerometers operate under similar principles to mechanical accelerometers except, instead of measuring the displacement of a mass, they measure acoustic waves/vibrations, electrical response, etc. caused by outside acceleration. MEMS-based accelerometers operate on the same principles as mechanical and solid state accelerometers at the micro scale (Woodman 2007). For example, it is common for MEMS-based accelerometers to use capacitive plates to measure the displacement of a reference, or proof, mass from equilibrium much like larger solid state accelerometers. Figure 15 shows a scanning electron microscope (SEM) image of such an accelerometer.

MEMS manufacturing techniques allow for mechanical and solid state accelerometers and other inertial sensors to be fabricated into small chips at the micro scale. While MEMS-based inertial sensors are convenient and cost effective, they exhibit a number of unique error characteristics. These error characteristics are explained in detail by Woodman (2007). Of note to the present work are an offset bias in the sensor's output signal that is constant with time for acceleration measurements and bias fluctuations in the output signal caused by temperature changes. The temperature dependence of the sensor output signal is particularly troubling given the many heat sources (batteries, backlights, etc.) present in modern smartphones.

Figure 16. Thermal image of smartphones following prolonged operation.

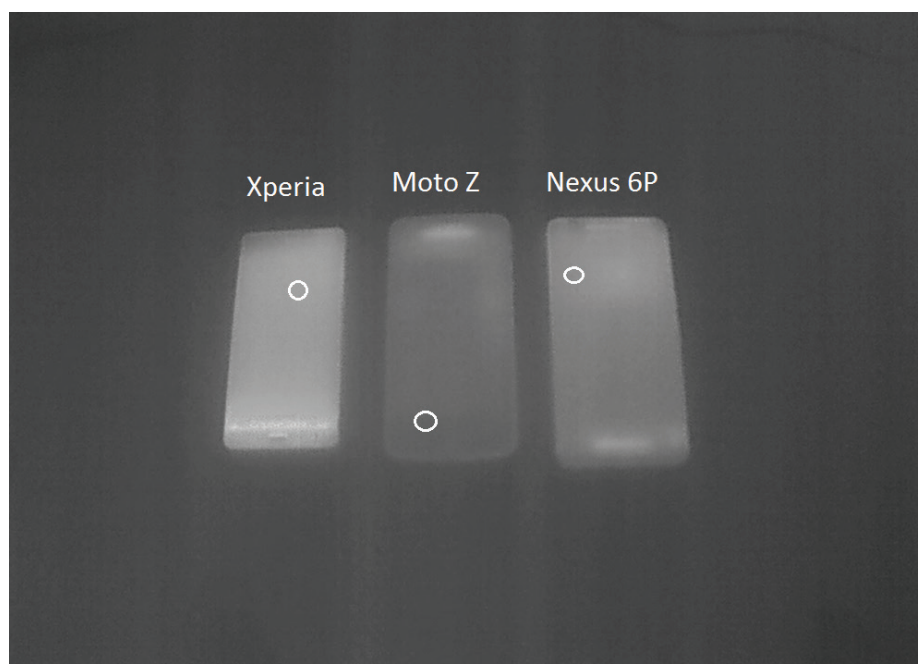


Under the theory that proximity to heat sources negatively affects accelerometer sensor output signal, a test was conducted on three smartphones (Sony Xperia X, Motorola Moto Z, Huawei Nexus 6P) with similar accelerometers in which the smartphones were allowed to run the accelerometer-based friction assessment app, ERDC DECEL, under the observation of a thermal camera, the FLIR Vue Pro. Figure 16 shows a thermal image of the three smartphones after 30 min of operation of the ERDC DECEL app. In Figure 16, the approximate positions of the IMUs are denoted by white circles. Deceleration data collected from the three test phones indicate that two of the phones repeat each other well (Xperia, Nexus) and the third (Moto Z) does not repeat the other two (see Figure 17). Based upon thermal data collected with the FLIR Vue Pro, it is clear that the Xperia and Nexus devices have similar thermal characteristics, and the third device, the Moto $\mathrm{Z}$, is unique to the other devices. From the thermal characteristics alone, it is expected that the Xperia and Nexus devices repeat each other well. This information reveals the importance of temperature control, both internal and external, when performing deceleration-based tests with MEMS accelerometers.

Figure 17. Deceleration vs. Lane for the thermal example.

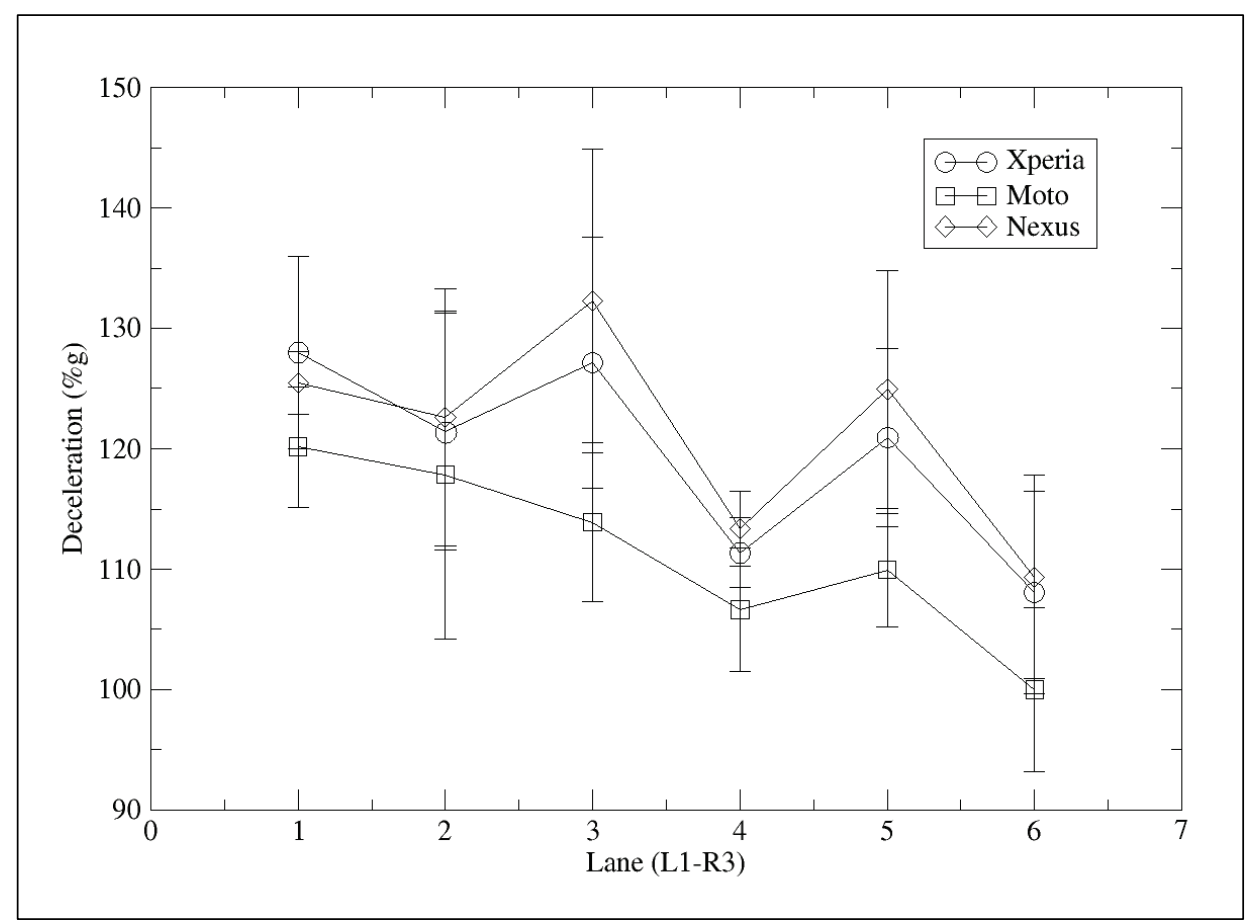




\subsection{Android development}

\subsubsection{Hardware}

A market survey was conducted and nine of the most widely used smartphones were purchased. Four additional duplicate phones were purchased for replicate testing (two iPhone 7s and two V20s). Among the nine smartphones were seven Android devices: ASUS ZenFone 3 Laser, HTC 10, Huawei Nexus 6P, LG V20, Motorola Moto Z Play, Samsung Galaxy S7, and Sony Xperia X. Wide variability in smartphone chipset was not considered a problem as processor/memory speed and memory capacity for each smartphone was found to be more than sufficient for rapid deceleration measurements. Variability in smartphone IMU was considered an important experimental control, thus smartphones with unique IMUs were purchased. Three of the smartphones (aforementioned in Section 5.1) had the same IMU manufacturer and model (Bosch BMI160): Sony Xperia X, Motorola Moto Z Play, and Huawei Nexus 6P. Table 5 shows specific IMU manufacturer and model information.

Table 5. List of smartphone inertial sensors.

\begin{tabular}{|l|l|l|l|l|l|}
\hline $\begin{array}{l}\text { Phone } \\
\text { Manuf. }\end{array}$ & Phone Model & IMU Manuf. & IMU Model & $\begin{array}{l}\text { Magnetometer } \\
\text { Manuf. }\end{array}$ & $\begin{array}{l}\text { Mangetometer } \\
\text { Model }\end{array}$ \\
\hline Samsung & Galaxy S7 & STMicroelectronics & LSM6DS3 & AKM & AK09911 \\
\hline Huawei & Nexus 6P & Bosch & BMI160 & Bosch & BMM150 \\
\hline LG & V20 & LGE,Bosch & LGE Custom & LGE, Bosch & LGE Custom \\
\hline HTC & 10 & HTC & HTC Custom & HTC & HTC Custom \\
\hline Sony & Xperia X & Bosch & BMI160 & AKM & AK09915 \\
\hline ASUS & ZenFone 3 & Invensense & ICM ACC & AKM & AK09916 \\
\hline Motorola & Moto Z & Bosch & BMI160 & AKM & AKM09912 \\
\hline Apple & iPhone 7 & Invensense & 773C & Unknown & Unknown \\
\hline Apple & SE & Invensense & EMS-A & Unknown & Unknown \\
\hline
\end{tabular}

The individual IMUs are typically outfitted with three accelerometers and three gyroscopes (one of each per 3-D axis). Another inertial sensor, a magnetometer, is usually separate from the larger IMU. Of interest to the present work are the accelerometers and magnetometers. The accelerometer is used to measure acceleration in three dimensions during braking. The magnetometer is used to measure absolute rotation in three dimensions during braking. On the Android platform, acceleration is 
presented in standard SI units of meters per second squared, $\frac{m}{s^{2}}$. The absolute rotation is presented as a quaternion (see Equation 26). Figure 18 shows phone orientation.

$$
\begin{gathered}
\vec{q}=\cos \left(\frac{\theta}{2}\right)+x \sin \left(\frac{\theta}{2}\right) \hat{\imath}+y \sin \left(\frac{\theta}{2}\right) \hat{\jmath}+z \sin \left(\frac{\theta}{2}\right) \hat{k} \\
=q_{r}+q_{x} \hat{\imath}+q_{y} \hat{\jmath}+q_{z} \hat{k}
\end{gathered}
$$

where, $\theta$ is the angle of rotation about $\vec{q}, \hat{\imath}, \hat{\jmath}$, and $\hat{k}$ are quaternion unit vectors, and $x, y$, and $z$ are real numbers. The quaternion, $\vec{q}$, can be converted into the three Euler angles (Blanco 2014) as seen in Equation 27.

$$
\left[\begin{array}{c}
\varphi \\
\theta \\
\psi
\end{array}\right]=\left[\begin{array}{c}
\arctan \left(\frac{2\left(q_{r} q_{z}+q_{x} q_{y}\right)}{1-2\left(q_{y}^{2}+q_{z}^{2}\right)}\right) \\
\arcsin \left(2\left(q_{r} q_{y}-q_{x} q_{z}\right)\right) \\
\arctan \left(\frac{2\left(q_{r} q_{x}+q_{y} q_{z}\right)}{1-2\left(q_{x}^{2}+q_{y}^{2}\right)}\right)
\end{array}\right]
$$

where, $\varphi$ is yaw (normal), $\theta$ is pitch (transverse), and $\psi$ is roll (longitudinal).

Figure 18. Smartphone 3-D orientation.

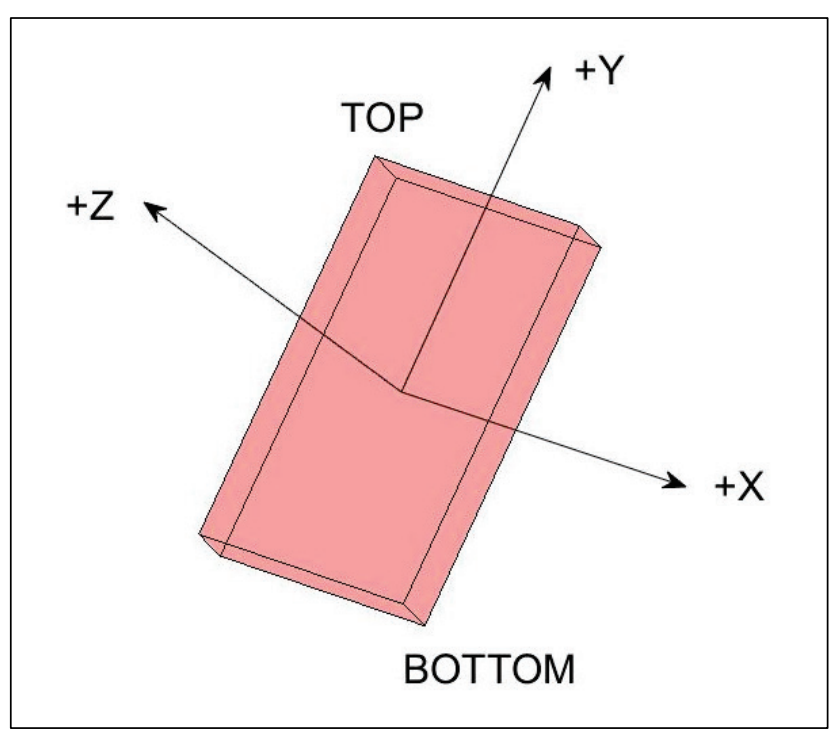




\subsubsection{Software}

Software capable of extracting data from the various inertial sensors onboard smartphones was developed for Android devices in the form of a mobile app (Figure 19). Android software was developed in Android's proprietary integrated development environment (IDE), Android Studio, using the Java programming language. There were no software limitations on inertial sensor sampling rate. A max sampling rate of approximately $200 \mathrm{~Hz}$ was achieved on all Android devices and is likely a hardware limitation. The Android software was developed for a minimum targeted software development kit (SDK) version of 15 (Android 4, Ice Cream Sandwich) and a targeted SDK version of 24 (Android 7, Nougat). Android devices were kept to the most up-to-date Android version allowed by the device manufacturer.

Figure 19. Android ERDC DECEL screenshots.
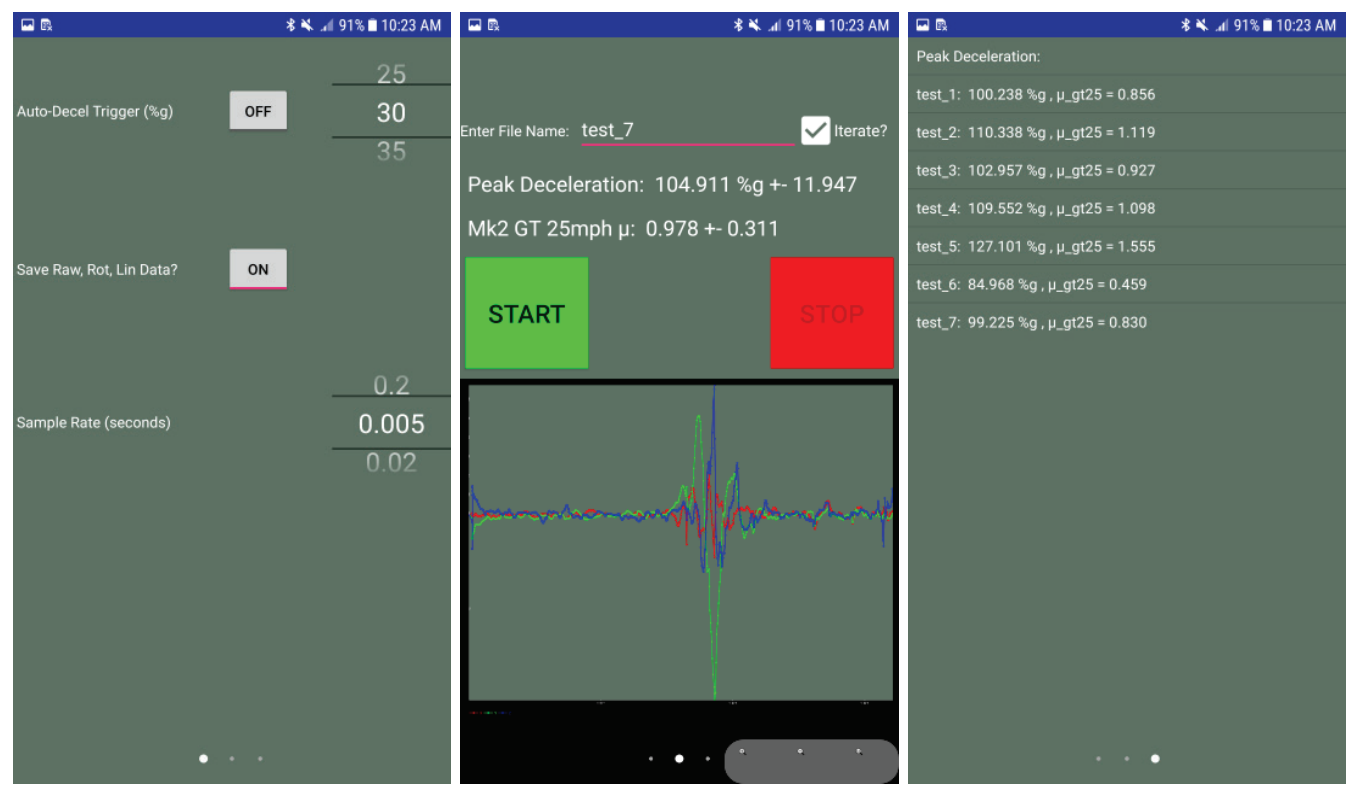

ERDC DECEL was developed to give users Start/Stop control over the device's inertial sensors. Along with manual Start/Stop functionality an automatic deceleration trigger was implemented. The automatic deceleration trigger requires the user to press the Start button and automatically begins data recording at a user-controlled deceleration threshold. Automatic data collection will continue until the deceleration event ends or when the deceleration reaches zero. Functionality was also implemented in the mobile app that allows users to customize data collection; i.e., choosing to save certain sensor data or record only peak data. The mobile app allows users to control the sample rate of the device 
using preset sensor sample rates: 5, 17, 50, and $200 \mathrm{~Hz}$. In order to reduce data loss, peak deceleration data is saved on-the-fly at the conclusion of every test. A plot of the three acceleration components $\left(a_{x}, a_{y}, a_{z}\right)$ is displayed at the bottom of the main screen upon test completion. The influence of Earth's gravity is removed from the acceleration data through the use of a software filter, specifically a Kalman filter.

\section{3 iOS development}

\subsubsection{Hardware}

Of the nine smartphones purchased were two Apple devices: iPhone 7 and iPhone SE. The Apple devices along with their respective inertial sensors are listed in Table 5 . Processor/memory speed and memory capacity were found to be more than sufficient for rapid deceleration measurements. Much like the Android devices, the Apple smartphones were equipped with two inertial sensors of interest: an accelerometer and magnetometer. On the Apple platform, acceleration is measured in units of acceleration of gravity, $g$. Absolute rotation is measured in Euler angles of yaw, pitch, and roll. Phone orientation can be seen in Figure 18.

\subsubsection{Software}

Figure 20. iOS ERDC DECEL screenshots.
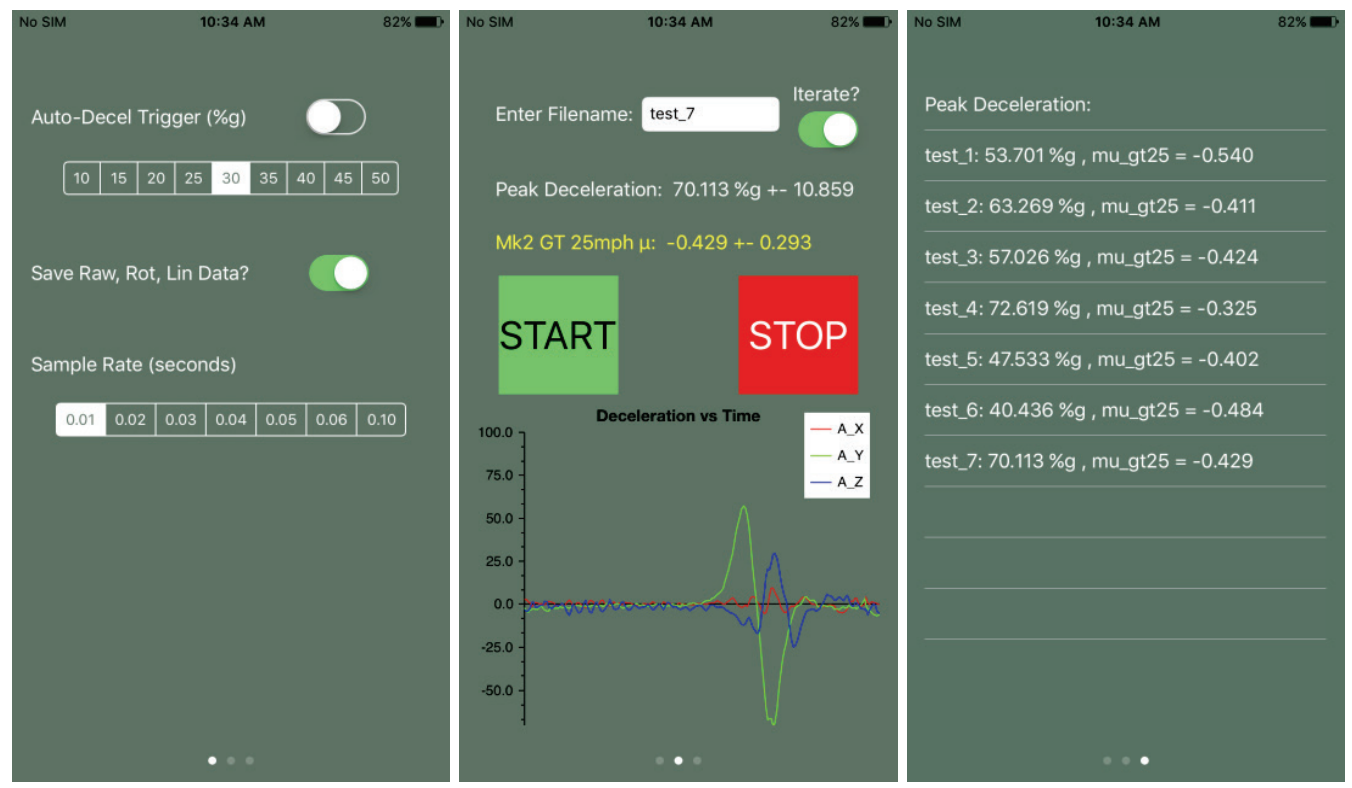

Much like the Android development process, software was developed for the Apple platform in the form of a mobile app in order to measure and record acceleration and rotation data from the onboard inertial sensors 
(Figure 20). Apple software was written for the iOS operating system in Apple's proprietary IDE Xcode 8 using the Swift programming language. The apple motion sensor manager, CoreMotion, limits by software the maximum IMU sampling frequency to around $100 \mathrm{~Hz}$. It is unknown whether or not hardware limitations contribute to the maximum sampling frequency cut off. The iOS deployment target was iOS 10.2 with a minimum deployment target of iOS 8.o. The Apple devices were kept to the most up-to-date software allowed by the device manufacturer. It is unclear what specific algorithm is used to filter the influence of Earth's gravity from the deceleration results.

\subsection{Bowmonk decelerometer}

For the purpose of validating smartphone accelerometer measurements, two Bowmonk AFM2 Mk3 decelerometers were tested. The Bowmonk device is considered the standard for deceleration-based measurements on airfields. Unlike smartphone accelerometers, the Bowmonk is designed for pavement deceleration measurements. The Bowmonk likely employs a high-grade MEMS-based accelerometer operating at a sampling rate of approximately $400 \mathrm{~Hz}$ and claims a measurement range of 0.0 to $1.4 \mathrm{~g}$ (Bowmonk 2017).

The Bowmonk device utilizes an automatic deceleration measurement trigger. When a fixed deceleration threshold is observed by the Bowmonk's internal accelerometer, deceleration data are recorded until the deceleration event ends. Device rotation is removed from the deceleration results by way of a slope measurement at the beginning of a series of tests. It is unclear whether or not the influence of Earth's gravity is also removed from the test results based on the slope measurement or by utilizing a software filter. 


\section{Results}

The following results will be derived from four rounds of testing at the Silver Flag test track. Table 6 shows a breakdown of equipment testing per round. Each round of testing sought to test the various deceleration-based equipment in different vehicles and scenarios.

Table 6. Testing breakdown by round.

\begin{tabular}{|c|c|c|c|c|c|}
\hline Round & Decelerometer & Smartphone & OBD & Test Vehicle & Pavement Cond. \\
\hline 1 & $\begin{array}{l}\text { 2x Bowmonk } \\
\text { AFM2 Mk3 }\end{array}$ & None & None & $\begin{array}{l}2017 \text { Toyota } \\
\text { Camry }\end{array}$ & Dry \\
\hline \multirow{5}{*}{2} & \multirow{5}{*}{$\begin{array}{l}\text { 2x Bowmonk } \\
\text { AFM2 Mk3 }\end{array}$} & Samsung Galaxy S7 & \multirow{5}{*}{ None } & \multirow{5}{*}{$\begin{array}{l}2016 \text { Chevy } \\
\text { Malibu }\end{array}$} & \multirow{5}{*}{ Dry } \\
\hline & & Huawei Nexus 6P & & & \\
\hline & & LG V20 & & & \\
\hline & & HTC 10 & & & \\
\hline & & Apple iPhone 7 & & & \\
\hline \multirow{9}{*}{3} & \multirow{9}{*}{$\begin{array}{l}\text { 2x Bowmonk } \\
\text { AFM2 Mk3 }\end{array}$} & Samsung Galaxy S7 & \multirow{3}{*}{$\begin{array}{l}\text { Auto Enginuity } \\
\text { ProLine VCI PC } \\
\text { ScanTool }\end{array}$} & \multirow{9}{*}{2016 Nissan Versa } & \multirow{9}{*}{ Dry and Wet } \\
\hline & & Huawei Nexus 6P & & & \\
\hline & & LG V20 & & & \\
\hline & & HTC 10 & & & \\
\hline & & Sony Xperia $\mathrm{X}$ & Bluetooth Scan & & \\
\hline & & ASUS ZenFone 3 & & & \\
\hline & & Motorola Moto Z & \multirow{3}{*}{$\begin{array}{l}\text { BAFX OBDII } \\
\text { Diagnostic } \\
\text { Interface }\end{array}$} & & \\
\hline & & Apple iPhone 7 & & & \\
\hline & & Apple iPhone SE & & & \\
\hline \multirow{9}{*}{4} & \multirow{9}{*}{$\begin{array}{l}\text { 2x Bowmonk } \\
\text { AFM2 Mk3 }\end{array}$} & Samsung Galaxy S7 & \multirow{9}{*}{$\begin{array}{l}\text { OBDLink MX } \\
\text { Bluetooth Scan } \\
\text { Tool }\end{array}$} & \multirow{9}{*}{$\begin{array}{l}2017 \text { Toyota } \\
\text { Camry }\end{array}$} & \multirow{9}{*}{ Dry and Wet } \\
\hline & & Huawei Nexus 6P & & & \\
\hline & & 3x LG V20 & & & \\
\hline & & HTC 10 & & & \\
\hline & & Sony Xperia X & & & \\
\hline & & ASUS ZenFone 3 & & & \\
\hline & & Motorola Moto Z & & & \\
\hline & & 3x Apple iPhone 7 & & & \\
\hline & & Apple iPhone SE & & & \\
\hline
\end{tabular}




\subsection{Bowmonk decelerometer}

The first round of testing shows the inaccuracy of deceleration measurement with novice drivers unfamiliar with brake testing (Figure 21). The four drivers referenced in Figure 21 were all given the same instructions: reach a speed of $20 \mathrm{mph}$ and when a specific point on the track is reached brake hard to a stop and repeat this five times for each SF test section.

Figure 21. Bowmonk deceleration vs. Lane with multiple drivers.

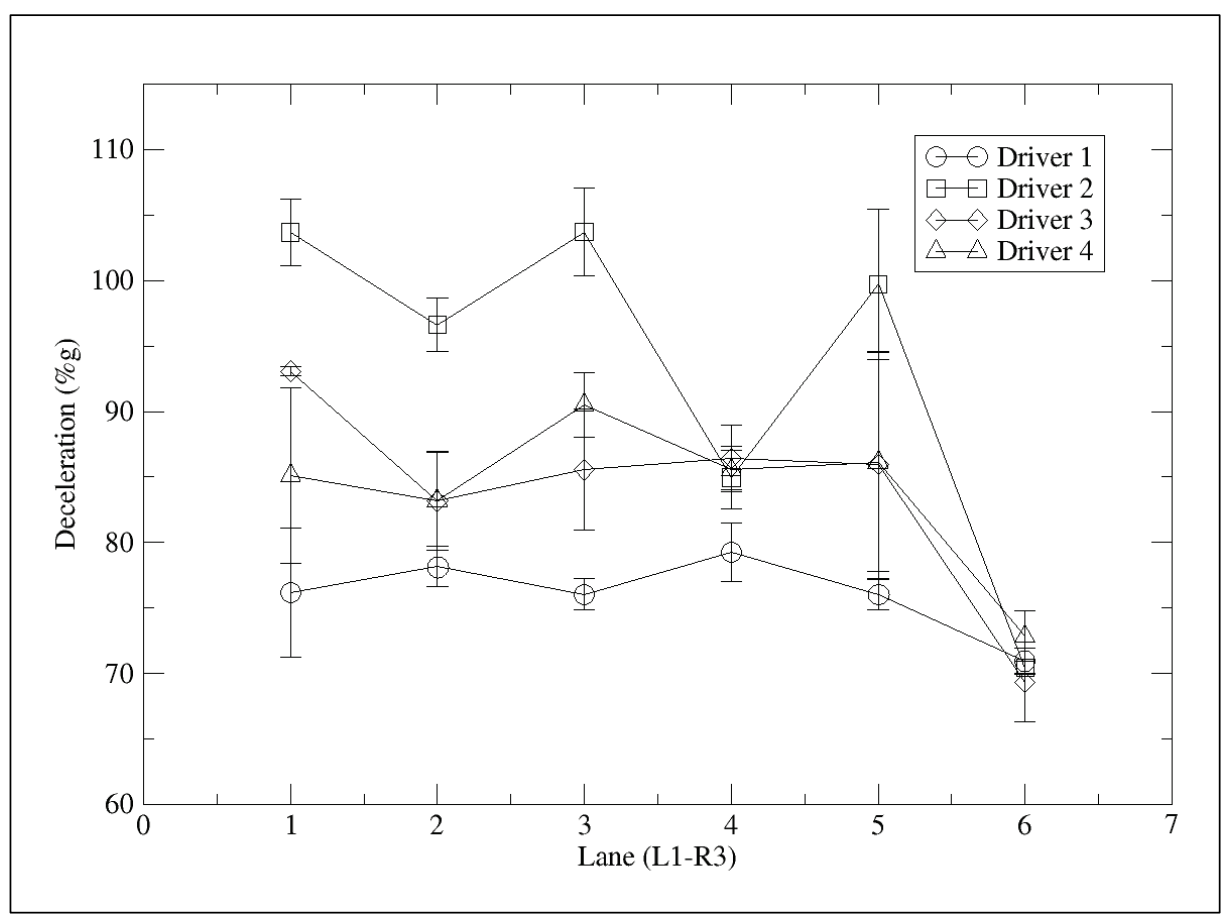

Data collected from the first round of testing is sufficient for correlation between the Bowmonk devices. The two Bowmonk decelerometers tested show very strong correlation with each other, indicating that the Bowmonk deceleration measurement is highly repeatable (Figure 22) with a linear regression COD of 0.997 . 
Figure 22. Bowmonk2 vs. Bowmonk1 deceleration linear regression.

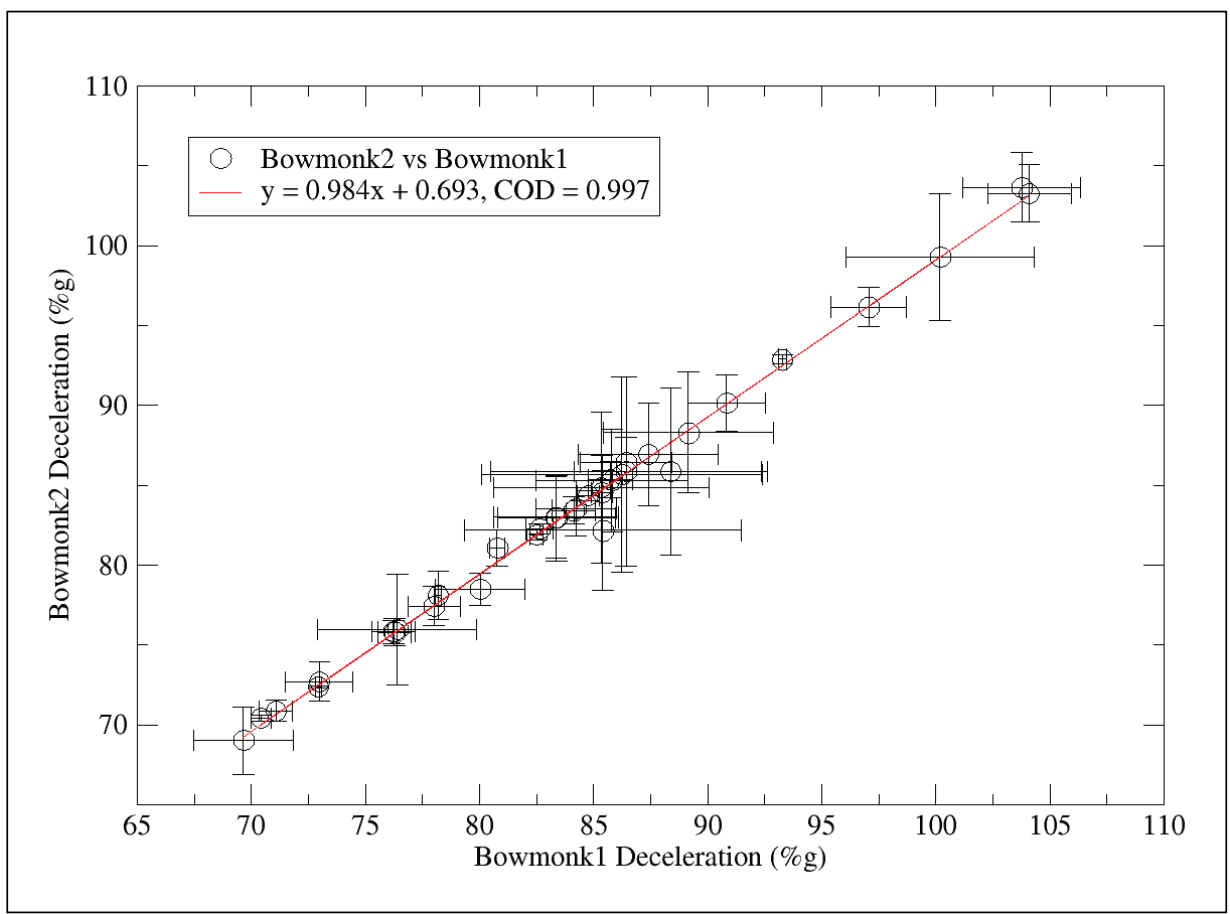

The linear equation associated with the regression in Figure 22 can be seen in Equation 28.

$$
y=0.984 x+0.693
$$

Deceleration data were also collected from the Bowmonk devices while in the two mounting positions referenced in Figure 10a and Figure 1ob respectively: front passenger-side floorboard (Velcro) and rear driver-side seat (seatbelt). A linear regression was performed comparing the Bowmonk mounted in the rear of the car and the Bowmonk mounted in the front of the car and strong correlation was found (Figure 23). The linear equation associated with the regression in Figure 23 can be seen in the equation below with a COD of 0.998 .

$$
y=0.999 x-0.822
$$


This strong 1-to-1 relationship between the Bowmonks mounted in different positions indicates that the Bowmonk deceleration output is invariant to the vehicle's center of mass. This is likely due to the large mass of the Bowmonk unit and high grade of the Bowmonk's accelerometer.

Figure 23. Bowmonk Back vs. Bowmonk Front deceleration linear regression.

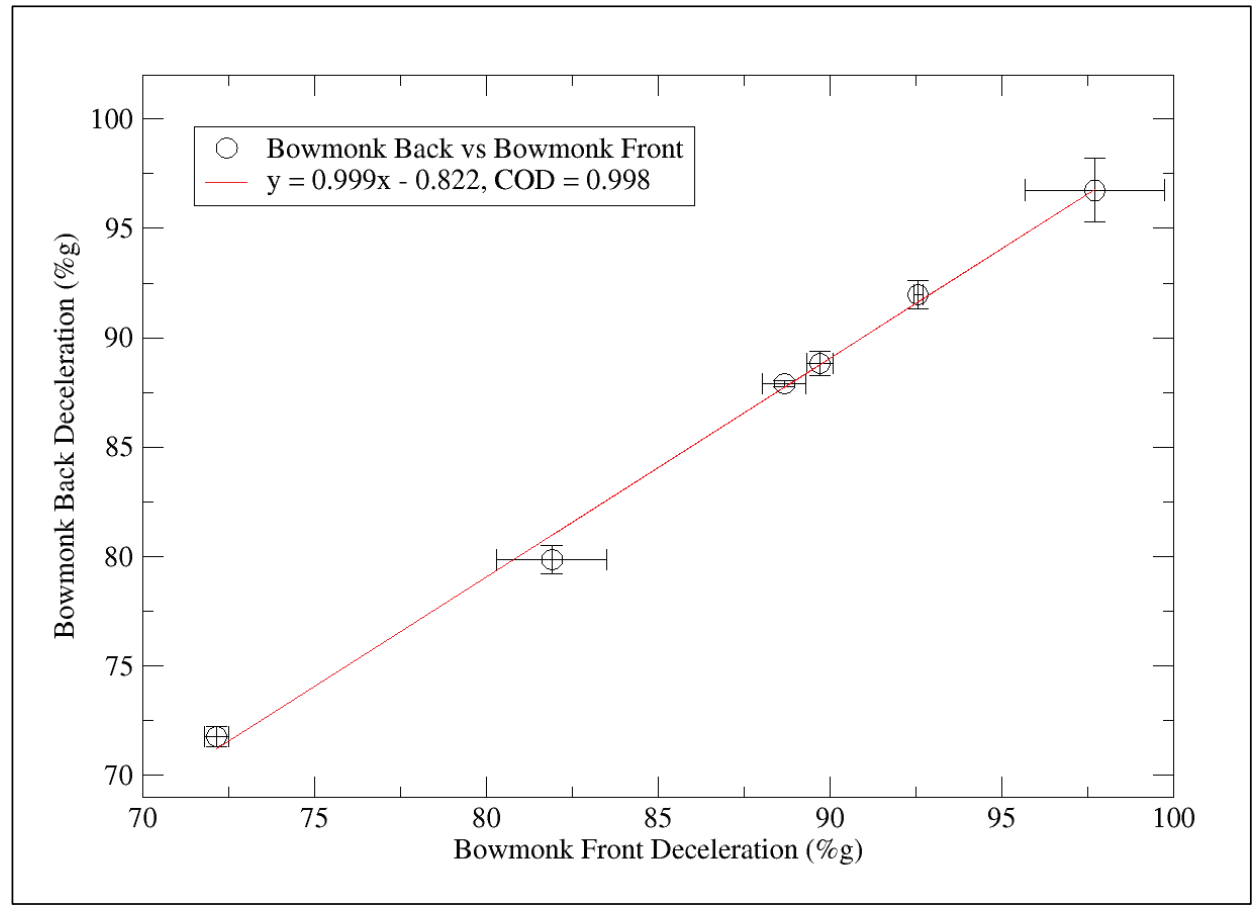

The consistency of the Bowmonk output makes it a suitable reference for all deceleration-type measurements collected during this effort. Smartphone decelerometer results to be detailed in the following section will be compared to the Bowmonk results as a deceleration standard.

Finally, it is important to seek correlation between the Bowmonk decelerometer and the Air Force standard CFME, the Mk2 GripTester. Data collected by ARA with the Mk2 GT at $25 \mathrm{mph}$ was used to derive a linear correlation between the two devices (Figure 24). According to the data in Figure 24, there is a strong linear relationship between the two devices with a COD of 0.906. It appears that there is a slight exponential influence to the data; however, this is likely due to the higher experimental error expected with deceleration testing. 
Figure 24. Mk2 GripTester 25 mph vs. Bowmonk linear regression.

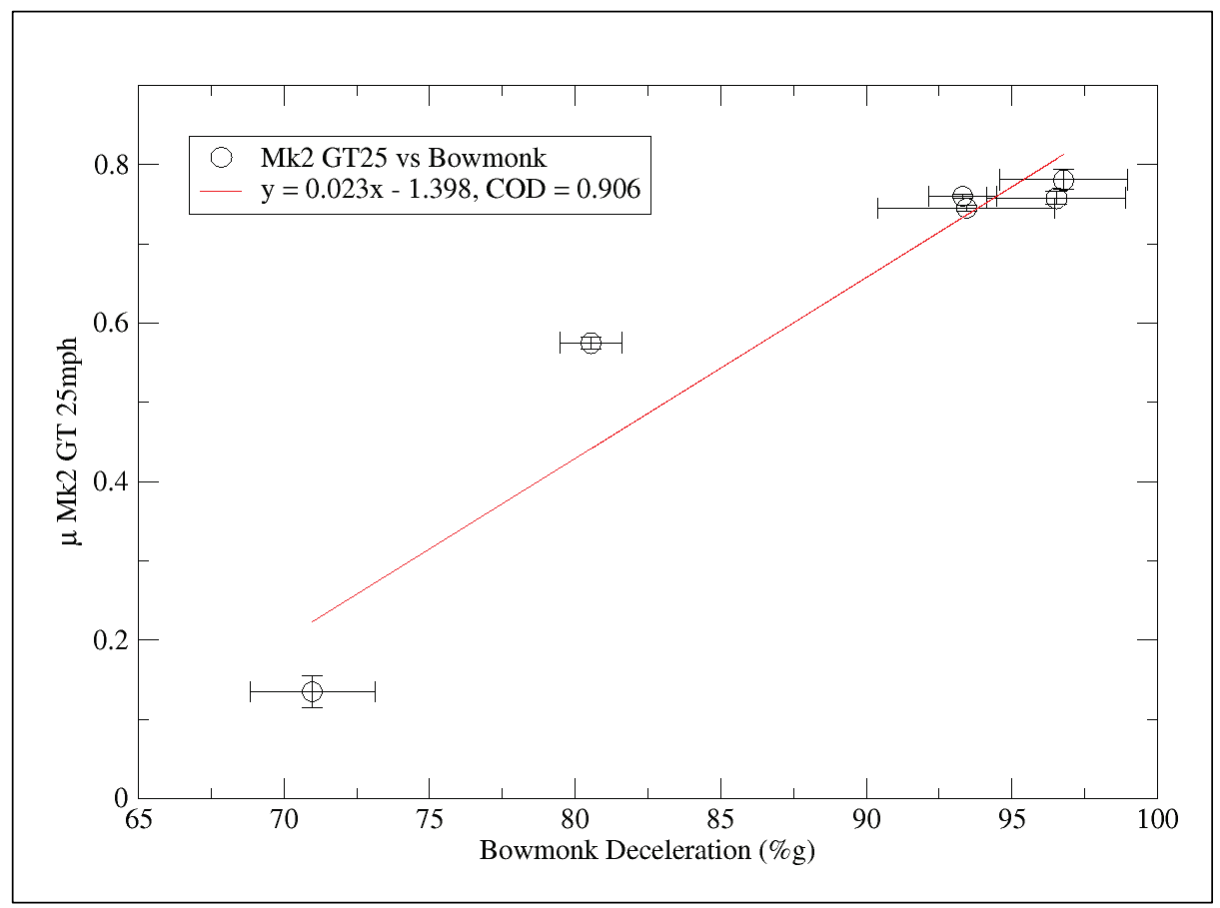

The predictability of the linear correlation referenced in Figure 24 is considered strong due not only to a COD close to one, but also a very low mean absolute error (MAE) of 0.058. More data is necessary at the intermediate friction coefficient ranges in order to develop a more definitive relationship.

\subsection{Smartphone decelerometer}

The deceleration results, collected via braking tests, for the smartphones vary widely. For example, the peak deceleration results per lane for all smartphones tested are shown in Figure 25. Note that the HTC 10 was tested but excluded from analysis in this report due to malfunction in the device's accelerometer. The driver dependency of braking tests as shown previously in Figure 21 also applies to the smartphone-based decelerometers. A vast number of experimental controls affect the outcome of a deceleration-based test and the smartphones tested are certainly not intended to be used to collect deceleration data during the braking action. As it was shown in the preceding section, the Bowmonk decelerometer was used as the deceleration measurement standard for braking tests. With that in mind, the first comparison was made between the smartphones and Bowmonks. 
Figure 25. Deceleration vs. Lane for all eight smartphones (excluding HTC 10).

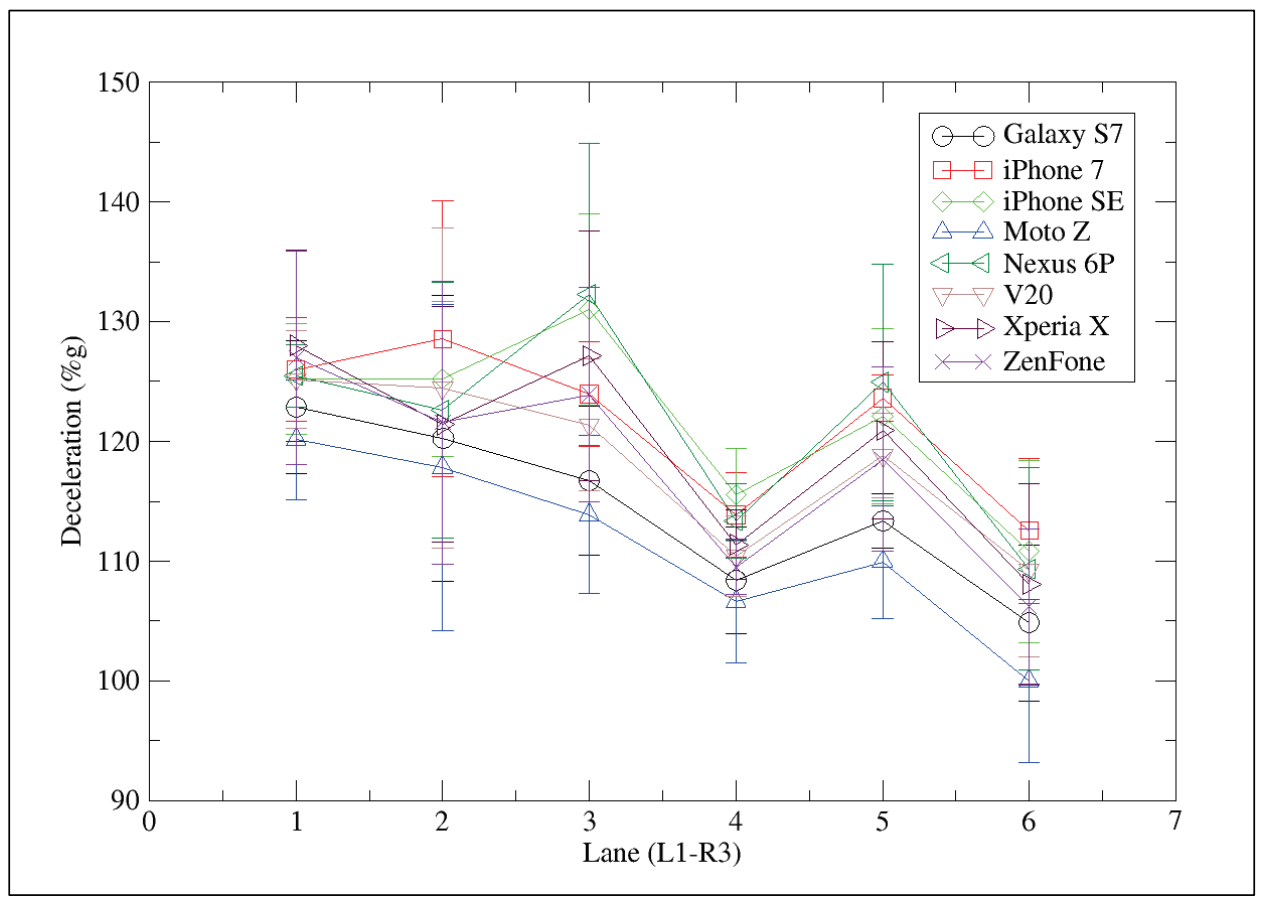

\subsubsection{Bowmonk vs. smartphone}

The results from Round 4 are ideal to make a comparison between the smartphones and Bowmonk devices as data were collected from both the seat and the floorboard for the smartphones simultaneously. This had not been done previously as Round 4 was the only round of testing to include replicate devices for the Apple iPhone 7 and LG V2O. During Round 4, the original iPhone 7 and $\mathrm{V} 20$ remained in the seat mount and the two replicate iPhone 7s and V2os were mounted in the floorboard next to the Bowmonk devices. The phone positions for Round 4 testing are in Figure 26.

Unlike the Bowmonk results referenced in Figure 23, the deceleration output of the smartphones most certainly relies upon the smartphone's position relative to the vehicle's center of mass. Strong linear correlation was found between the floorboard-mounted iPhone 7s and V20s (see Figure 27a for Bowmonk vs. iPhone 7 and Figure 27b for Bowmonk vs. V20). 
Figure 26. Phone layout during Round 4 testing.

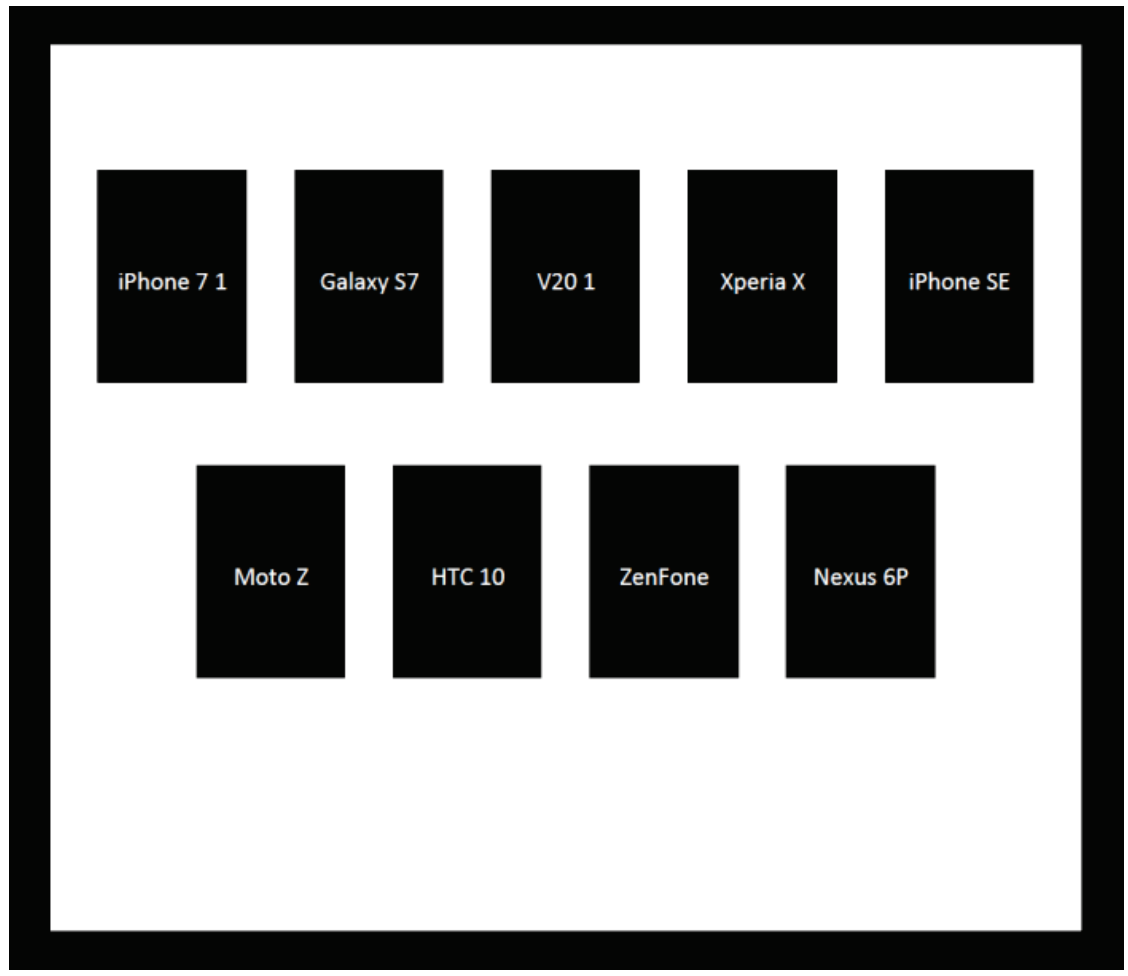

a) Phone layout in front seat mount.

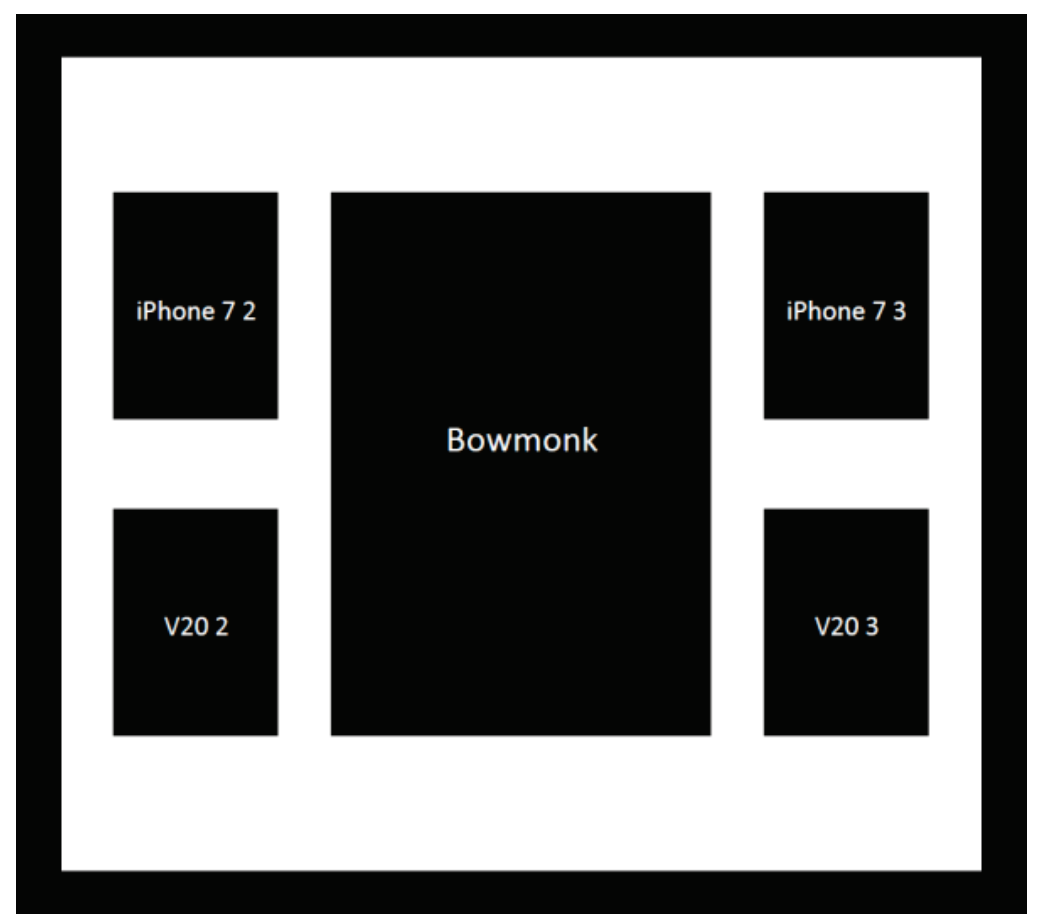

b) Phone layout in front floorboard. 
Figure 27. Bowmonk vs. Smartphone for both seat and floor mounts.

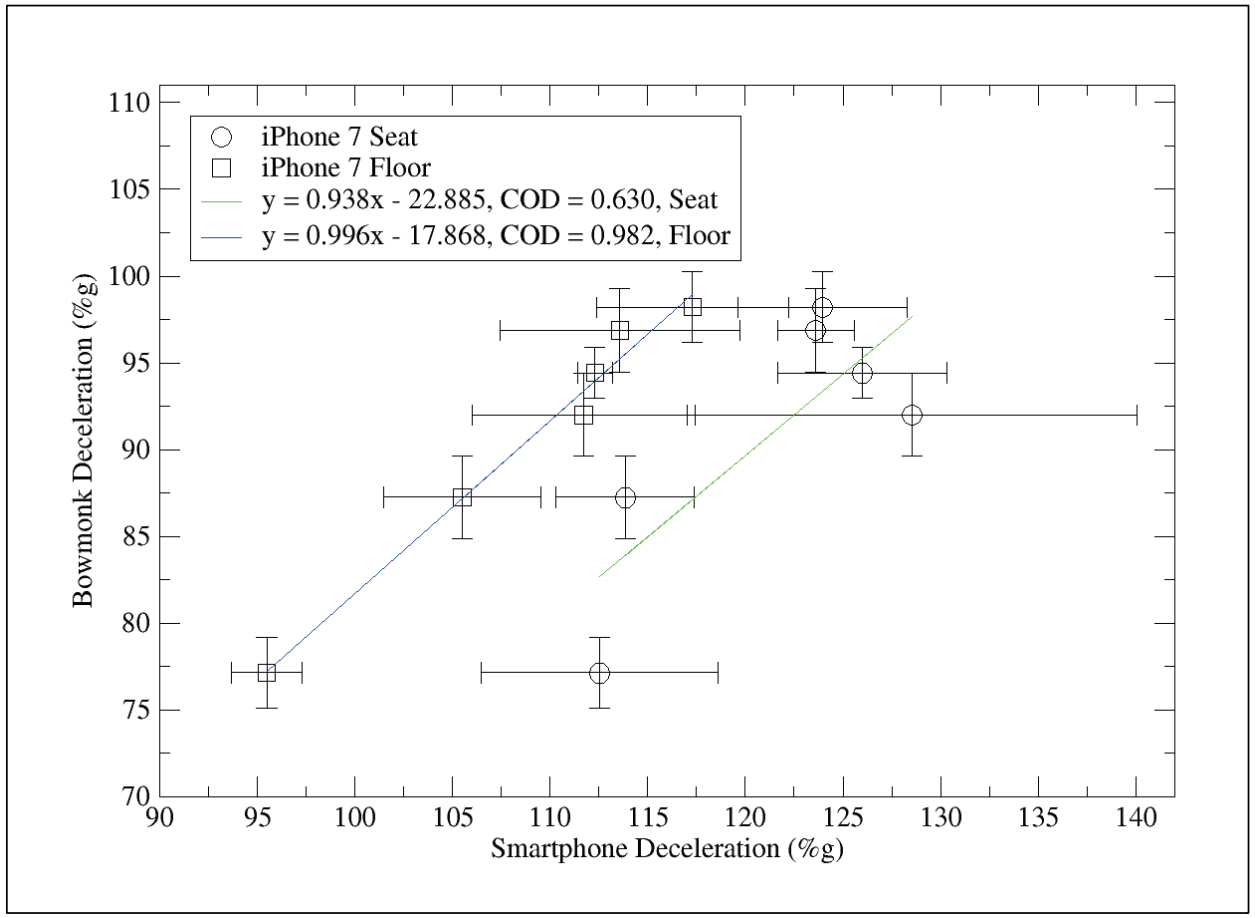

a) Bowmonk vs. iPhone 7 for both seat and floor mounts.

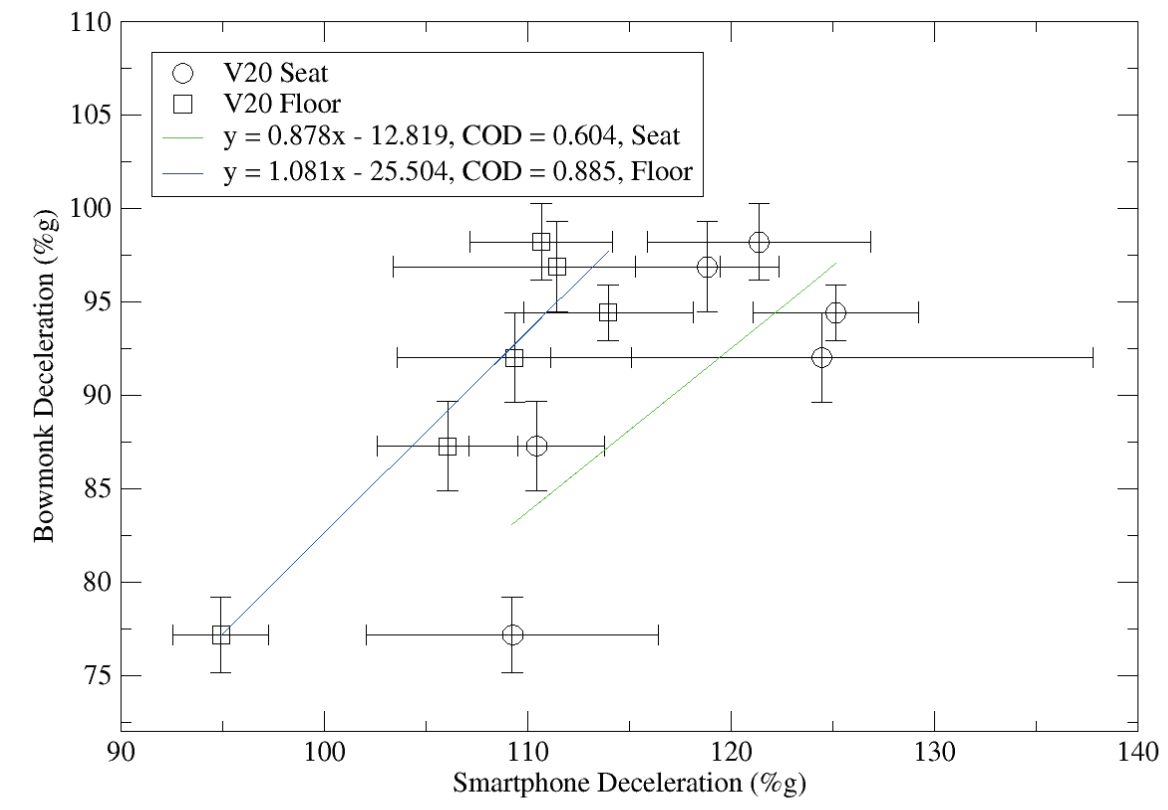

b) Bowmonk vs. V20 for both seat and floor mounts. 
As can be seen in Figure 27a, the goodness-of-fit parameter for the floormounted iPhone 7 (0.982) is significantly better than for the seat-mounted iPhone 7 (0.630). The same result can be seen in Figure 27b with the V20 smartphone: seat-mounted COD (0.604) and floor-mounted COD (0.885). As the Bowmonks and smartphones are highly correlated when tested in the same position, it is likely that the seatbelt-based mount introduces additional experimental error in comparison to the floorboard-based mount. This decrease in experimental error for the floorboard-mounted data can also be seen in the pooled standard deviations for the iPhone 7 (Seat: 3.037, Floor: 1.955) and V20 (Seat: 3.474, Floor: 1.865).

\subsubsection{Mk2 GripTester vs. smartphone}

As the Bowmonk devices showed high linear correlation with the Mk2 GripTester at $25 \mathrm{mph}$ (Mk2 GT25), the next comparison was made between the smartphones and the Mk2 GT25. The best candidates for high correlation with the Mk2 GT25 are the floor-mounted iPhone 7s and V2Os. Figure 28a shows linear regression results for the Mk2 GT25 vs. iPhone 7 data in both the seat and floor mounts. As expected the linear correlation between the Mk2 GT25 and iPhone 7 are strongest when the iPhone 7 is mounted in the floorboard. Equation 30 below shows the linear relation for the seat-mounted iPhone 7 with a COD of 0.691 and Equation 31 below for the linear relation between the floor-mounted iPhone 7 with a COD of 0.933 .

$$
\begin{aligned}
& y=0.032 x-3.215 \\
& y=0.032 x-2.795
\end{aligned}
$$

Figure 28b shows linear regression results for the Mk2 GT25 vs. V2o data in both the seat and floor mounts. Much like the iPhone 7, the V2O showed much better correlation in floor mount $(\mathrm{COD}=0.937)$ than in the seat mount $(\mathrm{COD}=0.653)$. Equation 32 and 33 below show seat- and floormounted V2O correlations, respectively.

$$
\begin{aligned}
& y=0.029 x-2.854 \\
& y=0.036 x-3.237
\end{aligned}
$$


Figure 28. Mk2 GT $25 \mathrm{mph}$ vs. Smartphone for both seat and floor mounts.

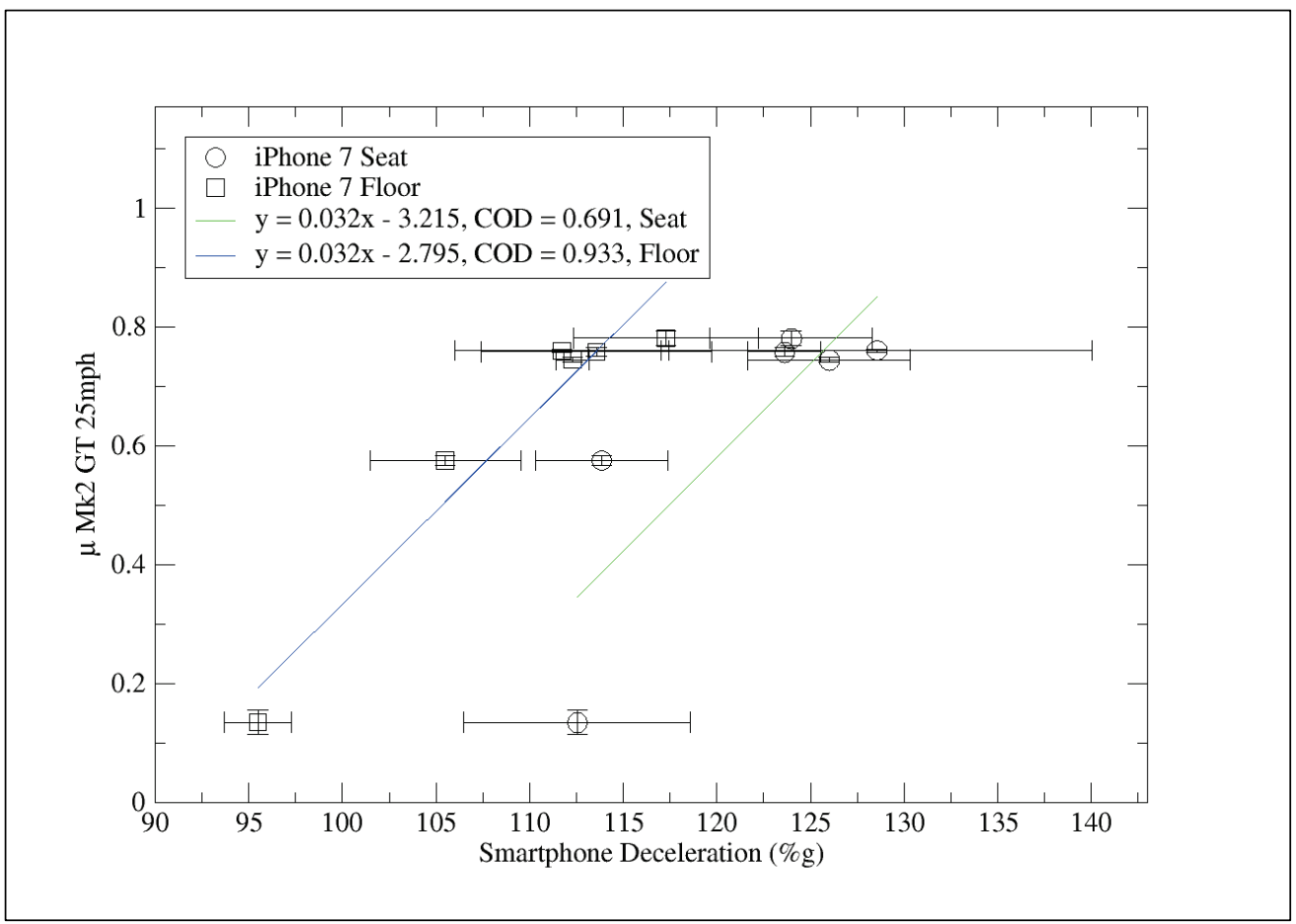

a) Mk2 GT25 vs. iPhone 7 peak deceleration.

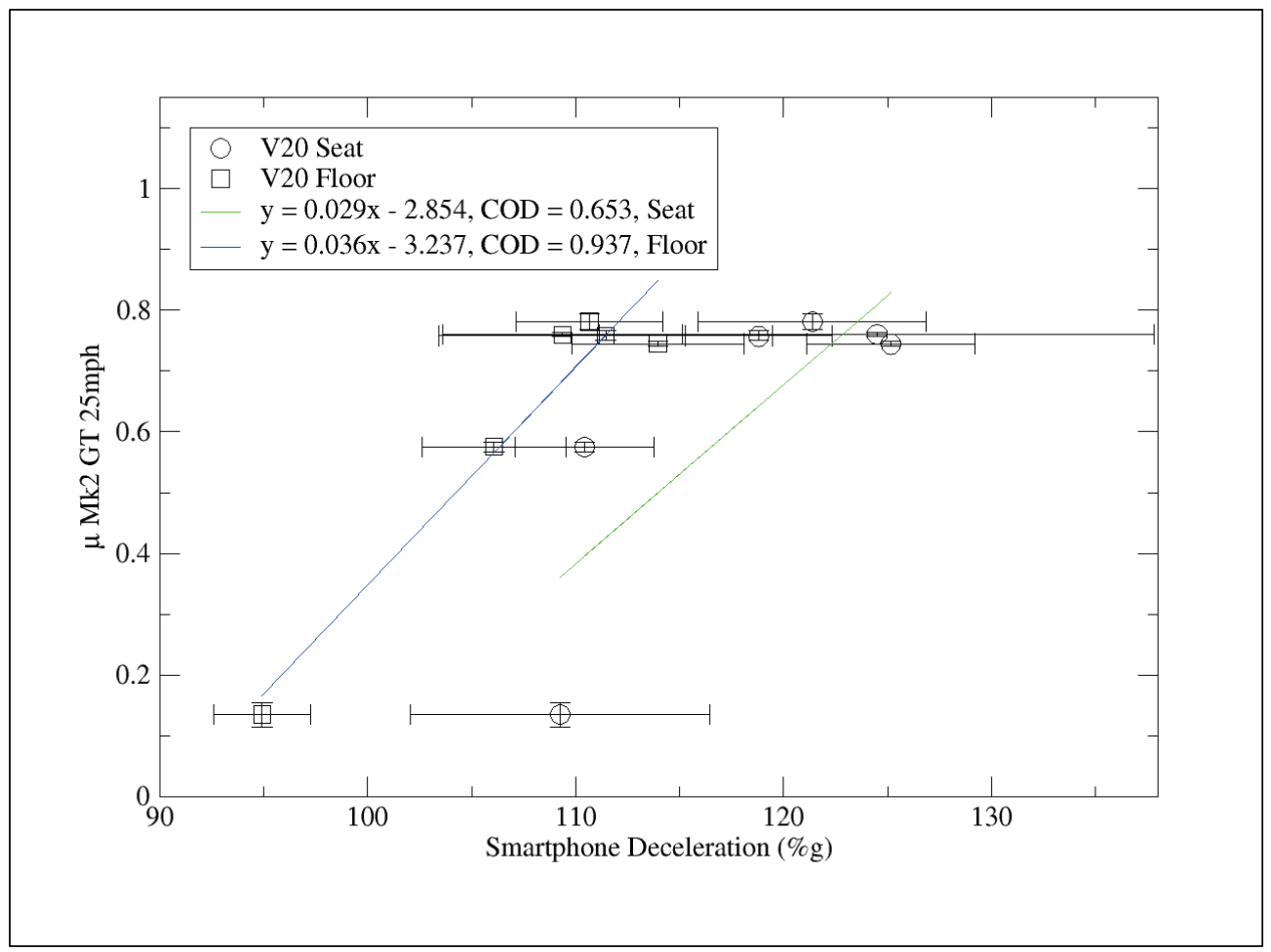

b) Mk2 GT25 vs. V20 for both seat and floor mounts. 
Linear regression results in Figure 27 and Figure 28 demonstrate that the smartphone deceleration measurements correlate well with both the standard for deceleration measurement (Bowmonk) and the standard for CFME measurement (Mk2 GT25). Using the floor-mounted smartphone correlations, Mk2 GT25 predictions were made for the iPhone 7 and V2O and are plotted in Figure 29.

Figure 29. Mk2 GT $25 \mathrm{mph}$ predictions for iPhone 7 and V20 deceleration data.

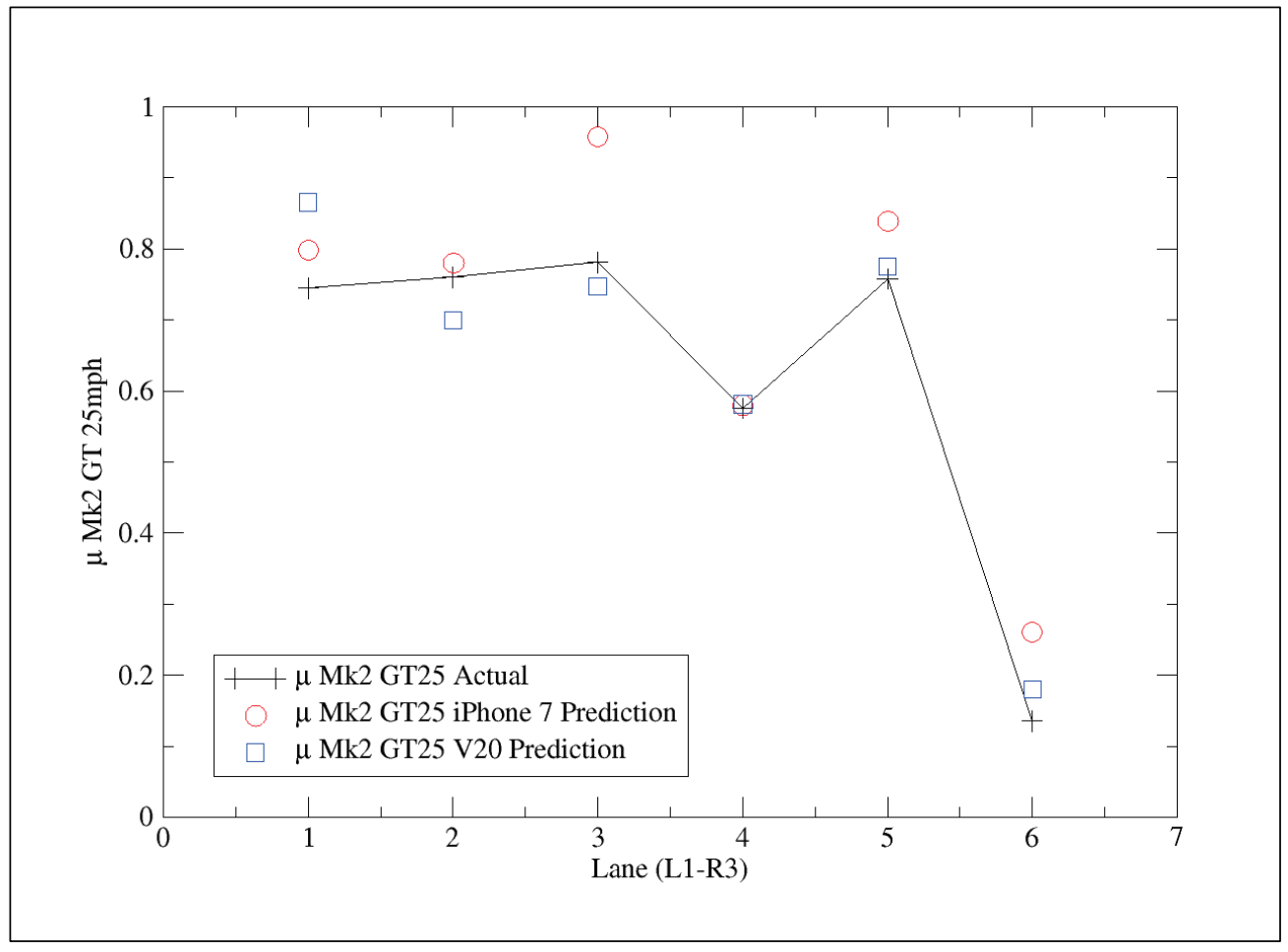

The iPhone 7 and V20 predictions in Figure 29 carry a MAE of 0.077 and 0.047 , respectively.

\subsubsection{IFI model conversion of smartphone data}

While it is useful to correlate the $20 \mathrm{mph}$ braking test deceleration data collected during this study to the Mk2 GT at $25 \mathrm{mph}$, it is much more useful to correlate the same braking test to the higher speed Mk2 GT at $60 \mathrm{mph}$. To accomplish this the IFI model (see Section 2.5) was used to convert, using a macrotexture measurement, the $20 \mathrm{mph}$ braking test measurement to a theoretically equivalent $60 \mathrm{mph}$ measurement. Figure 30 shows IFIconverted iPhone 7 and V2o predictions. 
Figure 30. Mk2 GT $60 \mathrm{mph}$ predictions for iPhone 7 and V20 deceleration data.

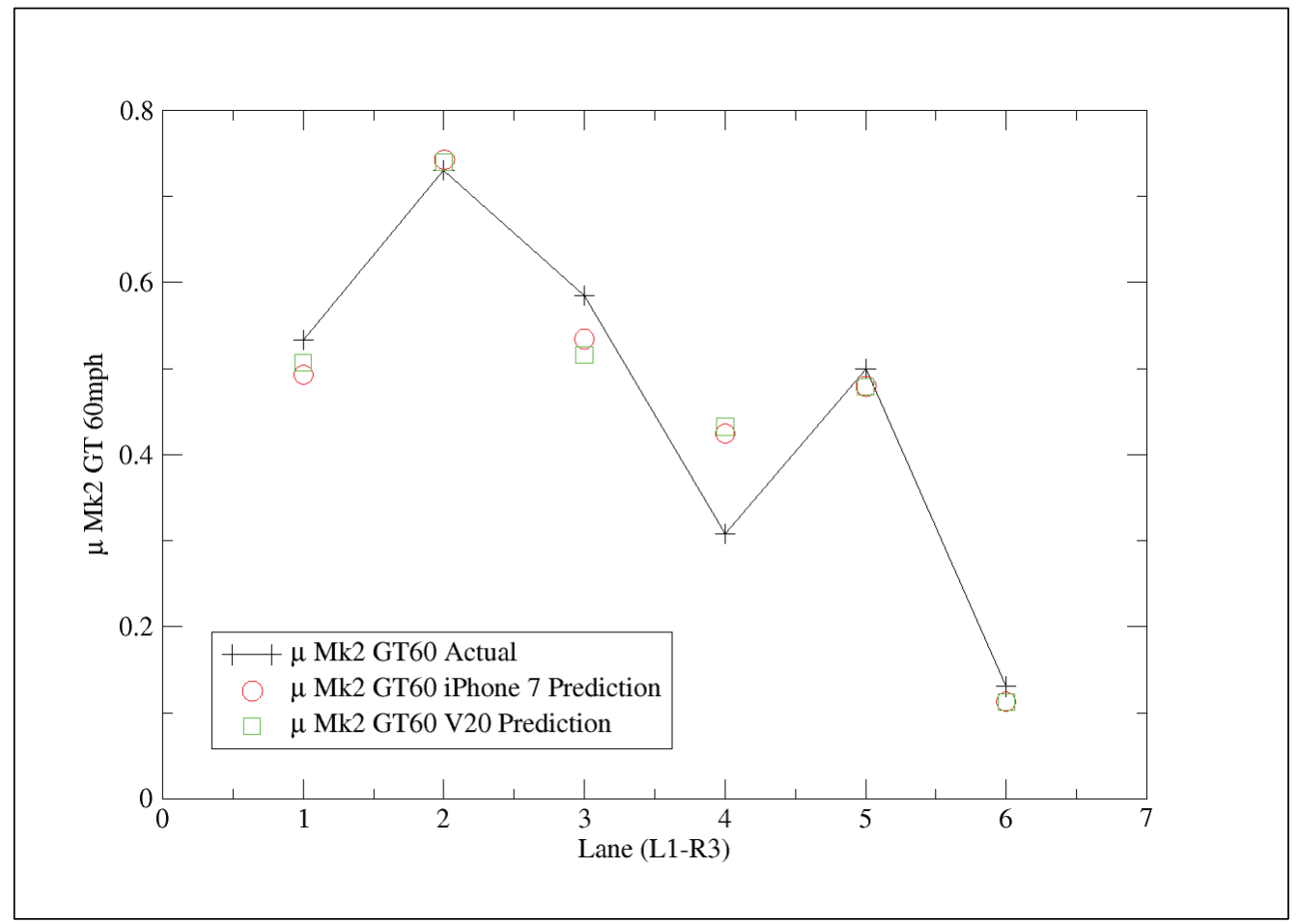

The iPhone 7 and V20 predictions in Figure 30 carry a MAE of 0.0426 and 0.0446 , respectively.

\subsubsection{Full vs. compact-size car}

Results presented in the preceding and following sections used a fixed fullsize car for all tests. It is important to make a distinction between braking tests conducted in full-size cars and braking tests conducted in compactsize cars. The importance of this distinction is drawn from the Mk2 GT 25 mph results in Figure 4. Data collected by ARA show that even highly accurate and precise CFME measurements made at $25 \mathrm{mph}$ are only able to differentiate three distinct surfaces, i.e., L1/L2/L3/R2 (high MPD), R1 (moderately low MPD), and R3 (very low MPD). It is imperative, then, that the deceleration-based technique developed in the present work be able to differentiate between at least these three distinct surfaces.

First, Figure 31 shows a plot of Smartphone Deceleration vs. Lane for the various phones tested in a compact-size test vehicle. 
Figure 31. Smartphone Deceleration vs. Lane using a compact-size car.

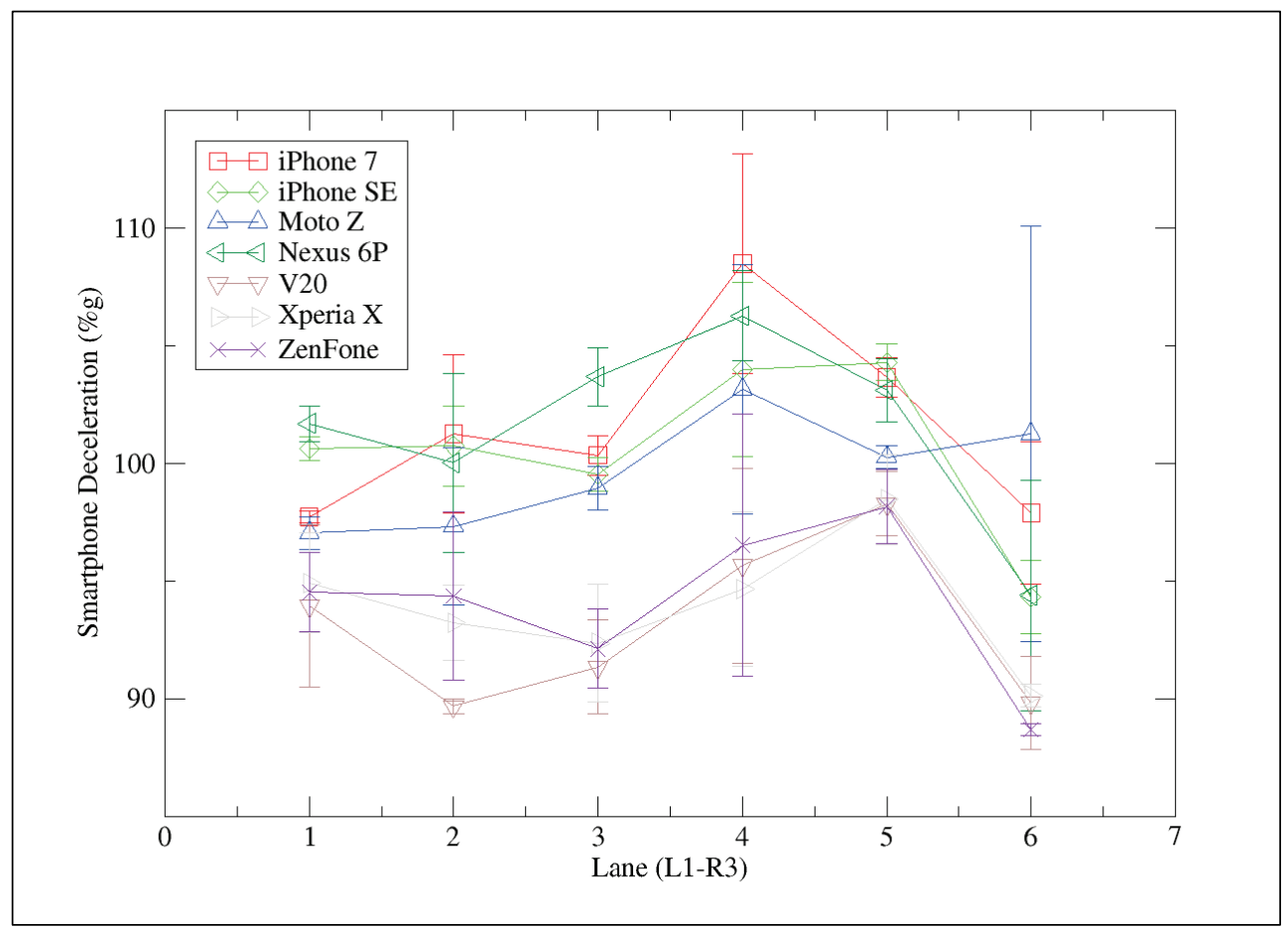

Among the large scatter in the data shown in Figure 31, it is apparent that the smaller size testing vehicle is unable to observe all friction levels seen while testing with larger testing vehicles. This is likely due to the decreased contribution of the hysteretic (deformation) component to friction (deceleration). Specifically, the lower weight of the compact-size test vehicle reduces the ability of the macrotexture particles in the pavement to deform the rubber tire, therefore reducing the rubber tire's ability to respond to the deformation. It is particularly troubling in the results of Figure 31 that the low MPD sections ( $\mathrm{R} 1$ and $\mathrm{R}_{3}$ ) respond with similar peak deceleration values compared to the high MPD sections (L1, L2, L3, R2). Additional experimental error can be contributed to the seat mount used during compact-size car testing.

\subsubsection{Consistency within full-size vehicle range}

Data were collected in Rounds 2 and 4 using two different full-size vehicles: a 2016 Chevy Malibu and a 2017 Toyota Camry. As only seatmounted smartphones were tested in Round 2, comparisons in this section will include only seat-mounted smartphones from Round 4 .

Round 4 vs. Round 2 smartphone peak deceleration data are shown in Figure 32. Four smartphones were used in both the Round 4 and Round 2 
testing: the Galaxy S7, iPhone 7, Nexus 6P, and V20. The peak deceleration regressions for these smartphones are shown in Figure 32aFigure 32d, respectively.

Aside from the results for the LG V2O in Figure 32d, with a COD of 0.856 , the remainder of the four smartphones show poor linear correlation between rounds, with CODs of 0.529 (Galaxy S7), 0.681 (iPhone 6), and 0.656 (Nexus 6P). This further emphasizes the reliance of strict experimental controls when performing braking tests, to include not only the size of the vehicle but the specific vehicle. Even given the high COD with the V20 (0.856), the results are not sufficient to conclude that vehicle size is a sufficient experimental control. Ideally, the results in Figure 32 would reveal a slope of approximately one and a constant offset among the devices (y-intercept). This is not the case in any of the results in Figure 32. 
Figure 32 . Round 4 vs. Round 2 smartphone deceleration.

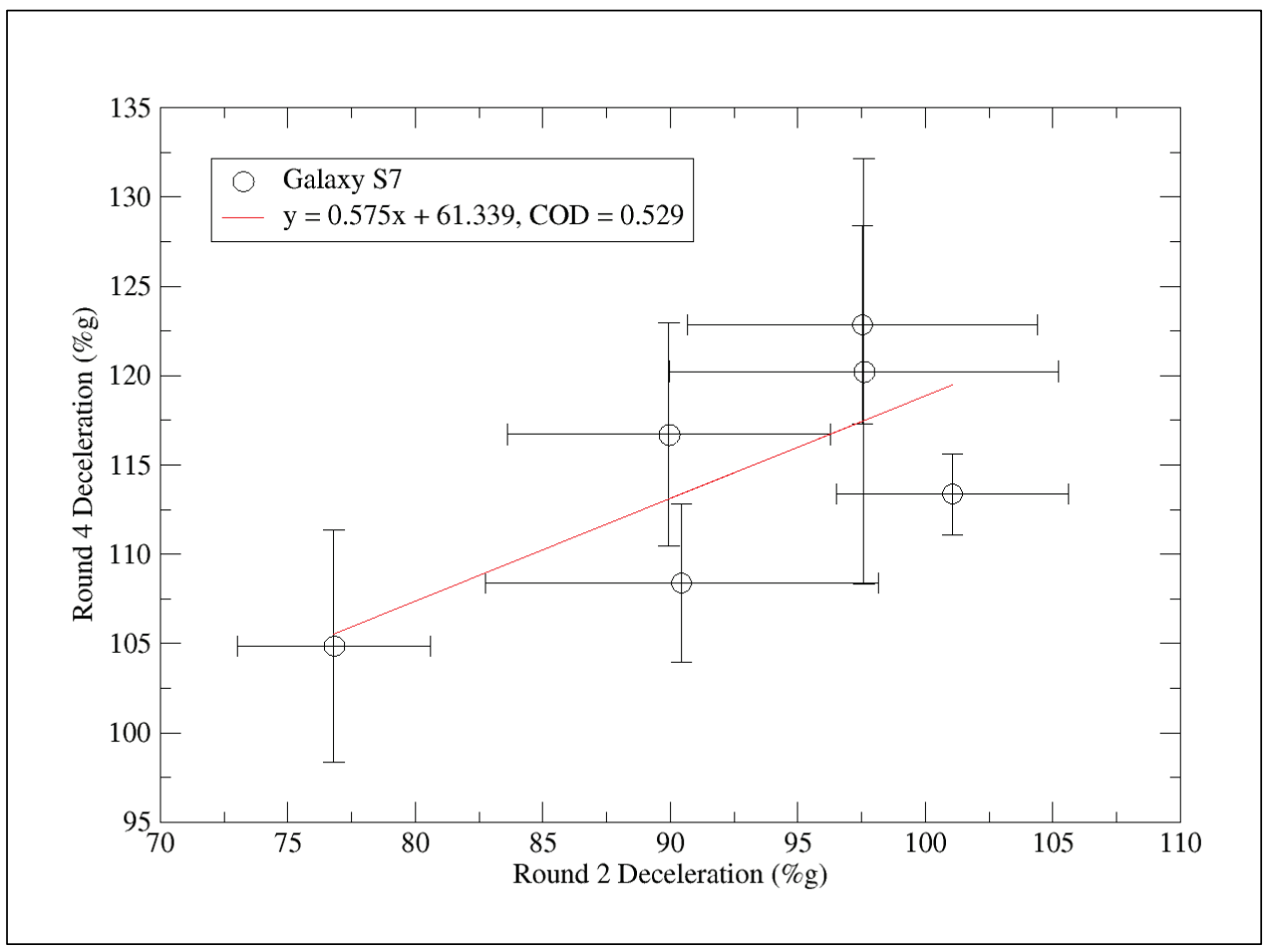

a) Round 4 vs. Round 2 deceleration for the Galaxy S7.

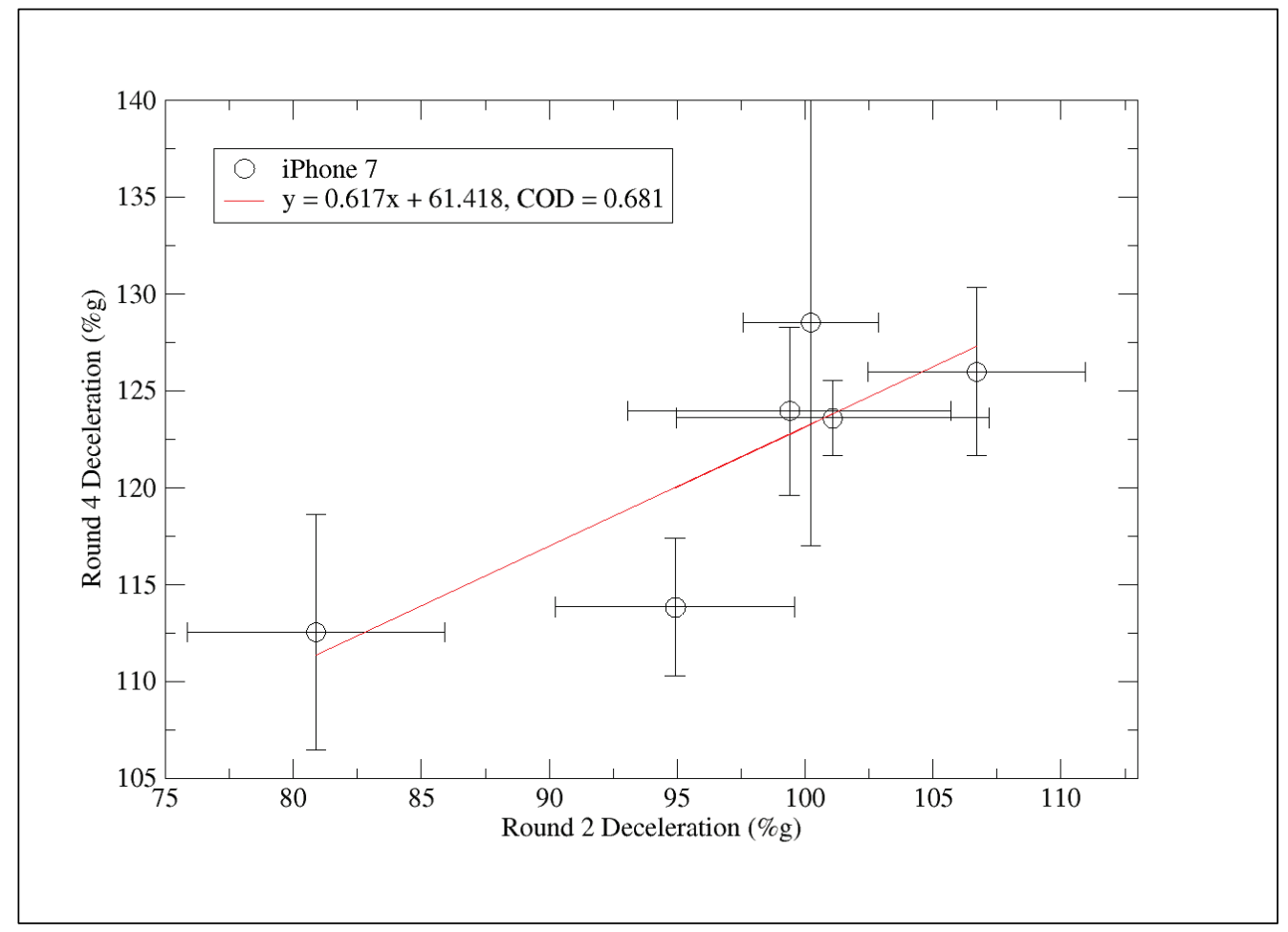

b) Round 4 vs. Round 2 deceleration for the iPhone 7 . 


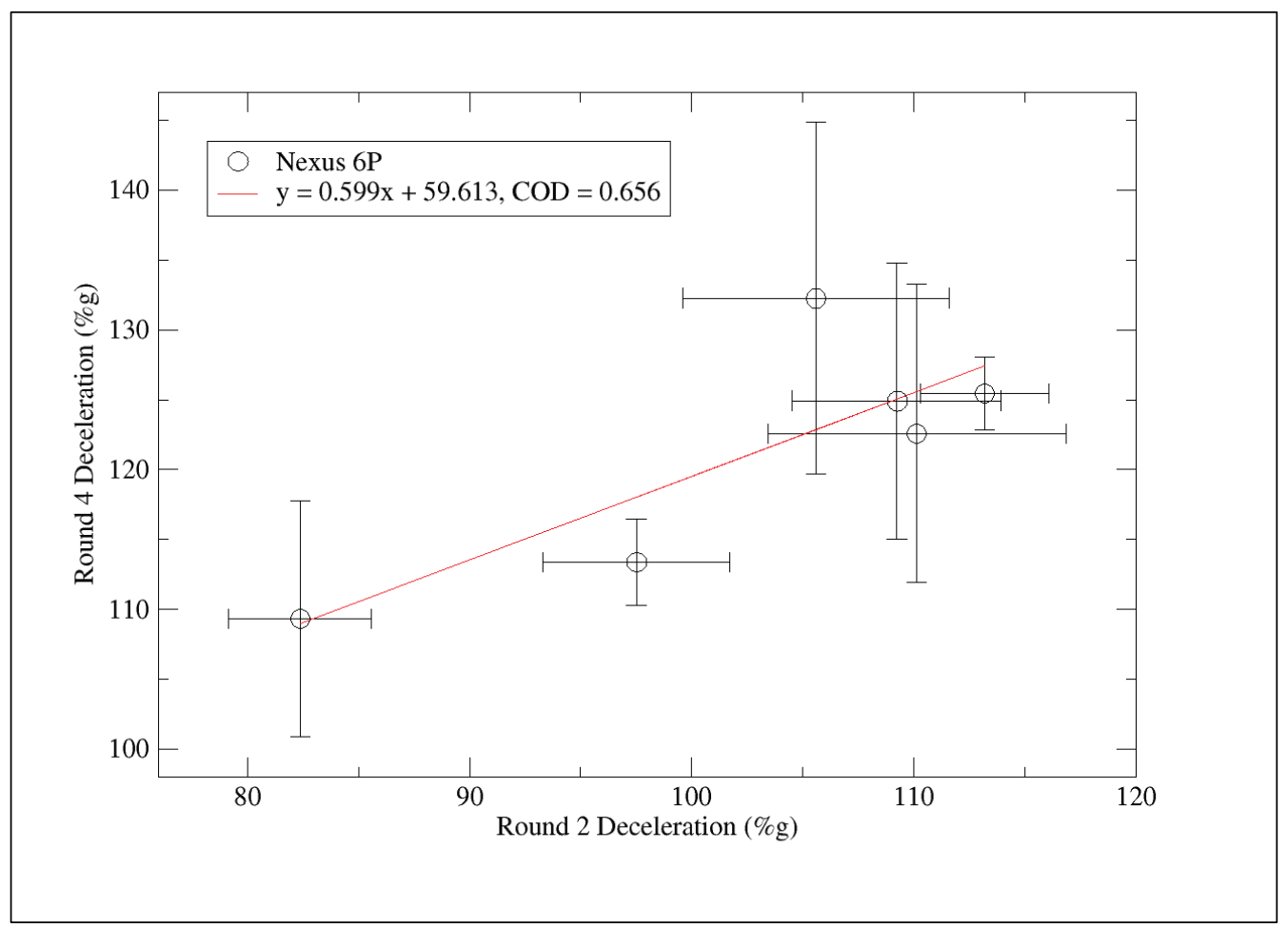

c) Round 4 vs. Round 2 deceleration for the Nexus $6 P$.

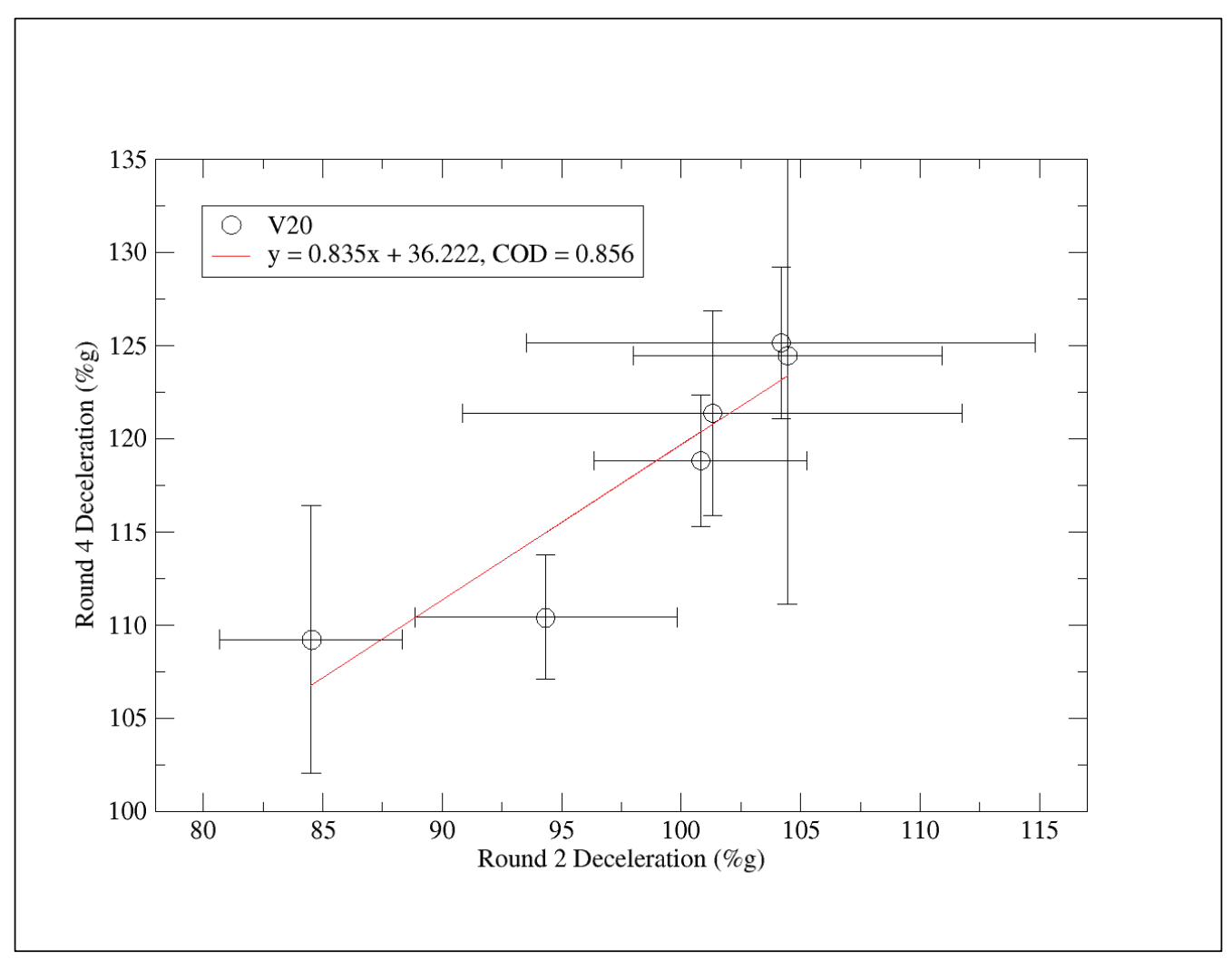

d) Round 4 vs. Round 2 deceleration for the V20. 


\subsubsection{Results during wet-pavement conditions}

Figure 33 shows the floorboard-mounted smartphone deceleration per lane during rainfall conditions at the Silver Flag test track using a full-size test car.

Figure 33. Smartphone deceleration vs. lane during rainfall conditions.

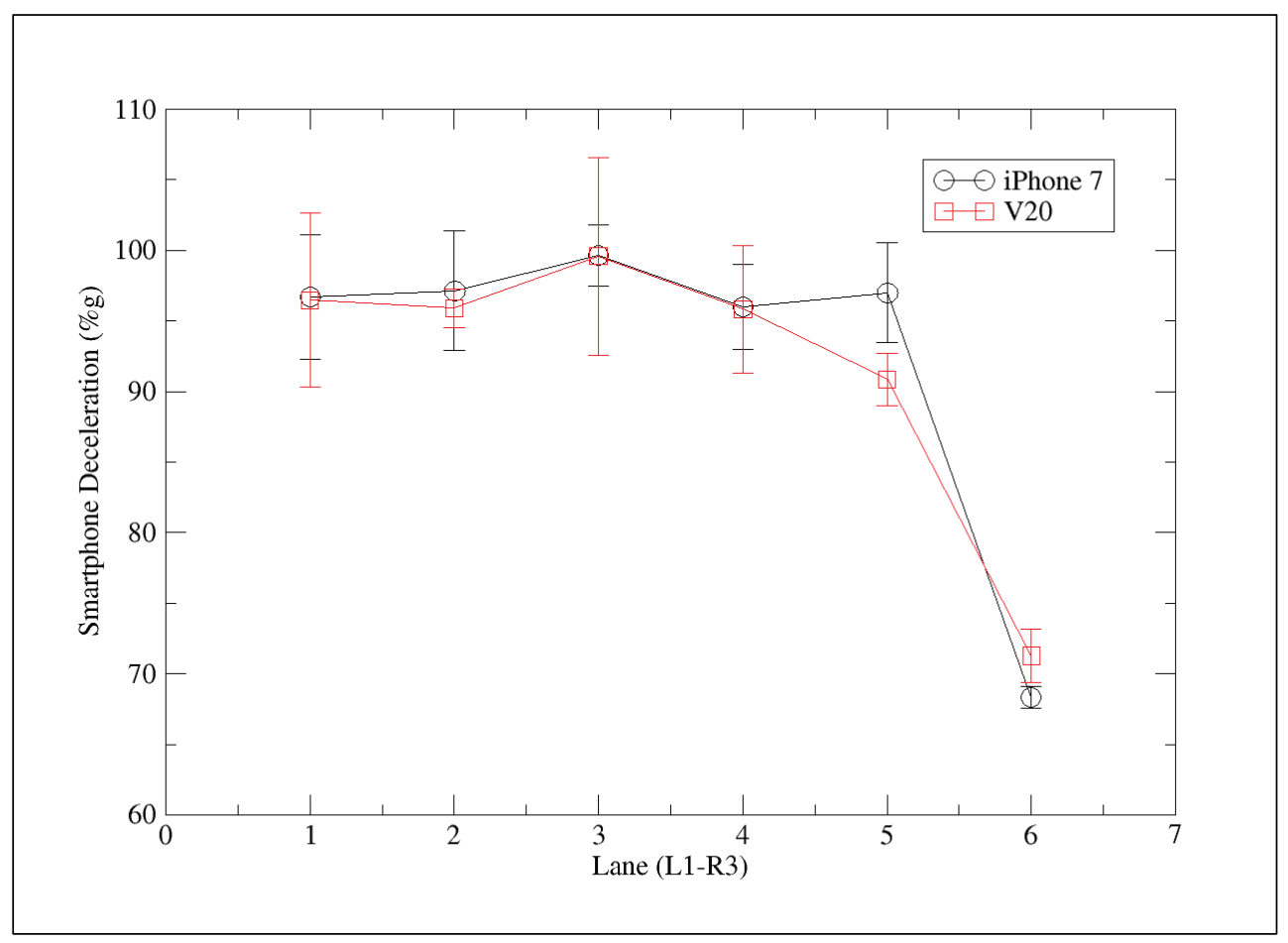

Similar to the weak deceleration response seen in the compact-size car testing, the results of Figure 33 reveal a lack of resolution in deceleration response during wet-pavement conditions. The weak deceleration response during rainfall conditions seen in Figure 33 indicates that brake testing on heavily water-contaminated pavements would need to compensate with a heavier testing vehicle and/or a faster testing speed. This also indicates that brake tests conducted during rainfall conditions would need to be paired with texture measurements in order to derive a useful friction response.

\subsubsection{Smartphone repeatability within manufacturer}

Replicate devices were purchased for the Apple iPhone 7 and LG V2O smartphones. During replicate testing, three iPhone 7s and three V20s were tested in the seat mount in a full-size car test vehicle. 
Figure 34. Smartphone deceleration vs. lane replicate testing.

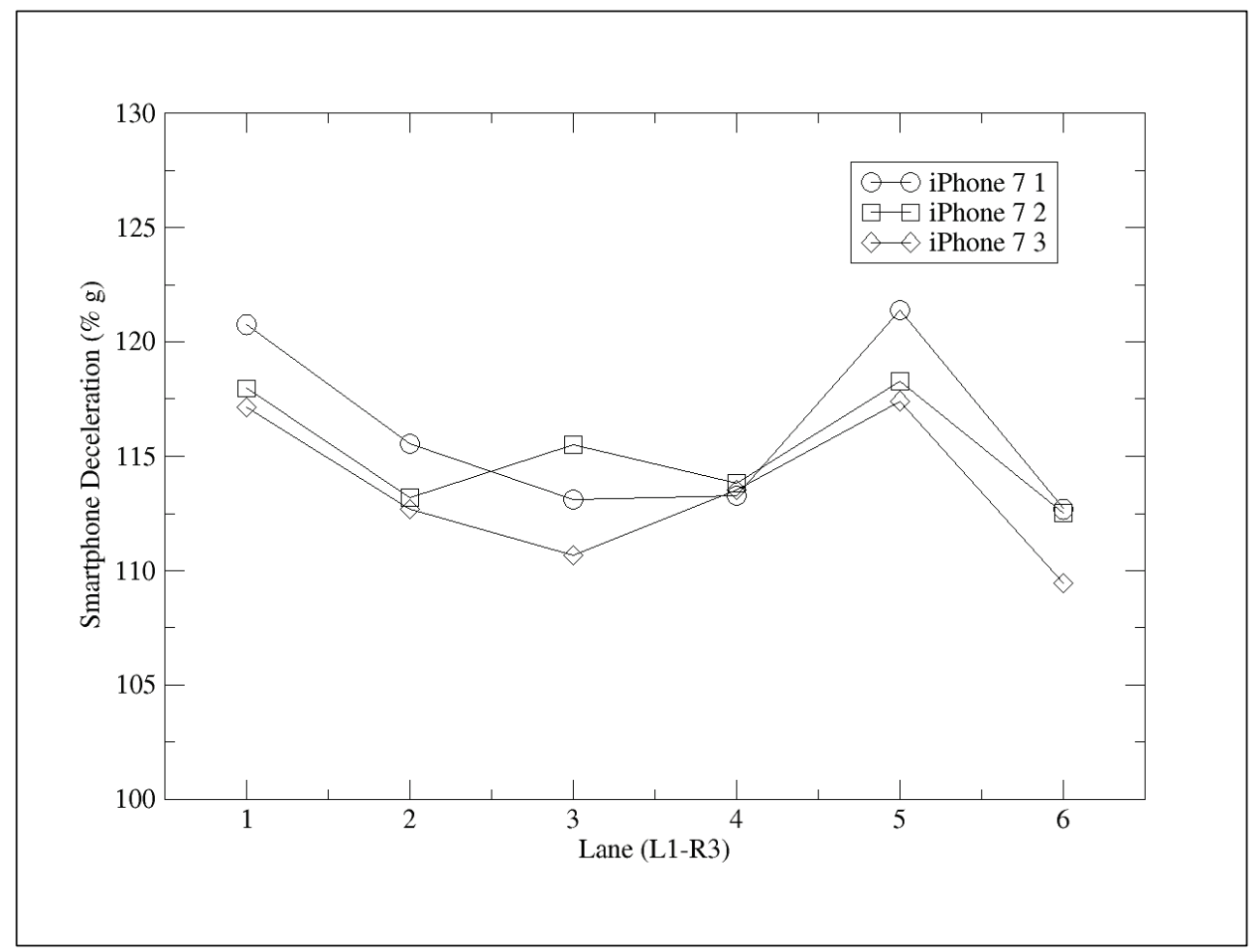

a) iPhone 7 deceleration vs. lane for three replicate devices.

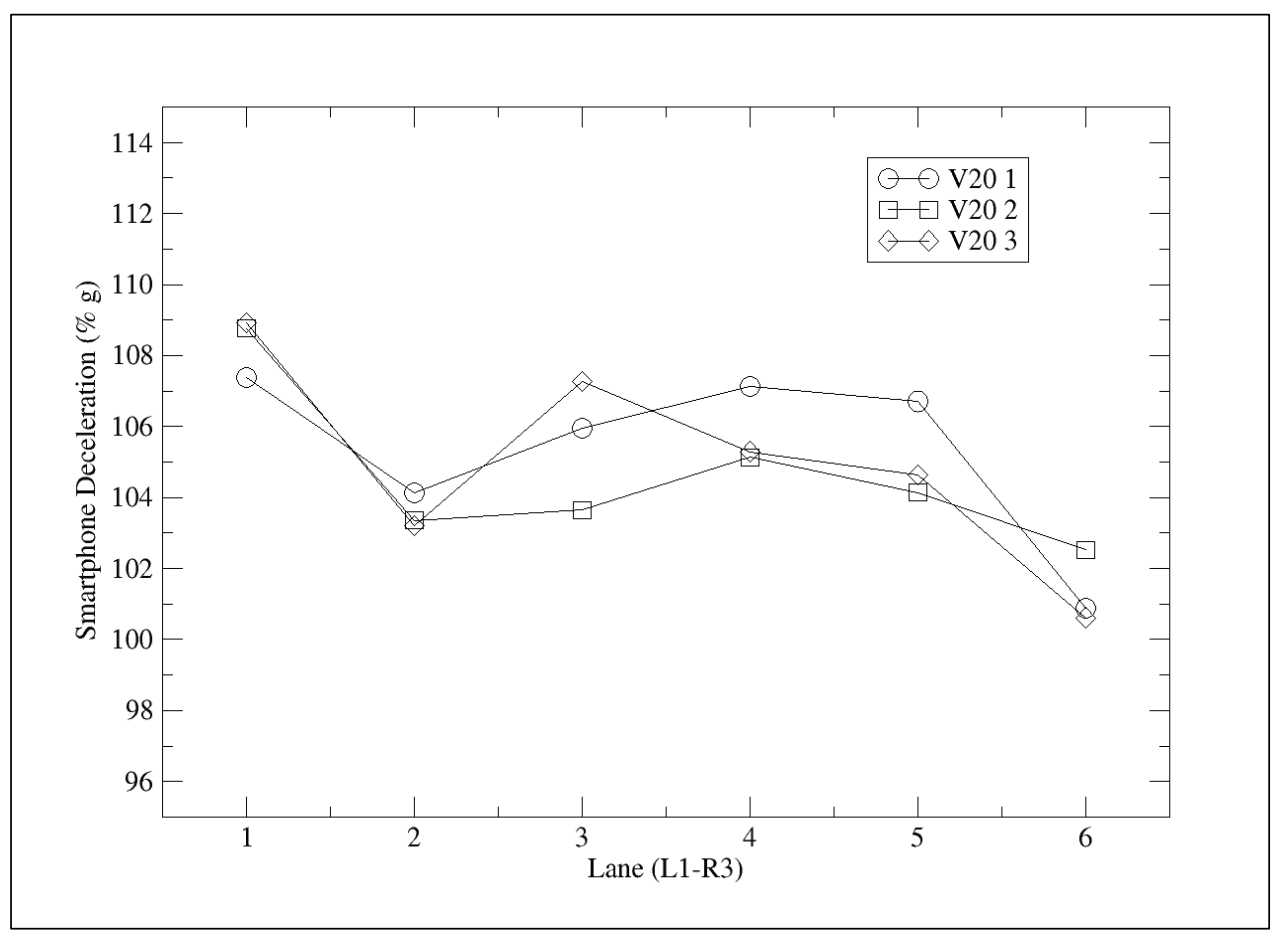

b) V20 deceleration vs. lane for three replicate devices. 
Replicate deceleration data for the iPhone 7 and V2O are in Figure 34a and Figure 34b, respectively. One-way ANOVAs performed on the raw replicate smartphone data show that, at the $95 \%$ confidence level, there is no significant difference in the smartphone population means. Pooled standard deviations are also low for the two devices: 1.48 for the iPhone 7 and 0.97 for the V2O.

\subsection{Vehicle ECU decelerometer}

Initial testing found that the equipment and user interface features of two of the three OBDII devices (BAFX and Auto Enginuity) were insufficient for deceleration measurement. The third device, the OBDLink MX, was found to be sufficient in deceleration measurement to continue testing in later rounds. It was found during testing that the OBDII devices have sufficient baud rate, or data transfer rate, to make for accurate measurement of acceleration; however, it was also found that the OBDII devices do not report sufficient precision to make for accurate acceleration measurement. The effect is that large portions of the deceleration peak are missing from the OBDII data leading to poor reporting of peak deceleration.

Figure 35. Deceleration vs. time comparison of the LG V2O and OBDLink MX.

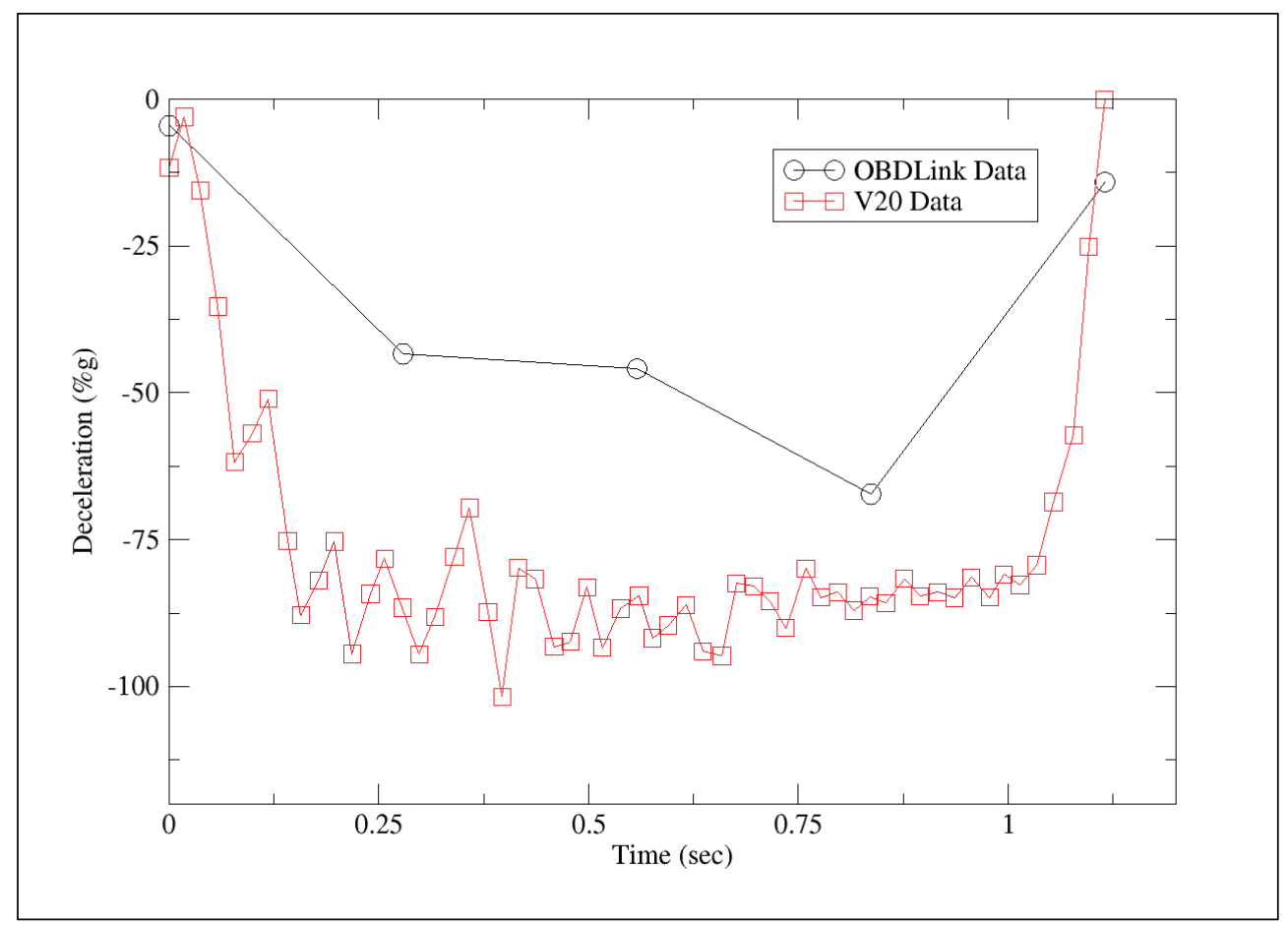


The majority of the data reported by the OBDII device was duplicate. For example, the deceleration vs. time comparison of the LG V2O smartphone and OBDLink MX OBDII device is in Figure 35. For a single deceleration peak, the V2O smartphone reports more than 50 unique deceleration measurements, while the OBDLink device reports only about 5 unique measurements.

With these limitations, the OBDLink MX device reported the frictional characteristics of the Silver Flag test track very poorly. Figure 36 shows the OBDLink MX peak deceleration values per Silver Flag lane. It is particularly troubling in Figure 36 that section R3, which has virtually no macrotexture, reports a higher peak deceleration than its neighboring sections R1 and R2 that should report higher than R3. The OBDLink data is not reporting the deceleration values of the Silver Flag test track accurately and this can be seen in the comparison of the Bowmonk to OBDLink peak deceleration data in Figure 37.

Figure 36. Deceleration vs. Lane for the OBDLink MX OBDII device.

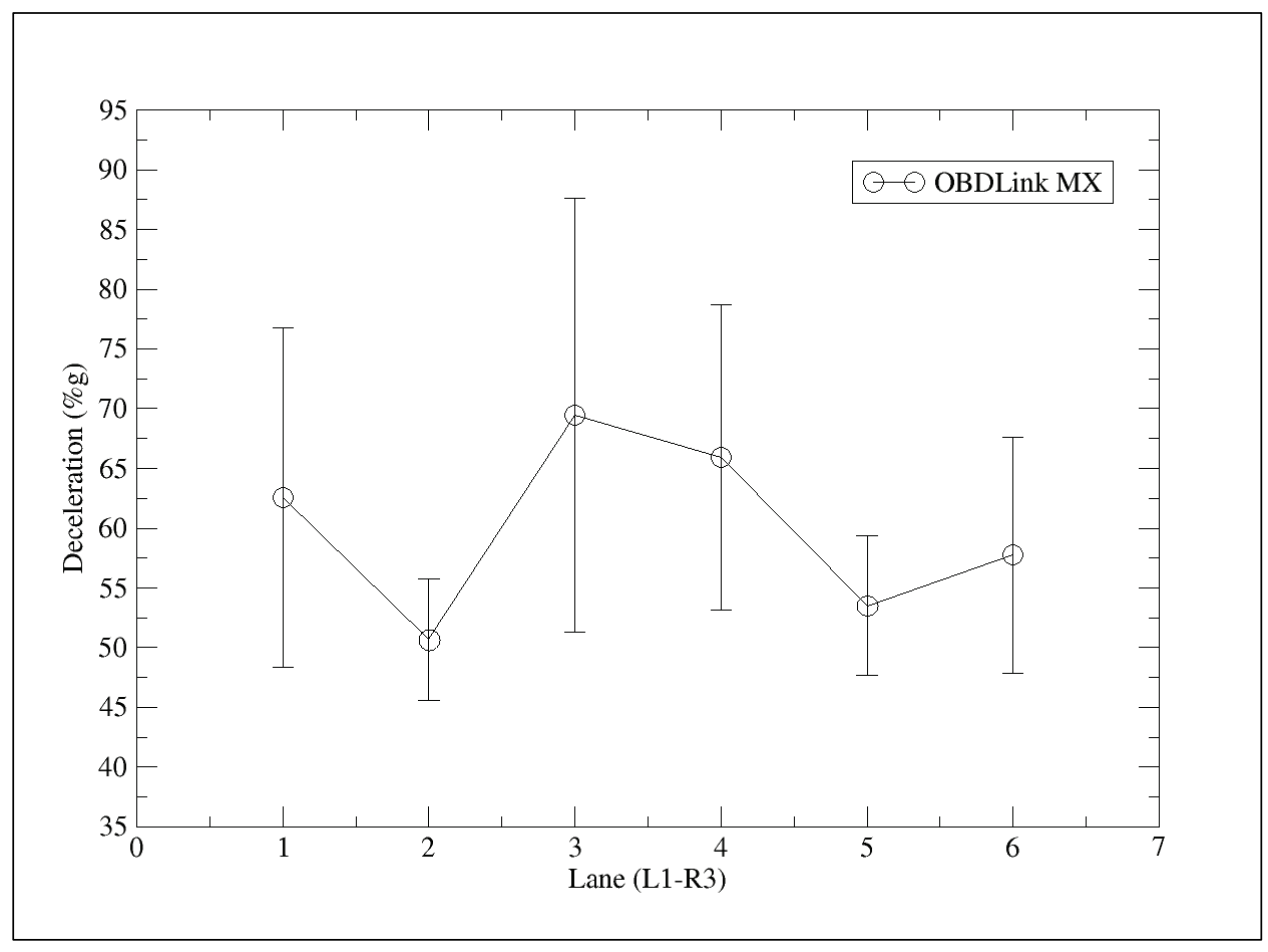


Figure 37. Bowmonk vs. OBDLink peak deceleration.

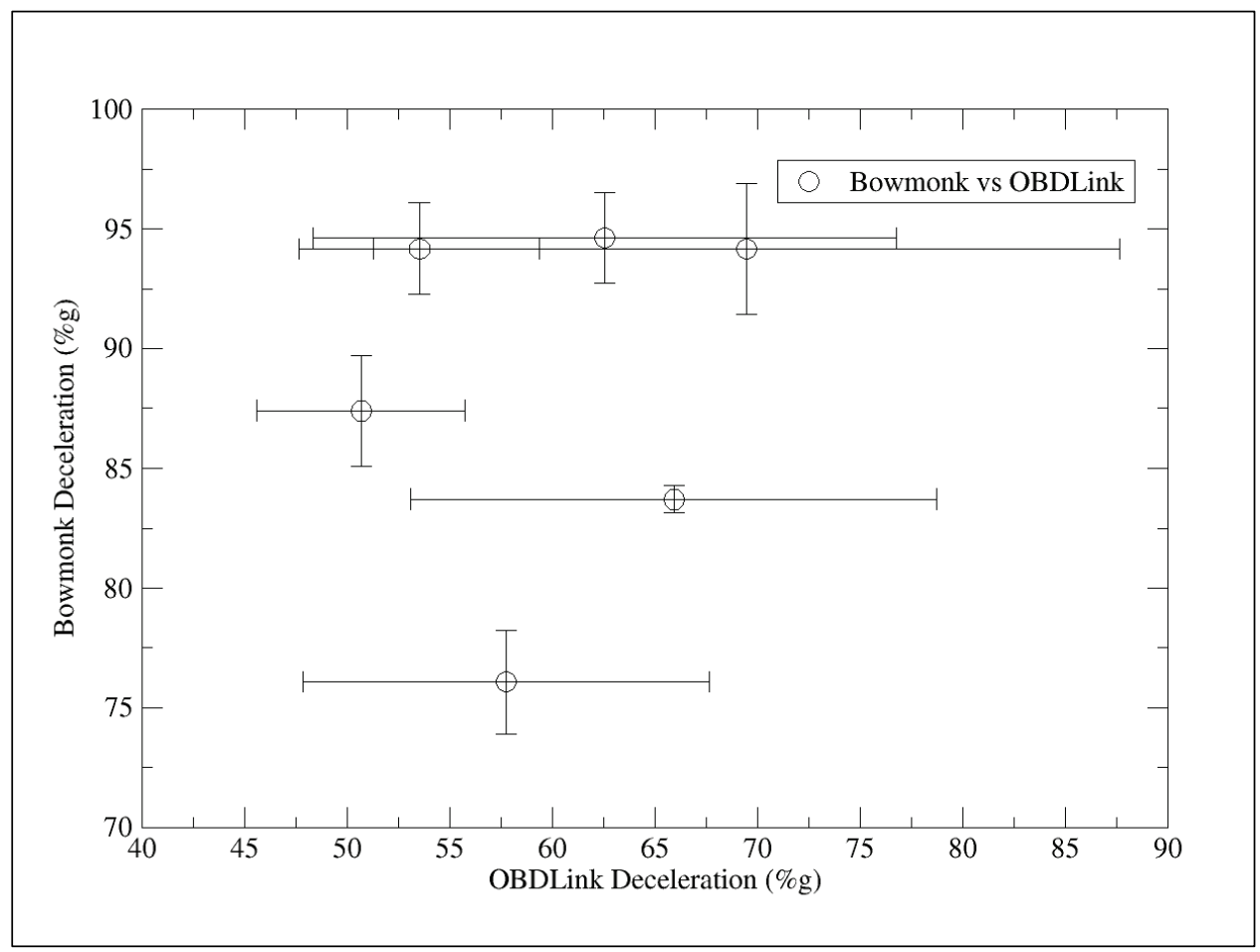

\subsection{Texture measurement}

High-resolution texture measurements collected in the center of each Silver Flag test section show the variety of profile depth and aggregate density. These texture measurements were obtained with an Ames 9400HD laser texture scanner. Note that high-resolution texture data from section R3 was corrupted and a lower-resolution texture measurement from the wheel path was used in Figure 38. Sections L1 (Figure 38a) and L3 (Figure 38c) appear very similar in agreement with their similar MPD measurements in Table 1 and Table 7. Section L2 (Figure 38b) has greater texture depth in comparison to the other sections also in agreement with the MPD values of the SF site. The self-leveling cement used to decrease the contribution of hysteresis to the force of friction used in sections R1 (Figure 38d) and R3 (Figure 38f) can be seen in the Ames LTS scans as a smooth surface underlying the aggregate particles. Section R2 (Figure 38e) has similar profile size to sections L1 and L2 in agreement with R2's similar but slightly lower macrotexture MPD. 
Figure 38. Texture measurements for the Silver Flag test track.

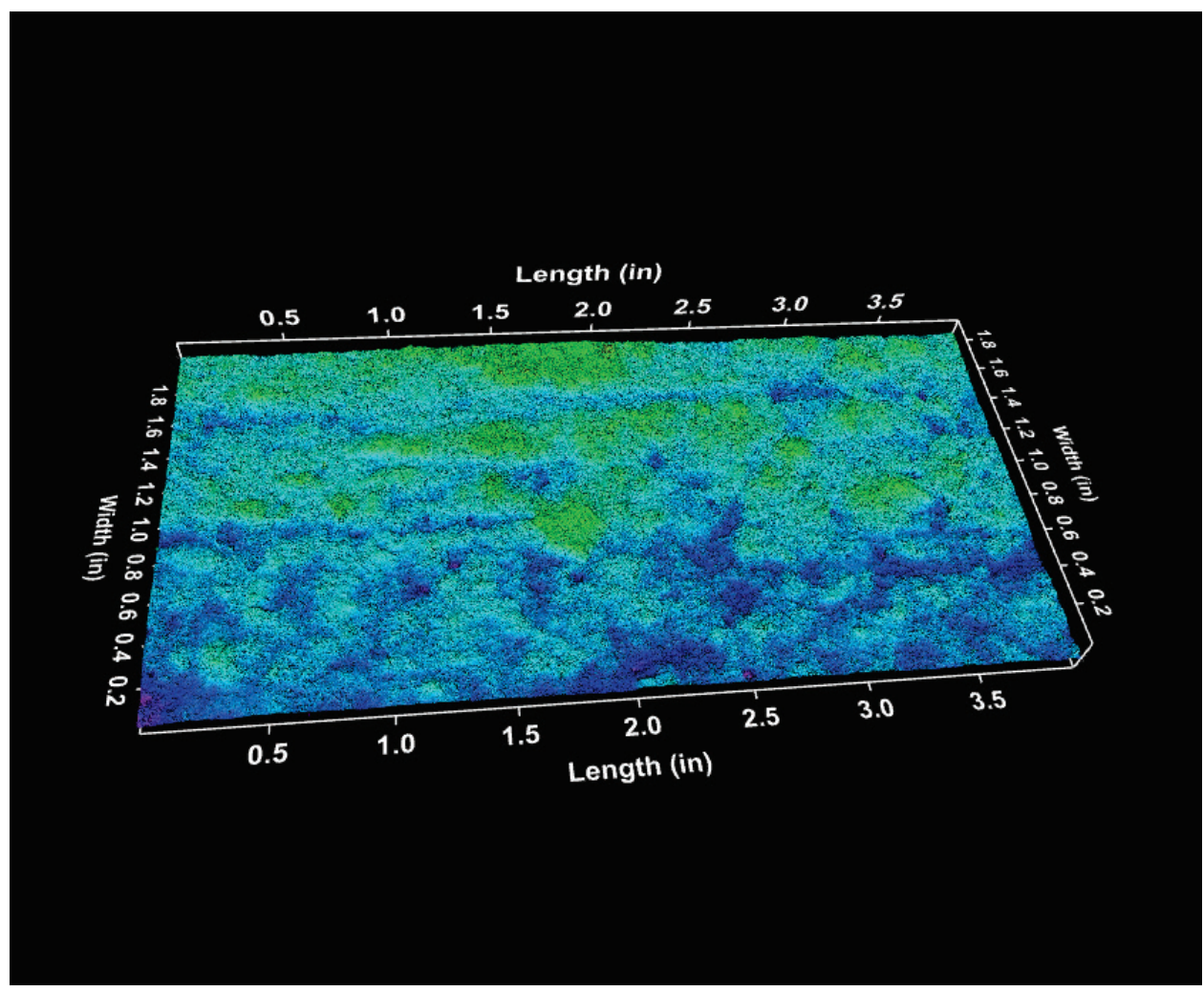

a) Section L1

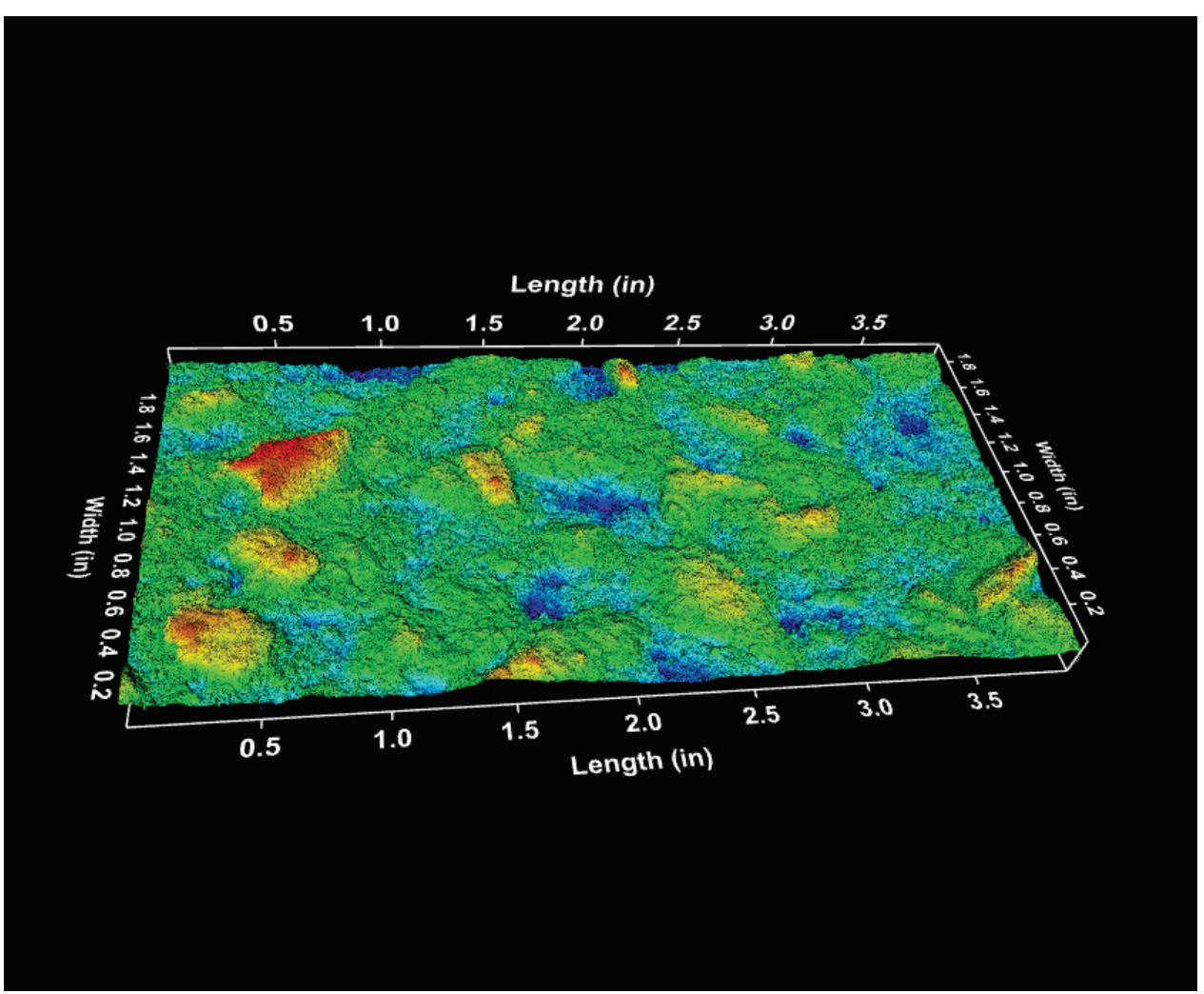

b) Section L2 


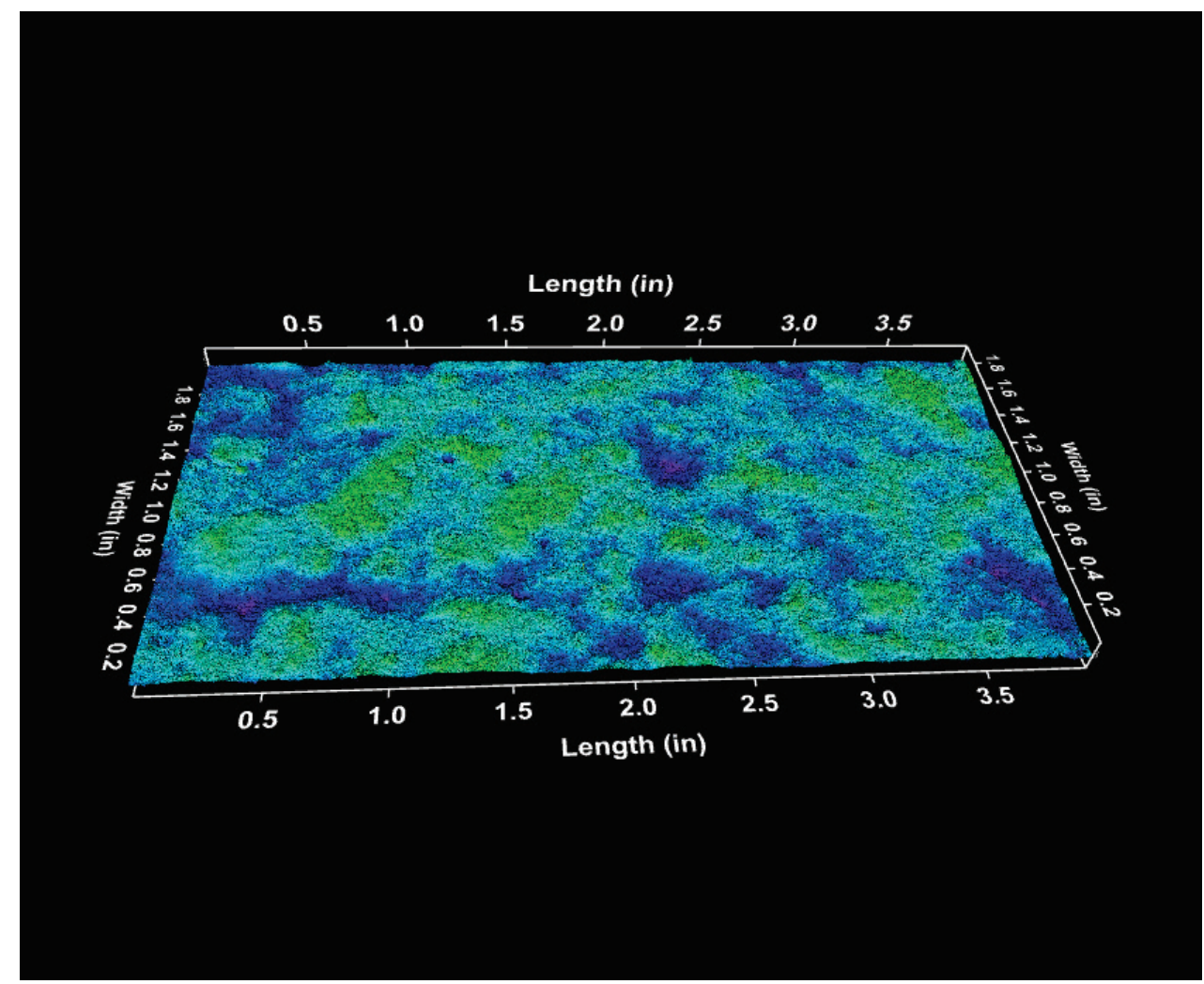

c) Section L3

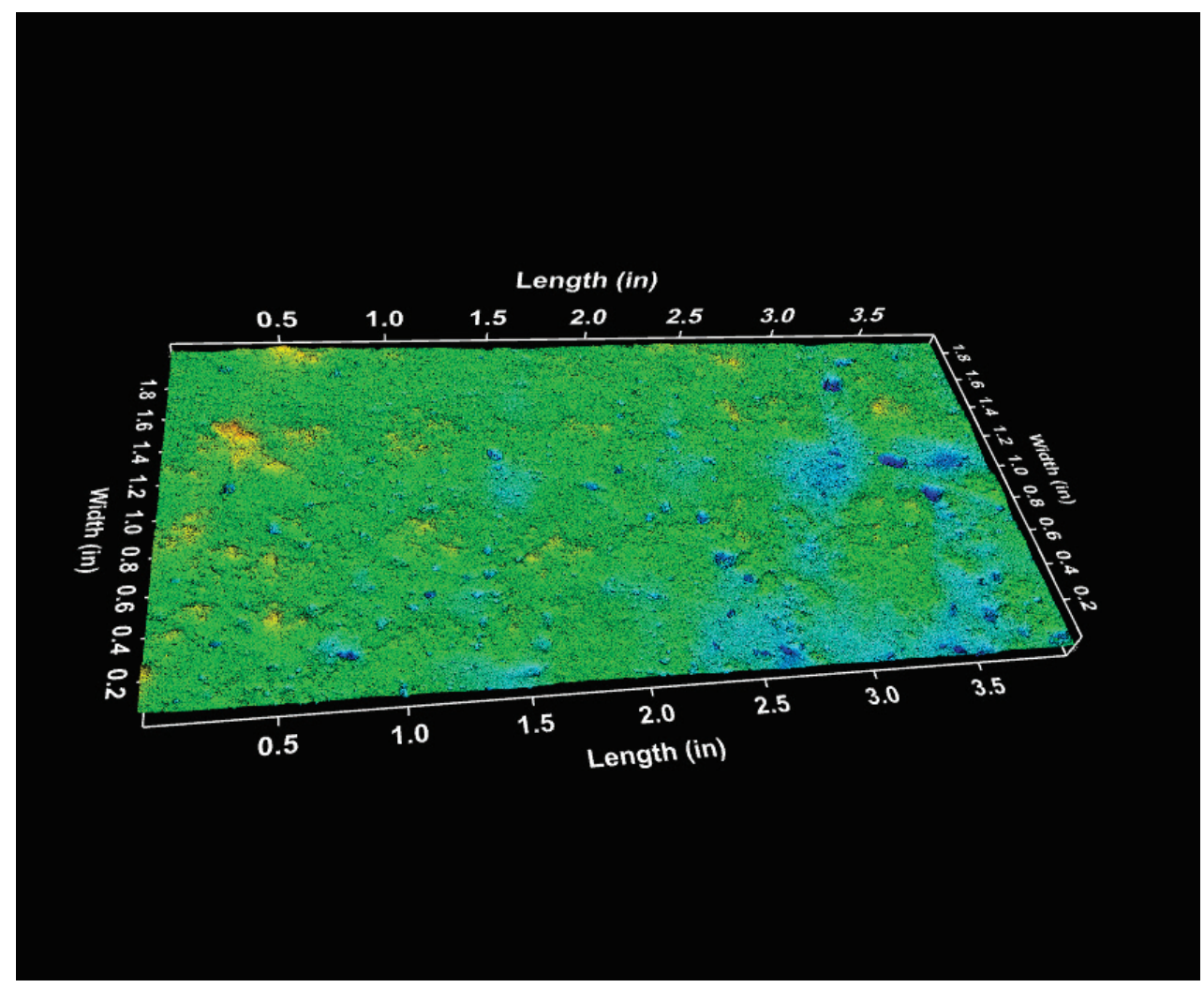

d) Section R1 


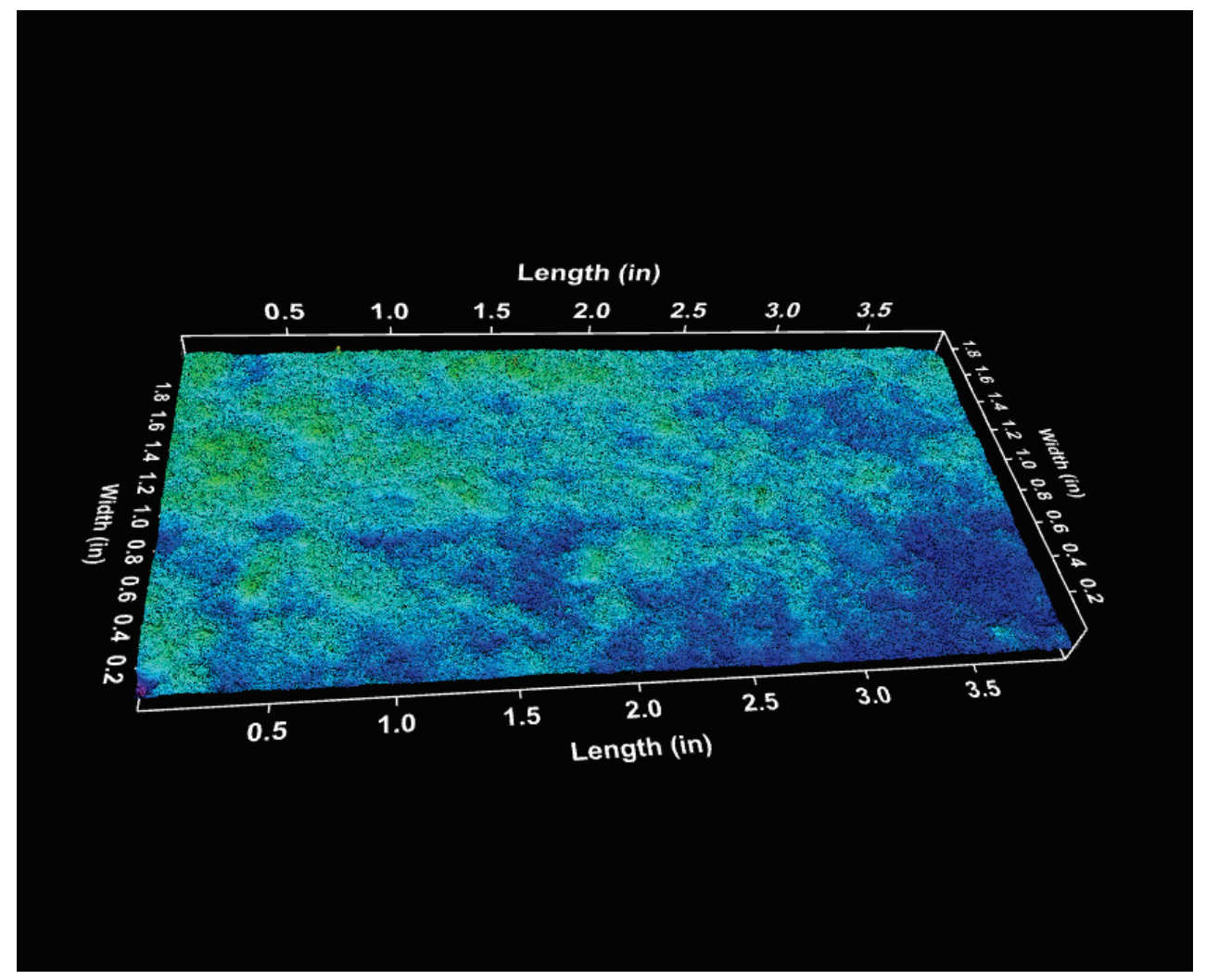

e) Section R2

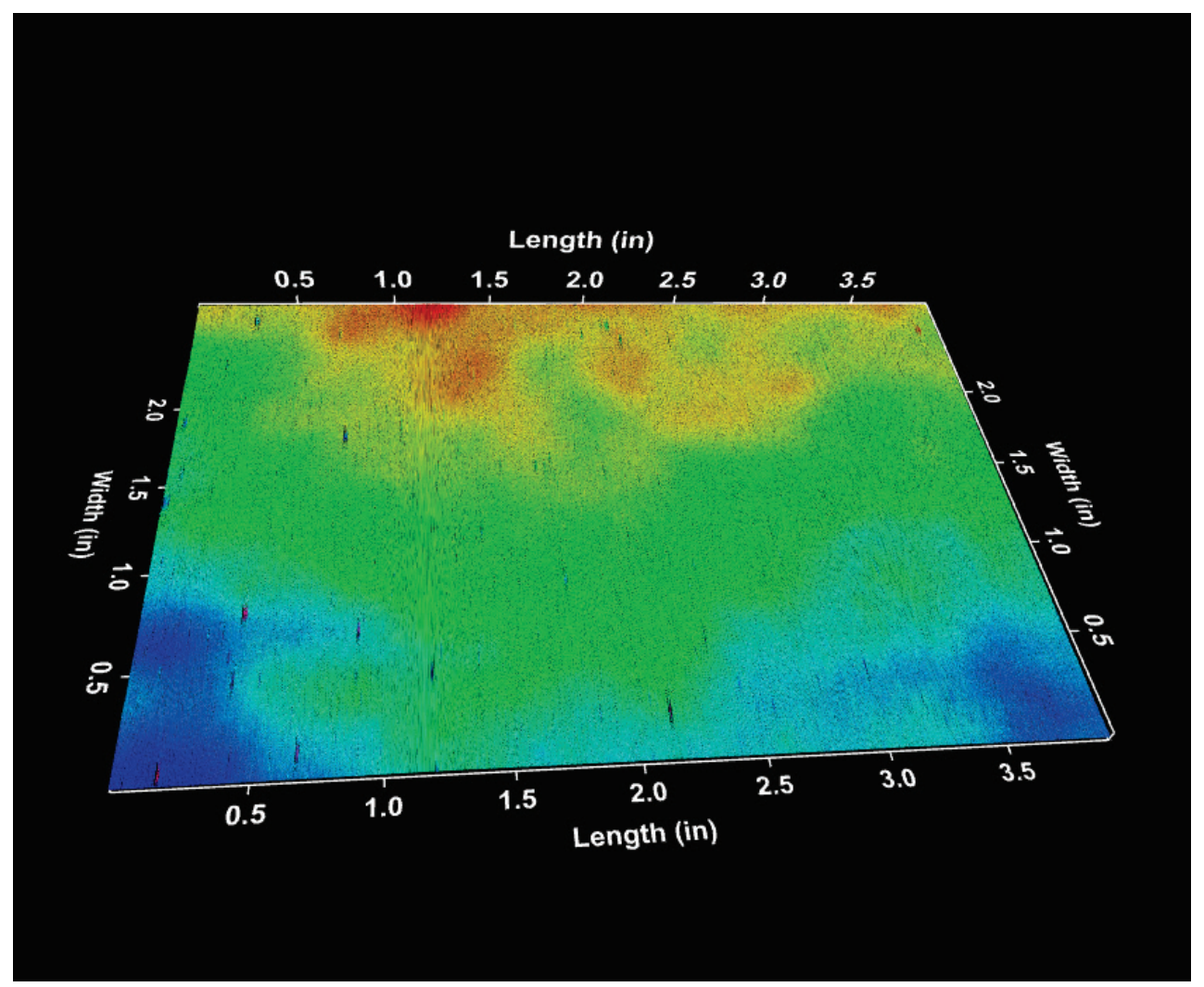

f) Section R3 
The ERDC also collected texture data using the Ames 9400HD LTS in the car wheel path at Silver Flag. FAA personnel in collaboration with ARA operated an Elatextur LTS in the center slabs of the Silver Flag test track. When the Silver Flag test track was constructed, CTM measurements were obtained to provide a construction reference for future work. Data from these collections are in Table 7.

Table 7. Texture measurements made at Silver Flag.

\begin{tabular}{|l|l|l|l|}
\hline Lane & Ames 9400HD & Elatextur & CTM \\
\hline L1 & $0.540 \pm 0.049$ & $0.576 \pm 0.062$ & 0.52 \\
\hline L2 & $1.106 \pm 0.075$ & $1.245 \pm 0.134$ & 1.35 \\
\hline L3 & $0.575 \pm 0.021$ & $0.580 \pm 0.038$ & 0.60 \\
\hline R1 & $0.473 \pm 0.042$ & $0.346 \pm 0.041$ & 0.38 \\
\hline R2 & $0.513 \pm 0.015$ & $0.440 \pm 0.050$ & 0.53 \\
\hline R3 & $0.084 \pm 0.021$ & $0.112 \pm 0.034$ & 0.09 \\
\hline
\end{tabular}

The Ames LTS data collected at the wheel path highly correlates to the original CTM measurements made on the site. Figure 39a shows a linear regression of CTM vs. Ames data with a COD of 0.984. The linear equation associated with the CTM vs. Ames regression is in Equation 34.

$$
y=1.263 x-0.114
$$

The Ames LTS data also highly correlate with the Elatextur measurements provided by the FAA. Figure 39b shows a linear regression of the Elatextur vs. Ames data with a COD of 0.978 . The linear equation associated with the Elatextur vs. Ames regression is in Equation 35.

$$
y=1.143 x-0.077
$$

These correlations indicate that the texture measurement devices used by the ERDC (Ames 9400HD) and the FAA (Elatextur) are linearly comparable to the ASTM-accepted CTM measurements. 
Figure 39. Comparison of three texture measurement devices.

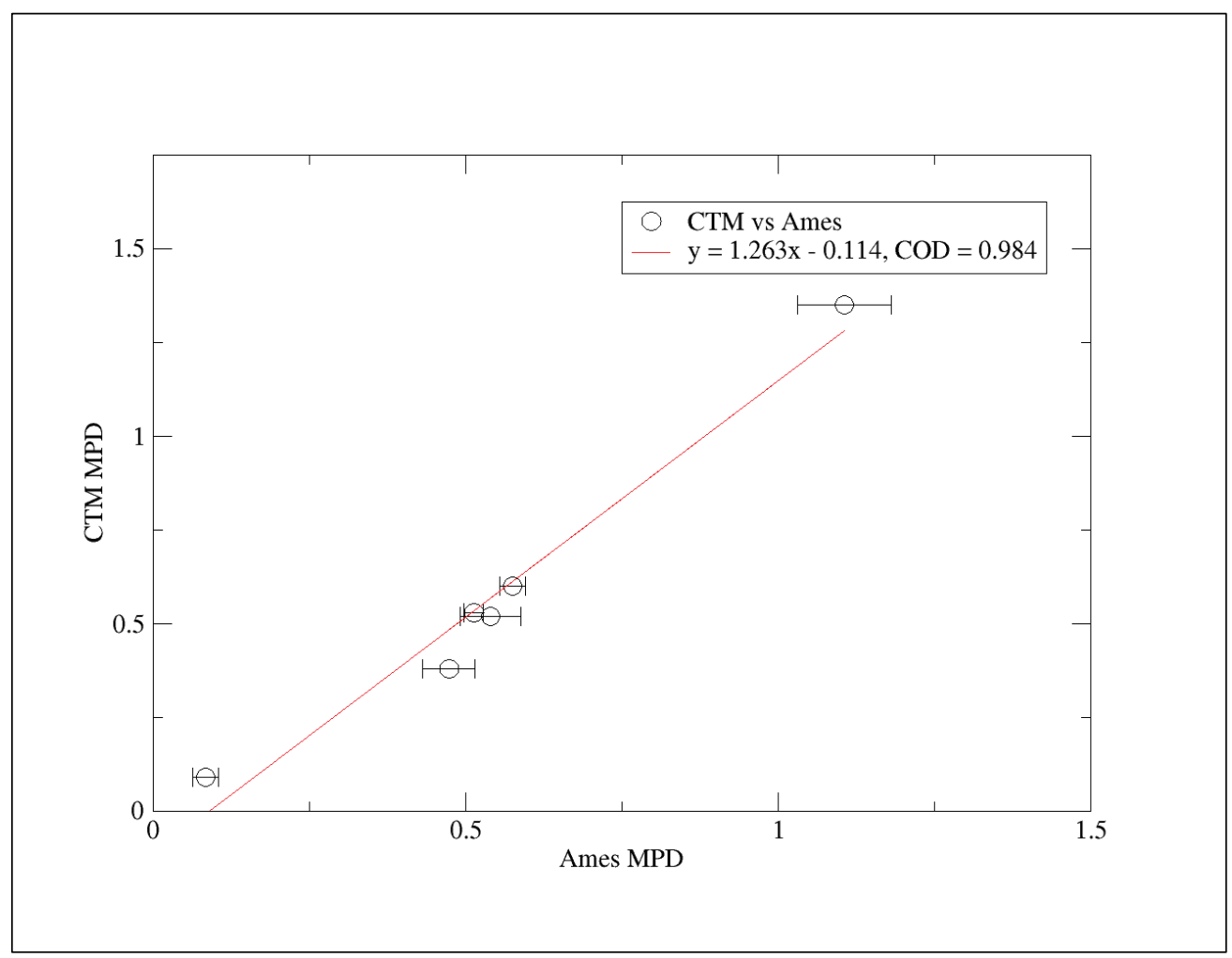

a) CTM vs. Ames regression

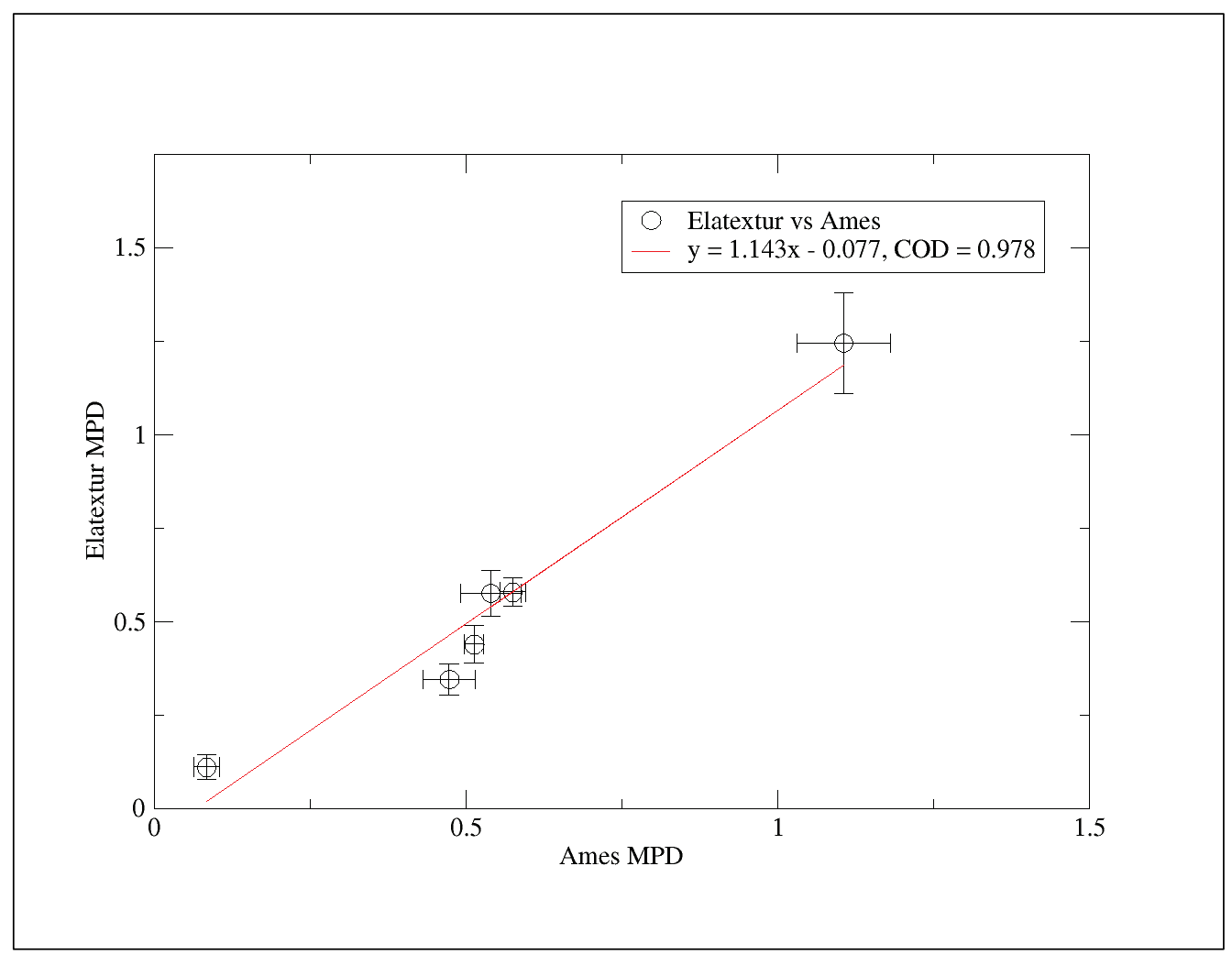

b) Elatexur vs. Ames regression 


\section{Conclusions and Recommendations}

The deceleration-based testing detailed here reveals a number of interesting conclusions unique to the smartphone-based technique used. The present study also reflects a number of conclusions common in deceleration-based testing prior to this study. It has been determined that improved correlation between accelerometer-based devices and CFMEs is limited by poor reproducibility common in deceleration-based testing. Specific conclusions of interest to project sponsors or other individuals seeking to employ the techniques developed here are detailed below.

\subsection{Conclusions}

- The Bowmonk AFM2 Mk3 decelerometer remains the standard for deceleration-based friction measurement. Figure 22 shows the high repeatability between Bowmonk devices. Figure 23 shows the 1-to-1 consistency while tested in different positions. Figure 24 shows the strong linear correlation to the CFME standard, i.e. Mk2 GT at $25 \mathrm{mph}$.

- The smartphone accelerometer-based technique described in the present work exhibits poor reproducibility between smartphone manufacturers. Figure 25 shows the large scatter in deceleration response from various smartphone brands as well as does Figure 21 for scatter in data due to driver inconsistency.

- The deceleration-based testing conducted shows that smartphones placed in the floorboard of the vehicle exhibit much lower experimental error than those mounted in the front passenger seat. Figure 27a and Figure 27b show Bowmonk vs. Smartphone linear correlations.

- The smartphone accelerometer-based friction measurement technique developed here correlates highly to both the Bowmonk decelerometer (Figure 27) and the Mk2 GripTester at $25 \mathrm{mph}$ (Figure 28, Figure 29, and Equations 30-33).

- Low MAE values, associated with Figure 30, indicate strong correlation with actual Mk2 GT $60 \mathrm{mph}$ measurements using the IFI model. Unlike the $25 \mathrm{mph}$ predictions in Figure 29, the IFI converted data shows sufficient resolution for both low and high friction portions of the $\mathrm{SF}$ test sections revealing the strong relationship between friction and macrotexture.

- Deceleration testing revealed that vehicle size is not a sufficient enough experimental control (Section 6.2.4). The model and manufacturer of the vehicle must also be controlled experimentally (Section 6.2.5). 
- The high repeatability of the smartphones tested (Section 6.2.7) indicates that the smartphone accelerometer-based technique may be suitable for friction change measurement.

- The vehicle ECU deceleration testing conducted in this study reveals the lack of sufficient precision in wheel speed data provided by the current state of vehicle on board computers (see Section 6.3).

\subsection{Recommendations}

It is recommended that the smartphone accelerometer-based friction measurement technique described here be tested on airfield operating surfaces containing rubber contamination in order to fully determine the technique's viability as a friction change measurement tool in the presence of surface contamination. Should correlation to higher-speed CFMEs be desired, it is recommended to standardize testing vehicle and driver braking action and perform vehicle/driver specific tests on a friction test track with at least six different friction/texture surfaces. It is recommended that any braking tests conducted with the ERDC DECEL app be conducted with the smartphone mounted securely in the floorboard. It is recommended that future studies be conducted on the use of vehicle ECUs as deceleration-based friction measurement devices with an emphasis on deriving more precise wheel speed data from vehicle onboard computers. 


\section{References}

ASTM International. 2009. Standard test method for measuring paved surface frictional properties using the dynamic friction tester. Designation: E1911-09a. West Conshohocken, PA: ASTM.

. 2013. Standard test method for measuring surface frictional properties using the British pendulum tester. Designation: E303-93. West Conshohocken, PA: ASTM.

. 2015a. Standard test method for skid resistance of paved surfaces using a fullscale tire. Designation: E274/E274M-15. West Conshohocken, PA: ASTM.

2015b. Standard specification for standard rib tire for pavement skidresistance tests. Designation: E501-08. West Conshohocken, PA: ASTM.

2015c. Standard specification for standard smooth tire for pavement skidresistance tests. Designation: E524-08. West Conshohocken, PA: ASTM.

. 2015d. Standard test method for testing side force friction on paved surfaces using the mu-meter. Designation: E670-09. West Conshohocken, PA: ASTM.

. 2015e. Standard test method for measuring pavement macrotexture depth using a volumetric technique. Designation: E965-15. West Conshohocken, PA: ASTM.

. 2015f. Standard practice for calculating pavement macrotexture mean profile depth. Designation: E1845-15. West Conshohocken, PA: ASTM.

2015g. Standard test method for friction coefficient measurements between tire and pavement using a variable slip technique. Designation: E1859/E1859M11. West Conshohocken, PA: ASTM.

. 2015h. Standard practice for calculating international friction index of a pavement surface. Designation: E1960-07. West Conshohocken, PA: ASTM.

. 2015i. Standard test method for measuring pavement macrotexture properties using the circular track meter. Designation: E2157-15. West Conshohocken, PA: ASTM.

. 2015j. Standard test method for measuring the skid resistance of pavements and other trafficked surfaces using a continuous reading, fixed-slip technique. Designation: E2340/E2340M-11. West Conshohocken, PA: ASTM.

. 2015k. Standard test method for measuring pavement texture drainage using an outflow meter. Designation: E2380/E2380M-15. West Conshohocken, PA: ASTM.

Bianchini, A., M. Heitzman, S. Maghsoodloo. 2011. Evaluation of temperature influence on friction measurements. Journal of Transportation Engineering 137(9):640647 . 
Blanco, J. L. 2014. A tutorial on SE(3) transformation parameterizations and onmanifold optimization. TR \#012010. Malaga, Spain: University of Malaga.

Bowmonk. 2017. Bowmonk AFM2 datasheet. www.bowmonk.com/uploads/files/2016/o6/afm2.pdf.

Cotter, B. W., J. C. Petermann, J. M. Heiser, S. C. Smith 2012. Evaluation of liquid detergents and methods used for airfield rubber removal. AFRL-RX-TY-TR2012-0077. Panama City, FL: Applied Research Associates Inc.

Crenshaw, B. M. 1972. Aircraft landing gear dynamic loads induced by soil landing fields. Volume 1. Prediction model and wheel loads. TR AFFDL-TR-70169.Wright-Patterson AFB: Air Force Flight Dynamics Laboratory.

Descornet, G. 2004. The HERMES project. $5^{\text {th }}$ Symposium on Pavement Surface Characteristics Conference, SURF 2004. Paris: World Road Association.

Ergun, M., I. Sukriye, and A. Faik Iyinam. 2005. Prediction of road surface friction coefficient using only macro- and microtexture measurements. Journal of Transportation Engineering 131.4(2005):311-319.

Federal Aviation Administration (FAA). 1997. Measurement, construction, and maintenance of skid-resistant airport pavement surfaces. Advisory Circular (AC) 150/5320-12C. Washington, DC: FAA.

Flintsch, G. W., E. L. Izeppi, K. K. McGhee, and J. A. Roa. 2009. Evaluation of international friction index coefficients for various devices. Transportation Research Record: Journal of the Transportation Research Board 2094(2):136143 .

Grosch, K. A. 1963. The relation between the friction and visco-elastic properties of rubber. Proceedings of the Royal Society of London, Series A 274:21.

Hanson, D., and B. Prowell. 2004. Evaluation of circular texture meter for measuring surface texture of pavements. NCAT Report No: 04-05. Auburn, AL: Auburn University.

Hegmon, R. R., and M. M. Mizoguchi. 1970. Pavement texture measurements by the sand patch and outflow meter methods. Automotive Safety Research Program Report S40, Study No. 67-11. University Park, PA: Pennsylvania State University.

Henry, J. J. 2000. Evaluation of pavement friction characteristics. Vol. 291. Washington, DC: Transportation Research Board.

Jackson, N. M., B. Choubane, C. R. Holzschuher, and S. Gokhale. 2007. Measuring pavement friction characteristics at variable speeds for added safety. In Pavement surface condition/performance assessment: reliability and relevancy of procedures and technologies. STP 1486. West Conshohocken, PA: ASTM.

Khasawneh, M. A. and R. Y. Liang. 2008. Correlation study between locked-wheel skid trailer and dynamic friction tester. TRB 87th Annual Meeting. Washington, DC.

Kummer, H. W. and W. E. Meyer. 1962. Measurement of skid resistance. In ASTM special technical publication no. 326, 3-28. West Conshohocken, PA: ASTM. 
.1967. Tentative skid-resistance requirements for main rural highways. NCHRP Report 37. Washington, DC: Transportation Research Board.

Lea, J., and D. Jones. 2007. Initial findings on skid resistance of unpaved roads. Transportation Research Record: Journal of the Transportation Research Board 2016(2007):49-55.

Leland, T. J. W, T. J. Yager, and U. T. Joyner. 1968. Effects of pavement texture on wetrunway braking performance. NASA TN D-4324. Hampton, VA: National Aeronautics and Space Administration.

Leu, M. C., and J. J. Henry. 1978. Prediction of skid resistance as a function of speed from pavement texture. Transportation Research Record 666. Washington, DC: Transportation Research Board, National Research Council.

1983. Prediction of skid resistance as a function of speed from pavement texture. Transportation Research Record 946. Washington, DC: Transportation Research Board, National Research Council.

Lidstrom, M. 1979. Aircraft rolling resistance in loose dry snow. VTI, Report 173A. Sweden: National Road \& Traffic Research Institute.

Meegoda, J. N., and S. Gao. 2015. Evaluation of pavement skid resistance using high speed texture measurement. Journal of Traffic and Transportation Engineering 2(6):382-390.

Mellor, M., and J. H. Smith. 1966. Strength studies of snow. Research Report 168. Hanover, NH: U.S. Army Cold Regions Research and Engineering Laboratory.

Moore, D. F. 1966. Prediction of skid-resistance gradient and drainage characteristics for pavements. Highway Research Record 131:181-203.

Moyer, R. A. 1934. Skidding characteristics of automobile tires on roadway surfaces and their relation to highway safety. Bulletin 120. Ames, IA: Iowa Engineering Experiment Station.

National Aeronautics and Space Administration (NASA). 1969. Pavement grooving and traction studies. NASA SP-5073. Washington, DC: NASA.

PIARC World Road Association. 1987. Report of the committee on surface characteristics. In Proceeding of XVIII World Road Congress, 13-19 September. Brussels, Belgium.

Pullen, A. B., L. Edwards, C. A. Rutland, J. S. Tingle. 2014. Field evaluation of ultra-high pressure water systems for runway rubber removal. ERDC/GSL TR-14-11. Vicksburg, MS: U.S. Army Engineer Research and Development Center.

Rado, Z. 1994. Analysis of texture profiles. PTI Report 9510. State College, PA: Pennsylvania Transportation Institute.

Richmond, P. W. 1990. Vehicle motion resistance due to snow. In Army Science Conference Proceedings, 12-15 June. Durham, NC. 
Rowe, R. S., and E. Hegedus. 1959. Drag coefficients of locomotion over viscous soils. Part II. Department of the Army, Ordnance Tank-Automotive Command, Report No. 54. Detroit, MI: Land Locomotion Laboratory.

Sengoz, B., A. Topal, and S. Tenyal. 2012. Comparison of pavement surface texture determination by sand patch test and 3D laser scanning. Periodica Polytechnica, Civil Engineering 56.1(2012):73.

Sinha, N. K. 1998. Characteristics of winter contaminates on runway surfaces in North Bay - January and February - March 1997 tests. National Research Council Canada NRC, LTR-ST-2159. Ottawa, Canada: National Research Council.

Tabor, D. 1959. The importance of hysteresis losses in the friction of lubricated rubber. In: Proceedings: $1^{\text {st }}$ International Skid Prevention Conference. Part 1, 211-218. Charlottesville, VA: Virginia Council of Highway Investigation and Research.

Turnage, G. W. 1967. Performance of soils under tire loads. Reports 1-6. No. AEWESTR-3-666-8. Vicksburg, MS: U.S. Army Engineer Waterways Experiment Station.

van Es, G. W. H. 1998. Rolling resistance of aircraft tires in dry snow. NLR Technical Report NRL-TR-98165. Amsterdam, The Netherlands: National Aerospace Laboratory. . 1999. A method for predicting the rolling resistance of aircraft tires in dry snow. NRL-TP-99240. Amsterdam, The Netherlands: National Aerospace Laboratory.

Wambold, J. C., C. E. Antle, J. J. Henry, and Z. Rado. 1995. International PIARC experiment to compare and harmonize texture and skid resistance measurements. Final Report. Paris: Permanent International Association of Road Congresses (PIARC).

Wambold, J. C., J. J. Henry, and A. Andresen. 1998. Third year joint winter runway friction program. Washington, DC: National Aeronautics and Space Administration.

Woodman, O. J. 2007. An introduction to inertial navigation. University of Cambridge, Computer Laboratory, UCAM-CL-TR-696. Cambridge, UK: University of Cambridge.

Yager, T. J., W. P. Phillips, W. B. Horne, and H. C. Sparks. 1970. A comparison of aircraft and ground vehicle stopping performance on dry, wet, flooded, slush-, snow-, and ice-covered runways. NASA TN D-6098. Washington, DC: National Aeronautics and Space Administration. 


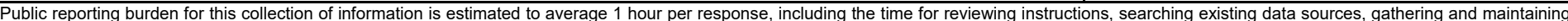

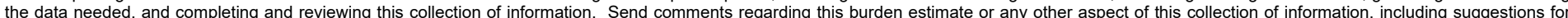

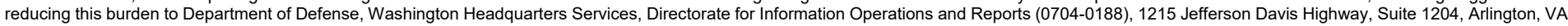

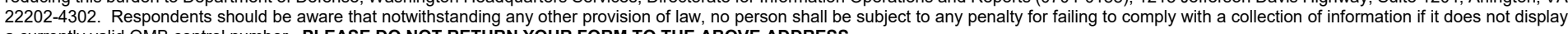
a currently valid OMB control number. PLEASE DO NOT RETURN YOUR FORM TO THE ABOVE ADDRESS.

\begin{tabular}{|l|l|l|} 
1. REPORT DATE (DD-MM-YYYY) & 2. REPORT TYPE & 3. DATES COVERED (FrOm - To)
\end{tabular} June 2019 Final

\section{TITLE AND SUBTITLE}

5a. CONTRACT NUMBER

Development of Deceleration-based Runway Friction Measurement Methods

5b. GRANT NUMBER

5c. PROGRAM ELEMENT NUMBER

\section{AUTHOR(S)}

Andrew B. Ward, Craig A. Rutland, and Jeb S. Tingle

5d. PROJECT NUMBER

473719

5e. TASK NUMBER

5f. WORK UNIT NUMBER

\section{PERFORMING ORGANIZATION NAME(S) AND ADDRESS(ES)}

8. PERFORMING ORGANIZATION REPORT NUMBER

Geotechnical and Structures Laboratory

U.S. Army Engineer Research and Development Center

ERDC TR-19-10

3909 Halls Ferry Road

Vicksburg, MS 39180-6199

9. SPONSORING / MONITORING AGENCY NAME(S) AND ADDRESS(ES)

Headquarters, U.S. Air Force Civil Engineer Center

Tyndall Air Force Base, FL 32403-5319

10. SPONSOR/MONITOR'S ACRONYM(S)

AFCEC

11. SPONSOR/MONITOR'S REPORT NUMBER(S)

\section{DISTRIBUTION / AVAILABILITY STATEMENT}

Approved for public release; distribution is unlimited.

\section{SUPPLEMENTARY NOTES}

\section{ABSTRACT}

Runway surface friction is a critical safety concern on all airfields; however, current friction measurement equipment is expensive. Airfield managers have identified a need for contingency friction assessment tools that are cost-effective and commonly found. The current Air Force standard for pavement friction measurement is a high-speed continuous friction measuring equipment (CFME) device, the Findley Irvine GripTester. Operation of the GripTester is both labor-intensive and cost-prohibitive. This report details the development of an alternative, more economical measure of a surface's frictional characteristics using accelerometers. Accelerometers were standard friction assessment tools in the late 20th century before CFMEs became standard practice. Accelerometer-based friction testers measure the peak deceleration of a vehicle during the braking motion. The vehicle's deceleration is proportional to the surface's friction coefficient. This report documents research conducted to evaluate the use of smartphone accelerometers and vehicle engine control units (ECUs) having sufficient accuracy and precision to function as deceleration-based friction assessment tools. Findings herein show that smartphone accelerometers, given sufficient experimental controls, can operate as deceleration-based friction assessment tools. This report also details unsuccessful attempts to extract usable deceleration data from vehicle ECUs and the potential future of such efforts. Regressions are presented that show correlation between smartphone deceleration measurements and high-speed GripTester measurements.

$\begin{array}{lll}\text { 15. SUBJECT TERMS } & & \text { macrotexture } \\ \text { Friction } & \text { Safety } & \text { microtexture } \\ \text { pavement friction } & \text { Friction - testing } & \text { deceleration } \\ \text { skid resistance } & \text { Accelerometers } & \text { smartphone }\end{array}$

16. SECURITY CLASSIFICATION OF:

\section{a. REPORT}

Unclassified

b. ABSTRACT
Unclassified

\section{c. THIS PAGE}

Unclassified
CFME

Bowmonk

GripTester

Runways (Aeronautics)

\begin{tabular}{l|c|l|}
$\begin{array}{l}\text { 17. LIMITATION } \\
\text { OF ABSTRACT }\end{array}$ & $\begin{array}{l}\text { 18. NUMBER } \\
\text { OF PAGES }\end{array}$ & $\begin{array}{l}\text { 19a. NAME OF RESPONSIBLE } \\
\text { PERSON }\end{array}$ \\
\cline { 3 - 3 } & 85 & $\begin{array}{l}\text { 19b. TELEPHONE NUMBER (include } \\
\text { area code) }\end{array}$ \\
& &
\end{tabular}

